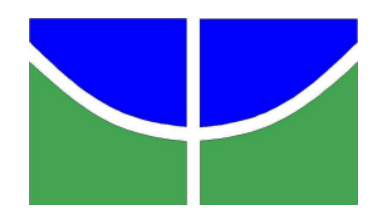

Universidade de Brasília

Instituto de Psicologia

Programa de Pós-Graduação em Psicologia Social,

do Trabalho e das Organizações (PSTO)

\title{
PRODUÇÃO CIENTÍFICA EM BIODIVERSIDADE, SOCIALIZAÇÃO E CARREIRA
}

Tese de doutorado

Doutoranda Jussara Pereira Prado

Orientador Prof. Dr. Hartmut Günther

Brasília

Novembro de 2014 


\section{Membros da Banca}

Prof. Hartmut Günther (Orientador)

\section{PSTO/UnB}

Prof ${ }^{\mathrm{a}}$ Jacqueline Leta

IBqM/UFRJ

Prof $^{a}$ Fernanda A. da Fonseca Sobral

SOL/UnB
Prof. Jairo Eduardo Borges-Andrade

PSTO/UnB

Prof $^{a}$ Juliana Porto

Prof. Cláudio Vaz Torres

PSTO/UnB

PSTO/UnB

suplente 


\section{Agradecimentos}

Agradeço a Capes, por autorizar o meu afastamento para a realização do doutorado pelo Plano Institucional de Desenvolvimento de Recursos Humanos PIDRH.

Agradeço ao Programa de Pós-Graduação em Psicologia Social, do Trabalho e das Organizações - PSTO da Universidade de Brasília, pela disponibilidade em acolher alunos com formações diversas e pela competência dos seus professores em lidar com os diferentes backgrounds. Encontrei no PSTO alguns dos melhores professores que já tive.

Ao meu orientador, Professor Hartmut Günther, agradeço em especial, por ter concordado em me orientar, pela orientação na construção deste projeto, pela disponibilidade em aceitar novas abordagens e pelo apoio durante o desenvolvimento do projeto. E por aturar algumas crises de ansiedade. Agradeço também à professora Isolda, parcialmente responsável pelo ambiente agradável e acolhedor proporcionado pelo Laboratório de Psicologia Ambiental (LPA). Professora, obrigada pelo incentivo, pelo carinho, pela sua doçura e presença amiga.

Meu 'muito obrigada' aos pesquisadores que responderam ao questionário e contribuíram com depoimentos, palavras de incentivo e interesse no tema da pesquisa. Esta pesquisa literalmente não poderia ter sido realizada sem a ajuda deles.

Agradeço ao Matthew Medeiros pela assessoria estatística e por rodar as análises no programa R. Aprendi muito com o Matt. À minha amiga Cátia, por resolver muitas das minhas dúvidas matemáticas e também as inúmeras outras dúvidas, pelas quais agradeço também às minhas amigas Rita e Céline. 
Vários colegas do LPA e do PSTO marcaram esta fase e agradeço a todos pela amizade. Eu agradeço especialmente ao André Moniz, que nas vésperas de sua própria defesa de tese, me ajudou a montar o questionário na plataforma hospedada em seu site pessoal em muitas horas de trabalho e amizade. Agradecimentos também ao Daniel Kinpara pelas inúmeras dicas, sugestões e conselhos em relação ao projeto. Muito obrigada à Ingrid Luiza, ao Fábio de Cristo, ao Daniel Kinpara e ao André Moniz pela revisão do texto sobre seleção de modelos. Miguel e Clarissa Marini fizeram a revisão final do texto completo. Os erros que permaneceram são de minha responsabilidade.

Algumas colegas do PSTO foram especialmente importantes pela amizade e pelo carinho: Ana Márcia, Lígia Carolina e Patrícia Emanuele. As minhas amigas da CAPES fizeram toda a diferença antes, durante e após a licença: Amanda Olímpio, Nancy Santos e Thaís Aveiro, a quem agradeço pelo carinho e apoio. Agradeço também à Marisa Mamede, amiga do CNPq.

Agradeço ao meu marido Miguel Marini por tantas coisas que fica difícil enumerar. Pelo apoio, incentivo, orientação informal, assessoria estatística, dicas, conselhos, revisão de texto, paciência com as inúmeras crises de ansiedade, por me manter no rumo, por acreditar em mim e pelo seu amor em todas as horas.

Às minhas filhas, agradeço pelo apoio, pelo carinho, por estarem por perto, por terem tido paciência com a minha falta de tempo para tantos assuntos e por terem assumido tantas tarefas que eu deixei de lado pra me dedicar ao doutorado. Obrigada Cla, obrigada Ciça.

Aos meus pais agradeço por, mesmo de longe, e sendo a filha já tão madura, ainda estarem lá pra me incentivar e dizer que desta vez vai dar certo. 


\section{Sumário}

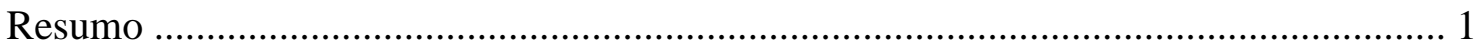

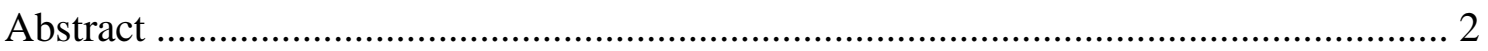

Prefácio - Produção Científica em Biodiversidade, Socialização e Carreira ................. 3

Revisão - Ciência, Pós-Graduação e Produção Científica no Brasil .......................... 4

Pós-Graduação no Brasil ............................................................................... 5

Carreira em Pesquisa e Produção Científica no Brasil ................................................

Contexto Organizacional da Pesquisa e Comunidade Científica...................10

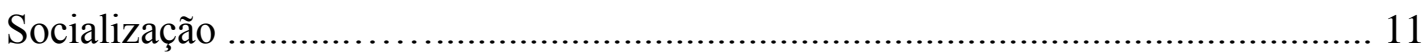

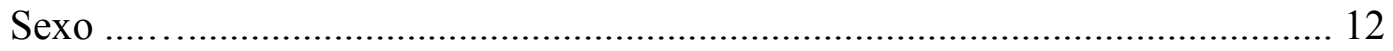

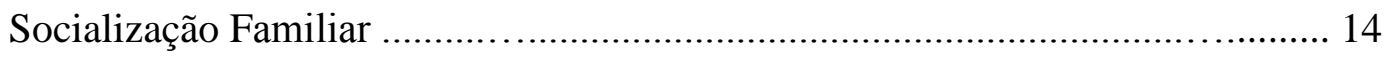

Socialização Acadêmica ............................................................................. 16

Socialização Acadêmica Transnacional ........................................................ 19

Biodiversidade ........................................................ 21

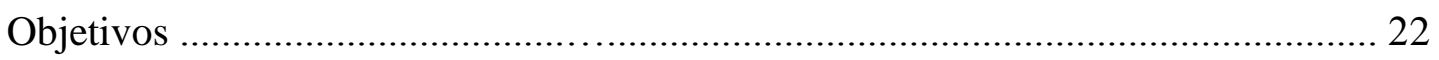

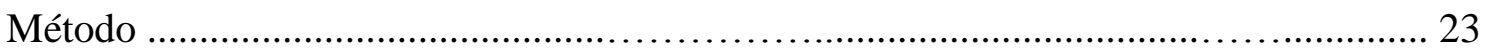

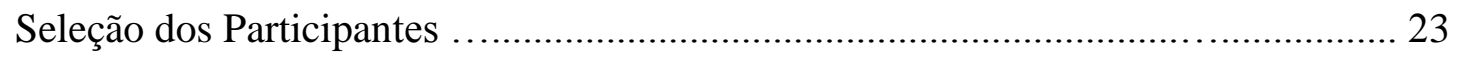

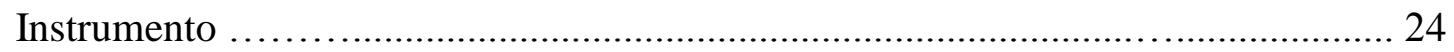

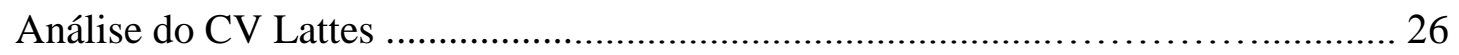

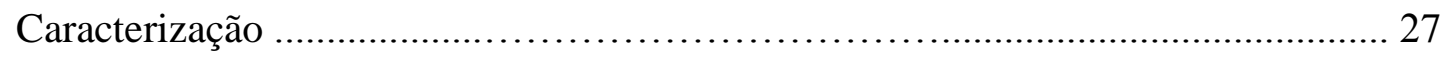

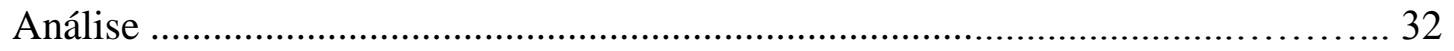




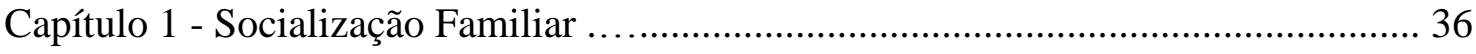

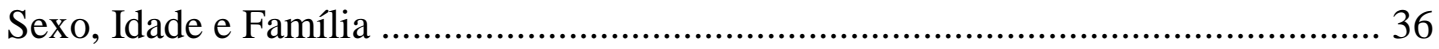

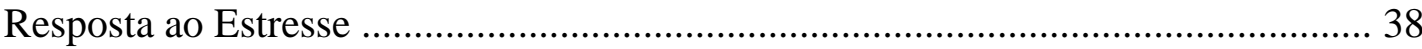

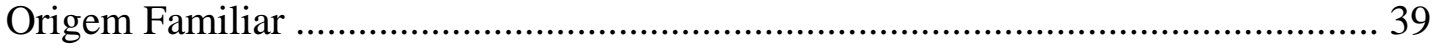

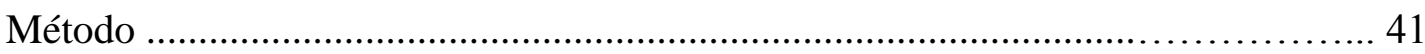

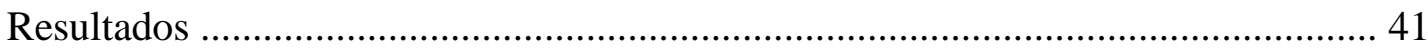

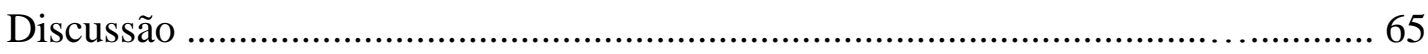

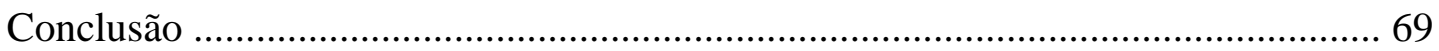

Capítulo 2 - Socialização Acadêmica ................................................................. 71

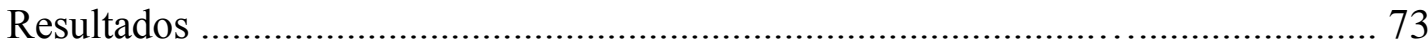

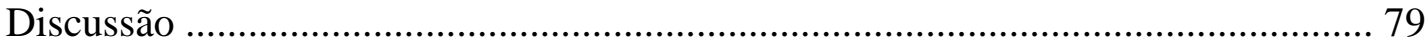

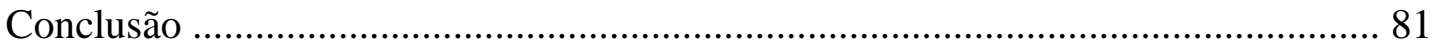

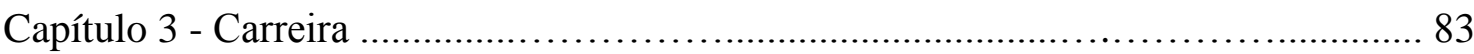

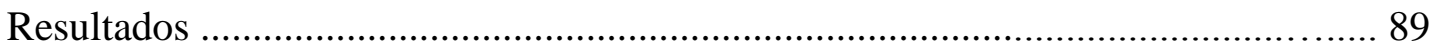

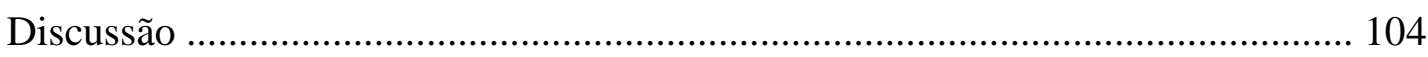

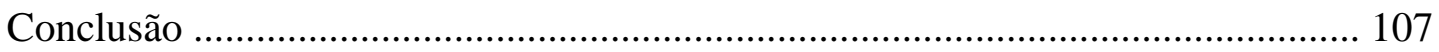

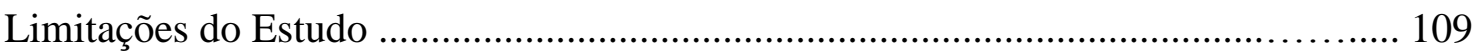

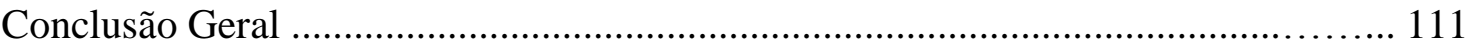

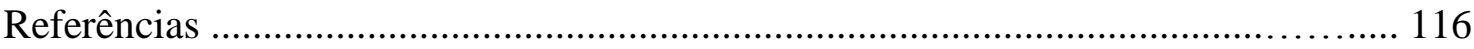

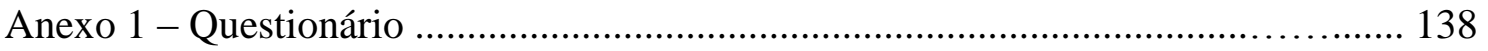




\section{Resumo}

Em busca de um modelo de predição de produção científica no contexto brasileiro, nesta pesquisa foram analisadas variáveis relacionadas à socialização familiar e acadêmica e à carreira de pesquisadores da área de Biodiversidade que concluíram o doutorado no Brasil ou no exterior, entre 1989 e 2002. O número de artigos publicados em periódicos nacionais e internacionais foi utilizado como indicador de produção científica. Os dados foram obtidos a partir dos currículos inseridos na Plataforma Lattes e por meio de um survey aplicado via e-mail. A análise dos dados foi feita por meio da Seleção de Modelos pelo Critério de Informação de Akaike - AIC. Os resultados mostraram que as variáveis com maior efeito positivo na produtividade científica foram: sexo; co-autoria de artigos com o orientador de doutorado; orientação de alunos e colaboração científica nacional e internacional. A maior produção científica internacional foi encontrada entre os pesquisadores que realizaram o doutorado no exterior e colaboraram internacionalmente.

Palavras-chave: produção científica; socialização; carreira; sexo; colaboração científica; doutorado no exterior; biodiversidade 


\begin{abstract}
In search of a predictive model of scientific publication for the Brazilian context, variables related to family socialization; academic socialization and career of Biodiversity researchers who concluded their doctorate in Brazil or abroad, between 1989 and 2002 were analysed. The number of articles published in Brazilian and international journals were considered as indicators of scientific productivity. Data for this study were gathered from the Curriculum Vitae in the Lattes software platform and by an on line survey. Statistical analysis used Model Selection by Akaike Information Criteria-AIC. Results showed that the variables with greater positive effect on productivity were: gender; co-authorship of articles with doctorate advisor; advising graduate students; local and international scientific collaboration. Higher production of international articles was found among researchers who studied abroad and collaborated internationally.
\end{abstract}

Key words: scientific production; socialization; career; gender; scientific collaboration; $\mathrm{PhD}$ abroad;biodiversity 


\section{Prefácio - Produção Científica em Biodiversidade, Socialização e Carreira}

A produtividade científica de um pesquisador pode ser influenciada por fatores pessoais, institucionais, culturais ou econômicos que podem contribuir, isoladamente ou em conjunto, para explicar seu comportamento em relação à comunicação pública dos resultados de sua pesquisa: a produção científica. Em busca de um modelo que aproxime as abordagens da socialização e da carreira de pesquisador para predizer produção científica no contexto brasileiro, nesta pesquisa foram analisados aspectos relacionados à socialização, considerando características pessoais e familiares dos pesquisadores e aspectos relacionados à socialização acadêmica. Foram analisados ainda, fatores relacionados à carreira de pesquisador.

Esta pesquisa está organizada em cinco partes. Na primeira parte apresento a revisão da literatura sobre os principais temas da pesquisa; a segunda parte apresenta o método utilizado para a coleta e análise dos dados e os dados demográficos que caracterizam a população estudada. Os resultados das análises são apresentados em três capítulos: o Capítulo 1 trata das características pessoais e da socialização familiar. Neste capítulo são analisadas as variáveis: sexo; idade; fase da carreira; casamento; número de filhos; crises e origem familiar. No Capítulo 2 é apresentado o tema socialização acadêmica e as variáveis analisadas são: papel do orientador doutorado no Brasil e doutorado no exterior. No Capítulo 3 são discutidas questões relacionadas à carreira: orientação de alunos de mestrado e doutorado e colaboração científica local, doméstica e internacional. Na última parte são apresentadas as limitações do estudo e a conclusão geral da pesquisa. 


\section{Revisão - Ciência, Pós-Graduação e Produção Científica no Brasil}

A ciência é um elemento estratégico de desenvolvimento das nações. Pesquisas recentes mostram que a produção científica de um país é um indicador de desenvolvimento econômico e humano muito mais eficiente do que o Produto Interno Bruto ou o Índice de Desenvolvimento Humano (Jaffe et al., 2013). A associação crescente entre os indicadores de ciência, tecnologia e inovação e os indicadores de desenvolvimento (OECD, 2005) leva à reflexão sobre a importância do conhecimento científico e da pesquisa para a melhoria da capacidade científica e tecnológica, principalmente nos países em desenvolvimento (Poblacion \& Oliveira, 2006).

A importância da publicação de artigos científicos como indicador de produção científica tem levado a um crescente interesse na identificação dos fatores que afetam a produtividade dos pesquisadores (Gonzalez-Brambila \& Veloso, 2007). Este tema tem inspirado pesquisas, principalmente em países desenvolvidos, como os Estados Unidos (Creswell, 1985), países da Europa (Turner \& Mairesse, 2003) e Coréia do Sul (Shin \& Cummings, 2010). No entanto, os resultados obtidos nestes países não servem como modelos para explicar a produtividade científica acadêmica em outros países, uma vez que grande parte das variáveis relevantes é dependente do contexto (Teodorescu, 2000), que obviamente é bastante diferente, principalmente quando comparados países em estágios diferentes de desenvolvimento.

Em uma pesquisa sobre os determinantes de produtividade científica entre pesquisadores mexicanos mostrou não haver diminuição da produção científica em função do envelhecimento (Gonzalez-Brambila \& Veloso, 2007), resultado diferente daquele obtido em países desenvolvidos (Levin \& Stephan, 1991). Em estudos 
realizados com pesquisadores das Filipinas (Ynalvez \& Shrum, 2011), Gana, Quênia e Índia (Miller, Duque, \& Shrum, 2012), não foi encontrada relação entre colaboração e aumento da produção científica, resultado diferente dos encontrados em inúmeros estudos realizados em países desenvolvidos, dentre eles o de Lee e Bozeman (2005).

A estabilidade no emprego e a forma de obtê-la também podem afetar a produtividade científica dos pesquisadores. Em estudos sobre determinantes de produtividade realizados nos EUA, o "tenure track", processo de aquisição de estabilidade, é um dos fatores contextuais conhecidos por afetar a produtividade científica dos pesquisadores (Zainab, 1999). Enquanto não obtém a estabilidade no cargo, os pesquisadores estadunidenses precisam manter um elevado nível de produtividade que muitas vezes não se mantém uma vez alcançado o status de pesquisador estável.

Para situar o contexto no qual é produzida a pesquisa e a produção científica no Brasil, apresento a seguir, uma breve revisão sobre a história da pós-graduação brasileira.

\section{Pós-Graduação no Brasil}

No início do século XX, predominava no Brasil a ideia de que o conhecimento científico e técnico deveria ser utilizado para tornar o país mais moderno e eficiente e a prioridade era formar técnicos e engenheiros. Esta noção foi sendo aos poucos, substituída pelo conceito da ciência associada à cultura e o objetivo passou a ser o de criar um país civilizado e não apenas industrializado e moderno. Neste contexto, a prioridade passou a ser a formação de pesquisadores autônomos e a pesquisa básica tornou-se prioritária (Schwartzman, 2005). A história da pós-graduação no Brasil é 
recente. Na primeira metade do século 20, poucas universidades brasileiras ofereciam cursos de pós-graduação, o número de pessoas que possuía o título de doutor era muito reduzido (Beiguelman, 1998) e obter um título acadêmico no exterior dependia de recursos financeiros próprios.

Os primórdios da pós-graduação brasileira têm início na década de 1930 com a proposta de implantação de uma pós-graduação baseada nos moldes europeus. Este modelo foi implementado no curso de doutorado em Direito da Universidade do Rio de Janeiro, no curso de doutorado da Faculdade Nacional de Filosofia, no Rio de Janeiro e no doutorado da Faculdade de Filosofia, Ciências e Letras da USP (Santos, 2003). Os precursores mais importantes da pós-graduação do Brasil, no entanto, foram os cursos de Ciências Físicas e Biológicas e o curso de Engenharia da Universidade do Brasil (atual Universidade Federal do Rio de Janeiro - UFRJ), criados no início da década de 1960 a partir do modelo americano, além dos cursos do Instituto Tecnológico da Aeronáutica - ITA, da Escola Superior de Agricultura e Veterinária de Viçosa - ESAV, da Universidade Federal Rural do Rio de Janeiro - UFRRJ e da Universidade de Brasília - UnB (Santos, 2003).

A partir dos anos 50, foram criadas a Coordenação de Aperfeiçoamento de Pessoal de Nível Superior (CAPES) e o Conselho Nacional de Desenvolvimento Científico e Tecnológico (CNPq), quando teve início o movimento de estudantes e profissionais brasileiros para o exterior com apoio do governo, na forma de bolsas de mestrado e doutorado. No início de 1969, estas agências de fomento criaram um sistema institucional de bolsas de mestrado e doutorado no país e no exterior, a partir do qual o país começou a se inserir no movimento de internacionalização da ciência (Cury, 2004). 
A consolidação da pós-graduação brasileira teve início com a Lei de Reforma Universitária de 1968. A exigência de mestrado e doutorado para a carreira docente universitária e a incumbência atribuída à CAPES e ao CNPq de promover a formação e o aperfeiçoamento do pessoal docente de ensino superior impulsionaram a criação de uma política nacional de pós-graduação (Cury, 2005). Com o Plano Nacional de PósGraduação de 1975-1979, houve um grande aumento na concessão anual de bolsas de estudo no país e no exterior, permitindo aos docentes da pós-graduação, muitos dos quais sem doutorado (Balbachevsky, 2007), a obtenção de títulos de doutorado no Brasil ou em universidades estrangeiras, especialmente nos EUA, França e Inglaterra (Martins, 1991). Atualmente, mais da metade (51,4\%) dos docentes em instituições públicas de ensino superior têm doutorado, enquanto na rede privada de ensino superior os doutores somam 36,7\% (INEP, 2013). Mesmo quando o título de doutor não é exigido nos concursos e contratações, esta formação é extremamente valorizada, ao menos nas instituições de ensino federal e estadual (CGEE, 2010).

\section{Carreira em Pesquisa e Produção Científica no Brasil}

A expressão "publish or perish" (Garfield, 1996) resume a importância atribuída à produção científica para o sucesso na carreira do pesquisador. A pesquisa é uma das principais atividades na carreira científica (Kaulisch \& Enders, 2005) e a publicação dos resultados é o principal processo social da ciência, por meio do qual a pesquisa é divulgada e verificada (Meadows, 1999). O artigo científico é o veículo de comunicação mais utilizado em diversas áreas da ciência, apoiado na certificação pelos pares e na rapidez na veiculação de informações (Mugnaini, Carvalho, \& Campanatti-Ostiz, 2006). 
A quantidade de artigos publicados e a qualidade das publicações são os indicadores mais utilizados na avaliação do desempenho científico de um pesquisador ou de um Programa de Pós-Graduação (Yamamoto, Tourinho, Bastos, \& Menandro, 2012) ou de um país (Toutkoushian \& Bellas, 1999; S.M.S.P. Ferreira, 2010), embora seu uso como indicador apresente algumas limitações. A publicação de artigos nem sempre reflete a produção científica dos pesquisadores (Meadows, 1999), uma vez que o conceito de produção científica é muito mais abrangente e inclui realizações relacionadas à pesquisa, ao ensino, às tecnologias e técnicas que o pesquisador pode disponibilizar na prestação de serviços à sociedade (Mugnaini et al., 2006).

Outra limitação importante diz respeito às características particulares de cada área, às diferentes maneiras de fazer pesquisa e às diferentes formas de comunicar os resultados (Meadows, 1999). Em ciências como a Física, a Química e a Biologia, os artigos são prioritariamente publicados em periódicos de circulação internacional, no idioma inglês (Mueller, 2005). Nas Ciências Humanas e Sociais, as pesquisas tendem a produzir textos mais longos, publicados não só como artigos, mas também como livros e capítulos de livros. Enquanto que nas áreas tecnológicas, a prioridade são os relatórios e os trabalhos apresentados em congressos (Mueller, 2005). Segundo esta autora, as diferenças entre estas áreas devem ser levadas em conta no estabelecimento dos indicadores e dos critérios de avaliação da produção científica.

No Brasil, a institucionalização da pesquisa nas universidades e a integração da Pós-Graduação no Sistema Nacional de Ciência e Tecnologia foram definidas pelo Plano Nacional de Pós-Graduação de 1986. Assim, no Brasil, como na maior parte dos países, a pesquisa científica e tecnológica se concentra em (poucas) universidades e institutos de pesquisa (De Meis \& Leta, 1996), instituições que valorizam a publicação 
de artigos para a divulgação do conhecimento para a comunidade científica (Poblacion \& Oliveira, 2006).

Nas instituições consideradas como sendo de pesquisa, a grande concentração de doutores contratados em regime de dedicação exclusiva favorece o desenvolvimento de pesquisa e a orientação de alunos. Estas instituições, algumas federais, outras estaduais e algumas universidades privadas, como as Pontíficas Universidades Católicas - PUCs e a Fundação Getúlio Vargas, são responsáveis por parte substancial da pesquisa científica brasileira (Balbachevsky, 2007).

Nas universidades públicas brasileiras, os pesquisadores são efetivados após o cumprimento de um estágio probatório de três anos, no qual a produtividade científica elevada não é exigida para a aquisição de estabilidade. Por esta razão, no Brasil, o padrão de produtividade no início da carreira pode estar associado a fatores diferentes daqueles encontrados em sistemas acadêmicos como o dos EUA, onde a estabilidade está associada a níveis elevados de produtividade.

O sistema de C\&T brasileiro possui outras características particulares. A avaliação da pós-graduação brasileira está baseada em indicadores de produtividade científica dos docentes e em mecanismos de incentivo dos quais fazem parte a concessão de bolsas, auxílios e financiamentos. Estas características diferenciam o Brasil de outros países. Além disso, o estímulo representado pela Bolsa de Produtividade em Pesquisa do CNPq, por exemplo, cujo processo de atribuição baseiase principalmente na quantidade e no impacto da produção científica e no qual não há garantias de estabilidade, representa outra diferença importante que justifica a necessidade de cautela na comparação de estudos realizados no Brasil com aqueles 
obtidos em outros países, principalmente nos países em estágios diferentes de desenvolvimento.

Diversos fatores são apontados como responsáveis pelo aumento da produção científica brasileira (Castro, 1985; Lima, Velho, \& Faria, 2012; Meneguini \& Packer, 2006; Packer \& Meneguini, 2006). Dentre estes, o investimento público nos sistemas educacional e científico, materializado na formação de novos pesquisadores, foi relacionado à melhoria do desempenho científico em todas as áreas do conhecimento (De Meis, Arruda, \& Guimarães, 2007; Leta, Lannes, \& De Meis, 1998). Para garantir que o investimento em formação de pesquisadores no Brasil ou no exterior seja revertido em aumento da produtividade científica, é preciso conhecer o papel dos inúmeros fatores tanto de nível individual, quanto do nível do contexto da produção científica (Zainab, 1999) que podem afetar os pesquisadores de forma positiva ou negativa, ao longo do processo de socialização e na carreira acadêmica.

\section{Contexto Organizacional da Pesquisa e Comunidade Científica}

Na carreira científica, os pesquisadores estão inseridos não apenas no contexto organizacional da universidade ou instituto de pesquisa ao qual estão vinculados profissionalmente. Como membros de uma comunidade científica, estão sujeitos também ao contexto social no qual ocorre a produção científica daquela área. $\mathrm{Na}$ organização acadêmica ou de pesquisa, os pesquisadores desenvolvem seu trabalho em uma realidade de contextos que se sobrepõem, dando origem a características peculiares da carreira científica (Kaulisch \& Enders, 2005).

Do contexto da produção científica devem fazer parte não só as organizações acadêmicas, de pesquisa e comunidades científicas, mas também as peculiaridades do 
sistema de C\&T de cada país (Gonzalez-Brambila \& Veloso, 2007), principalmente as diferenças encontradas entre os países desenvolvidos e em desenvolvimento. Algumas dessas diferenças estão relacionadas à disponibilidade de recursos financeiros para a pesquisa (Leta, Glanzel, \& Thijs, 2006). Nos países em desenvolvimento, os recursos de apoio à pesquisa, como bibliotecas, laboratórios e equipamento de pesquisa não se mostraram relevantes como preditores de produtividade científica (Teodorescu, 2000). Com relação ao tempo dedicado para a pesquisa, foi encontrado que nos países em desenvolvimento, as atividades relacionadas ao ensino (Wanner, Lewis, \& Gregorio, 1981) ou administração (Teodorescu, 2000), não parecem ter influência sobre a produtividade. Por outro lado, em pesquisas estadunidenses, a dedicação relativa entre ensino e pesquisa é um importante preditor de produtividade científica (Teodorescu, 2000). As dificuldades relacionadas ao uso de um idioma estrangeiro para a comunicação científica (Leta et al., 2006; Meneguini \& Packer, 2007); dificuldades de acesso às publicações científicas (Lawrence, 2003) e às tecnologias de comunicação (Duque et al., 2005), também contribuem para acentuar as diferenças entre países desenvolvidos e em desenvolvimento em termos de produção científica.

\section{Socialização}

Apresento a seguir a revisão da literatura sobre algumas das variáveis relacionadas aos processos de socialização tanto no âmbito familiar quanto acadêmico. Estes processos podem ter impactos diferentes sobre as pessoas, em função de características pessoais, como o sexo, por exemplo. Apresento a seguir uma breve revisão sobre esta variável. 


\section{Sexo.}

As diferenças entre os sexos na produção de artigos científicos têm sido bastante exploradas na literatura (Borrego, Barrios, Villarroya, \& Ollé, 2010; Lewinson, 2001; O’Brien \& Hapgood, 2012; Symonds, Gemmell, Braisher, Gorringe, \& Elgar, 2006; Velho \& León, 1998). Os homens publicam mais artigos, em média, em comparação com as mulheres e as explicações comumente apresentadas para as diferenças em produtividade estão relacionadas às associações entre sexo e motivação, a aspectos sociais e culturais, como a socialização para papéis sexuais e os níveis de investimento na educação feminina (Velho \& León, 1998). Fatores psicológicos tais como sentimento de inadequação, ansiedade diante de avaliações, perfeccionismo e baixa autoestima são apontadas como responsáveis pela menor representatividade feminina entre os docentes de universidades norte-americanas (Bronstein, Rothblum, \& Solomon, 1993). Outras explicações estão relacionadas à qualidade da formação acadêmica, qualidade do ambiente de trabalho, tempo dedicado para a pesquisa e área do conhecimento (Blackburn, Behymer, \& Hall, 1978). Um conjunto de fatores culturais, biológicos, da estrutura social da ciência e da organização da carreira acadêmica contribuem para o desempenho observado das mulheres na carreira científica. A divisão sexual desigual do trabalho, inclusive as tarefas domésticas (Olinto, 2011) e a falta de flexibilidade para acomodar as demandas associadas à maternidade (Ceci \& Williams, 2011; D’Amico, Vermigli, \& Canetto, 2011; Goulden, Mason, \& Frasch, 2011) são elementos apontados como responsáveis pela reconhecida desigualdade entre homens e mulheres na ciência.

Algumas evidências mostram que os homens e as mulheres são mais semelhantes em termos de citações do que de número de publicações (Cole \& Zuckerman, 1984; Long, 1992). Em um estudo sobre a produtividade científica de doutoras formadas na 
Espanha, foi encontrado que os artigos publicados pelas mulheres foram mais frequentemente citados que os artigos publicados pelos homens e que estas publicaram seus artigos em periódicos de maior impacto (Borrego et al., 2010). Resultados diferentes foram encontrados em um estudo sobre os pesquisadores mais citados das áreas de Ciência Ambiental e Ecologia, no qual se verificou que 93\% pertenciam ao gênero masculino (Parker, Lortie, \& Allesina, 2010). Duas décadas antes, em um estudo sobre os pesquisadores da área de Ecologia mais produtivos em termos de número e impacto das citações, as mulheres estavam ausentes (Primack \& O’Leary, 1989).

O Brasil é um dos poucos países onde as mulheres superam os homens em número de doutores, tendo passado a representar em 2008, 51,5\% dos doutores titulados (CGEE, 2010). Apesar do aumento da participação feminina entre os doutores brasileiros nas diversas áreas do conhecimento e na área de Biologia em particular, diversos indicadores ainda mostram desigualdades sexuais desfavoráveis para as mulheres: (1) Dentre os pesquisadores com maior produção científica, os homens respondem por $86 \%$ da produção (Leta \& Batista, 2009); (2) a maior parte das doutoras atua como docentes do ensino médio (CGEE, 2010); e (3) para as que ingressam na carreira acadêmica, as oportunidades de promoção e reconhecimento são inferiores às masculinas (Leta, 2003), fenômeno também encontrado na maioria dos países, como os Estados Unidos e Reino Unido (Acker, 1992). Considerando o grande número de doutoras tituladas anualmente no Brasil, se a igualdade entre os sexos na formação de doutores for alcançada também em termos de produção científica, isto poderia representar um avanço nos indicadores de ciência, tecnologia e inovação (OECD, 2005). 


\section{Socialização familiar.}

A origem familiar costuma ser estudada como um dos fatores relacionados ao desempenho escolar. Fazem parte do conceito de origem familiar: os capitais financeiro, humano e social (Coleman, 1988). O capital financeiro diz respeito aos recursos materiais que podem contribuir para o bom desempenho, como livros e um local apropriado para estudar. O capital humano refere-se à escolaridade dos pais e ao ambiente cognitivo que este grau de escolaridade pode propiciar para a aprendizagem dos filhos. O capital social refere-se às interações familiares que permitem que o capital humano dos pais seja acessado pelos filhos e engloba, portanto, não só a presença dos pais, quanto a atenção dedicada por estes aos filhos (Coleman, 1988). Embora questões relacionadas à origem familiar sejam usualmente discutidas no contexto do desempenho escolar infantil, algumas características do contexto familiar podem auxiliar na compreensão da trajetória acadêmica dos doutorandos brasileiros.

Com base em pesquisas realizadas com estudantes brasileiros na França nas décadas de 1980 e 1990, Brito (2004) identificou cinco indicadores ligados à família, capazes de influenciar a trajetória acadêmica dos doutorandos: (1) A origem familiar, que engloba a profissão exercida pelos pais, o nível de renda, o nível de escolaridade, o nível cultural da família e a familiaridade com o sistema acadêmico nacional e/ou internacional; (2) os recursos mobilizados pelas famílias, que têm relação com o grau de informação sobre o sistema acadêmico, as estratégias de escolarização e o apoio de familiares e amigos quanto à formação acadêmica no Brasil ou no exterior; (3) o grau de dependência familiar, que está associado à permanência ou não dos estudantes na casa dos pais, em função da proximidade de boas universidades próximas ao local de moradia; (4) a socialização profissional precoce, iniciada na família ou por meio do 
convívio com pessoas relevantes do círculo social; e (5) a presença de profissionais com formação universitária no círculo familiar que possam servir de modelo e transmitir informações sobre uma carreira de nível superior. A partir destes indicadores, dois modelos de trajetória foram criados: o 'Itinerário de Herdeiro' e o 'Itinerário de Ascensão pela via Escolar'. O Itinerário de Herdeiro (Bourdieu \& Passeron, 1964) é típico dos estudantes provenientes de famílias com bom nível de renda, familiaridade com a cultura, curiosidade científica e incorporação precoce de um "habitus" acadêmico. O Itinerário de Ascensão pela via Escolar ocorre em famílias que não possuem capital cultural ou informações sobre a carreira acadêmica. Nestas famílias, a ausência de uma socialização acadêmica precoce no contexto familiar é substituída por diferentes estratégias pela busca por oportunidades de escolarização de melhor qualidade (Brito, 2004).

Atualmente, a participação de estudantes brasileiros em cursos de doutorado no exterior independe de seu "Itinerário". A diminuição da dependência de recursos financeiros próprios para a realização do doutorado em função da criação das agências brasileiras de fomento e da concessão de bolsas para doutorado no exterior provoca uma desvinculação entre origem social e experiência acadêmica no exterior. No entanto, apesar desta desvinculação, a "superseleção nos programas de doutorado faz com que os que chegam atualmente ao exterior apresentem muitas das características dos herdeiros" (Brito, 2004, p. 102).

A importância da experiência acadêmica no exterior em uma fase inicial da trajetória acadêmica está relacionada ao significado atribuído pelos estudantes às novas informações encontradas na cultura estrangeira, determinado em função de suas experiências anteriores (Zull, 2012). O estudante de doutorado que tiver participado de 
um programa de mobilidade na graduação, como o Programa Ciência sem Fronteiras (Brasil, 2011), por exemplo, poderia compensar parcialmente a ausência dos elementos de socialização acadêmica e internacional, o que proporcionaria uma aproximação entre os dois tipos de Itinerário. Desta forma, de acordo com Zull (2012), a experiência internacional prévia poderia facilitar a inserção do aluno e diminuir as dificuldades de adaptação à cultura estrangeira.

\section{Socialização acadêmica.}

Outro conjunto de preditores de produtividade científica está relacionado à formação acadêmica. A revisão apresentada a seguir trata do tema socialização acadêmica e socialização acadêmica transnacional. A revisão sobre os fatores papel do orientador e local de doutorado será apresentada no Capítulo 2.

O objetivo principal do doutorado é a socialização dos novos pesquisadores para a realização de pesquisa de boa qualidade, conduzida de forma rigorosa (Golde \& Dore, 2004), original e independente (Gardner, 2008). Ao longo do processo de socialização, os doutorandos adquirem o conhecimento, os valores e desenvolvem as habilidades que os prepararão para produzir pesquisa reconhecida pela comunidade acadêmica e divulgada por meio da publicação científica (Weidman, 2010). Os doutorandos devem ser capazes de desenvolver pesquisa de forma autônoma e de obter recursos para o desenvolvimento de sua pesquisa. Para que possam dar continuidade à sua carreira científica, precisam se vincular profissionalmente a uma instituição que valorize e priorize a pesquisa científica (Weidman, 2010). A socialização no doutorado envolve um processo de ajustamento ao ambiente de pesquisa e de transição da identidade de estudante para a de pesquisador (Campbell, 2003). Por meio da socialização acadêmica, 
os doutorandos adquirem as habilidades e os valores do mundo acadêmico (Bakar, 2012) e começam a se sentir independentes e capazes de conduzir uma pesquisa, embora ainda necessitem de apoio e orientação. Este processo de aquisição de independência é necessário para a aceitação do estudante como um potencial pesquisador e para a sua futura inserção profissional (Gardner, 2008).

O processo de socialização no doutorado não se restringe apenas à preparação para a carreira de pesquisador acadêmico e ao aprendizado sobre a cultura acadêmica e institucional. Este processo envolve também a inserção na comunidade científica de uma determinada área do conhecimento e o aprendizado sobre a cultura desta comunidade (Gardner, 2008). Os programas de doutorado são estruturados em função das particularidades e das normas de cada área do conhecimento e os doutorandos tendem a se orientar em função das normas percebidas de sucesso na área de estudo escolhida (Tinto, 2012). Neste sentido, os doutorandos são socializados para fazer parte de uma comunidade científica específica. Independente das escolhas profissionais futuras, os doutorandos em formação são socializados nos hábitos profissionais, normas e práticas da comunidade científica da área do conhecimento na qual está inserido seu programa de doutorado (Golde, 2010).

O doutorado é um processo de socialização em culturas múltiplas (Austin, 2002), no qual os estudantes são preparados simultaneamente para o papel de doutorandos e para a carreira futura no contexto de uma comunidade científica específica (Gardner, 2008). Esse processo é determinante para o sucesso no processo de obtenção do título de doutor (Turner \& Thompson, 1993). O orientador tem um papel fundamental no aprendizado sobre a carreira e a comunidade científica da área e sua influência pode afetar diretamente o sucesso profissional do estudante (Tinto, 2012). Os estudantes 
relatam benefícios relacionados ao papel de seus orientadores como modelo, guia e conselheiros profissionais, com consequências positivas em sua auto-estima (Luna \& Cullen, 1998). Outros benefícios percebidos pelos doutorandos são o apoio psicossocial, a ajuda relacionada à carreira e a colaboração em pesquisa, considerados responsáveis pela avaliação positiva da experiência acadêmica durante o doutorado (Paglis, Green \& Bauer, 2006). Para os orientadores, a orientação significa a exposição constante a novos problemas teóricos e a diferentes práticas de pesquisa (Borges-Andrade, 1994).

Diversos autores utilizaram a abordagem da socialização nos estudos sobre o doutorado (Antony, 2002; Austin, 2002; Gardner, 2007, 2008; Golde, 2005; Golde \& Dore, 2004; Weidman \& Stein, 2003) e alguns modelos foram propostos para explicar o processo de socialização que ocorre no doutorado. Dentre os mais citados, o modelo de socialização na pós-graduação proposto por Weidman, Twale e Stein (2001) apresenta a socialização em quatro estágios: antecipatório, formal, informal e pessoal, sem levar em consideração as diferenças individuais ou institucionais ou da área do conhecimento na qual o doutorado está inserido. No modelo conceitual proposto por Gardner (2009), o foco está no desenvolvimento dos doutorandos, apresentado em uma sequência de três fases: entrada, integração e candidatura ao longo das quais ocorrem mudanças não só profissionais, mas pessoais e interpessoais, como resultado do equilíbrio entre os desafios enfrentados e o suporte recebido durante o doutorado.

Outro modelo proposto para explicar o progresso dos doutorandos foi elaborado com base em pesquisas sobre evasão escolar de estudantes da graduação (Tinto, 1975), com a incorporação dos fatores: suporte financeiro e relacionamento orientador/aluno (Girves \& Wemmerus, 1988). O modelo longitudinal de persistência no doutorado de Tinto (2012) fundamenta-se em seus estudos sobre a persistência na graduação e em 
pesquisas que mostram haver similaridades entre a graduação e a pós-graduação quanto aos fatores que afetam a persistência. Neste modelo, os atributos individuais e as experiências educacionais anteriores à entrada no doutorado, os compromissos externos (família e trabalho) e os recursos financeiros disponíveis são condicionantes do tipo de participação do aluno no programa de doutorado. Este modelo assume três aspectos principais relacionados ao doutorado: (1) as características normativas e estruturais específicas da área do conhecimento, que definem os padrões de comportamento e desempenho esperados; (2) a importância das interações com o orientador, cujo comportamento irá definir o tipo de experiência particular que cada doutorando terá no doutorado; (3) o caráter de socialização antecipatória profissional e a percepção da capacidade do curso em proporcionar acesso à carreira desejada. Neste modelo, as experiências adquiridas durante a última etapa do doutorado exercem um papel fundamental no futuro do pesquisador. Na fase final do doutorado, na qual a pesquisa é desenvolvida e a tese concluída, o doutorando adquire experiência com todas as etapas da condução de uma pesquisa, com a formalização do processo em um documento escrito e com a defesa pública da tese. O resultado final do processo de socialização dos doutorandos é a formação de profissionais altamente qualificados, preparados para dar início ao percurso em direção à aquisição de maior autonomia, necessária em sua atuação profissional (Tinto, 2012).

\section{Socialização acadêmica transnacional.}

O intercâmbio educacional é uma forma de interação transcultural praticada desde a Antiguidade (Brickman, 1950; Sylvester, 2002). No entanto, as questões relacionadas à adaptação a uma nova cultura só passaram a ser objeto de pesquisas após a 2a Guerra 
Mundial, em resposta ao aumento dos intercâmbios internacionais (Knight \& De Wit, 1995). No Brasil, o intercâmbio acadêmico internacional era inicialmente restrito às elites (Brito, 2004). Somente a partir dos anos 50 os estudantes de pós-graduação começaram a estudar no exterior com o apoio de bolsas de mestrado e doutorado concedidas pelo governo. As primeiras duas bolsas de doutorado pleno no exterior foram concedidas pela CAPES em 1952 (De Meis et al., 2007). A partir de 1994, a formação de mestres e doutores em programas de pós-graduação no país teve um crescimento acentuado em função do aumento da oferta de cursos de bom nível (Brasil, 2000) e gerou uma diminuição na oferta de bolsas para a realização de doutorado pleno no exterior (Velloso \& Velho, 1997). Associada à diminuição do número de bolsas de doutorado pleno, houve um aumento na concessão de bolsas de doutorado-sanduíche. Nesta modalidade de bolsa, os doutorandos adquirem familiaridade com o modo internacional de fazer ciência (Brito, 2004) em estágios de até um ano. De acordo com Velho (2001), no entanto, o doutorando em estágio sanduíche pode não ser "plenamente socializado" no programa de doutorado da universidade estrangeira, em função do menor grau de compromisso estabelecido entre este e a universidade ou grupo de pesquisa ou orientador no exterior.

Além da qualificação técnica e científica proporcionada pelo doutorado, quando este é realizado no exterior, há uma vantagem adicional que pode contribuir para o avanço da produção acadêmica nacional (Carvalho, 2002). Ao retornar para o país de origem, o pesquisador formado no exterior tem seu desempenho aumentado em função da imersão em redes profissionais em seu país de origem, da manutenção dos laços na rede da qual fazem parte seu orientador e demais colaboradores em pesquisa do país 
estrangeiro onde se formou e da promoção da cooperação entre estas redes científicas de ambos os países (Jin, Rousseau, Suttmeier, \& Cao, 2007).

\section{Biodiversidade}

A área de Biodiversidade foi escolhida como objeto desta pesquisa em função da importância dos artigos científicos como veículo de comunicação científica entre os pesquisadores desta área (Mueller, 2005) e pela minha familiaridade com a área, por ter cursado o mestrado em Ecologia e manter contato com a produção científica em temas relacionados à biodiversidade. Estes dois fatores justificam a escolha da área, embora qualquer outra poderia ter sido igualmente eleita, desde que tivesse características semelhantes em termos de tipo de publicação preferencial e que houvesse um especialista da área para avaliar a produção.

A área de Biodiversidade foi criada em 2013 pela reunião das antigas áreas de Botânica, Ecologia, Oceanografia Biológica e Zoologia e é constituída por 124 Programas de Pós-Graduação, sendo 78 Programas de Mestrado e Doutorado, 40 cursos de Mestrado acadêmico; cinco cursos de Mestrado profissional e um curso somente de Doutorado (CAPES, 2013).

No documento de área produzido pela Avaliação Trienal da CAPES de 2013 a área de Biodiversidade é apontada como sendo responsável por prover a sociedade com conceitos e ferramentas que permitam o uso sustentável do patrimônio ou capital biológico, considerando que o Brasil detém a maior biodiversidade e o maior estoque do carbono do planeta. Ainda neste documento, é feita menção ao fato de, no período entre 2007 e 2009, a formação de doutores em temas ligados à biodiversidade ser da ordem de um doutor por dia (CAPES, 2013). 


\section{Objetivos}

O objetivo desta pesquisa é identificar os fatores que predizem produção científica entre pesquisadores da área de Biodiversidade que atuam nas instituições de ensino e pesquisa do Brasil, de modo a contribuir para a construção de um modelo preditivo de produção científica para o contexto brasileiro.

Os objetivos específicos são: (1) comparar a importância relativa dos processos de socialização e dos fatores relacionados à carreira de pesquisador como preditores de produção científica; e (2) identificar as variáveis antecedentes da produção de artigos nacionais e internacionais.

A identificação dos fatores que interferem na capacidade dos pesquisadores de produzir e divulgar o conhecimento científico pode ter impactos positivos para a melhoria dos indicadores da capacidade científica e tecnológica, por meio da elaboração de estratégias de estímulo à produção científica e de ações concretas relacionadas à igualdade de oportunidades sociais, culturais e acadêmicas; de iniciativas de apoio aos pesquisadores durante sua formação; e de incentivo a práticas organizacionais compatíveis com a crescente demanda por aumento da quantidade e da qualidade da produção científica. 


\section{Método}

Para alcançar os objetivos estabelecidos, esta pesquisa foi realizada em duas etapas: (1) análise das respostas a um questionário enviado para os pesquisadores selecionados a partir dos currículos inseridos na Plataforma Lattes e (2) análise dos currículos e quantificação da produção científica.

\section{Seleção dos Participantes}

A Plataforma Lattes do CNPq, utilizada como fonte de informações para este estudo, é uma base de dados legitimada pela comunidade científica, a partir da qual é possível obter dados formais da vida acadêmica pregressa e atual dos pesquisadores. O cadastramento do currículo nesta plataforma é compulsório para todos os pesquisadores que atuam em Instituições de Ensino e Pesquisa no Brasil, desde 2002. O acesso aos currículos cadastrados é aberto ao público em geral e diversos filtros permitem direcionar a busca de currículos. Neste estudo foram utilizados os seguintes filtros: assunto - biodiversidade; base - doutores; nacionalidade - brasileira; formação acadêmica/titulação - doutorado; país, região, UF, instituição - toda(o)s; atuação profissional: grande área - Ciências Biológicas; área - Ecologia; subárea, especialidade - todas; atividade profissional/natureza da atividade - todas; atividade - atual; país Brasil; região, UF, instituição - todo(a)s.

Esta busca gerou inicialmente 2.582 currículos e foi reduzida depois para 670 currículos de pesquisadores que concluíram o doutorado entre 1989-2002. O período máximo (2002) foi estabelecido para obter um grupo de participantes com no mínimo 10 anos de atividade profissional (2003-2012). O período mínimo (1989) foi escolhido 
de modo a obter um grupo de tamanho razoável, mas não muito heterogêneo em termos de data de conclusão do doutorado. Foram incluídos, finalmente, os pesquisadores cujos currículos estavam atualizados, no mínimo seis meses após o período de referência para a quantificação das publicações, de modo a dar tempo para que estas fossem incluídas nos respectivos currículos. Este novo recorte gerou uma população de 566 pesquisadores cujos currículos foram analisados.

\section{Instrumentos}

Para o levantamento das informações relacionadas à vida pessoal e familiar dos pesquisadores foi realizado um survey on line utilizando um questionário enviado por email para os 566 pesquisadores selecionados. A população final deste estudo foi composta pelos 249 pesquisadores que responderam ao questionário, ou seja, $44 \%$ dos pesquisadores da população original.

\section{Questionário.}

O questionário (Anexo 1) foi estruturado no programa Lime Survey, hospedado na página de um pesquisador do Laboratório de Psicologia Ambiental da Universidade de Brasília. O Lime Survey é uma plataforma de pesquisa on line gratuita, disponível no site: www.limesurvey.org. Algumas das informações solicitadas no questionário poderiam ser obtidas no Lattes, mas foram incluídas no questionário para confirmação e aumento da precisão. As 21 perguntas foram organizadas em oito fases/temas: (1) Fase pré-universitária; (2) Doutorado; (3) Início da carreira - primeiros 10 anos após o doutorado; (4) Tempo de carreira; (5) Últimos 10 anos de atuação profissional; (6) 
Eventos pessoais/profissionais; (7) Vida pessoal x Carreira acadêmica; e (8) Identificação.

O teste do instrumento foi realizado com uma versão preliminar do questionário aplicada a um grupo de doutores em Ecologia que não seriam incluídos nesta pesquisa. As respostas, as dúvidas e as sugestões apresentadas contribuíram para a produção da versão final.

\section{Procedimento.}

Os endereços de e-mail dos 566 pesquisadores selecionados foram obtidos em sites de busca pela internet ou nos sites dos respectivos Programas de Pós-Graduação e Institutos de Pesquisa. Um convite personalizado via e-mail foi enviado para cada pesquisador, contendo uma carta de apresentação e o link para o questionário. Ao acessar o questionário, o pesquisador primeiramente visualizava um texto agradecendo o interesse em participar, explicando os objetivos e a importância da pesquisa e esclarecendo que ao preencher o questionário, entendia-se que o participante havia concordado em participar voluntariamente da pesquisa. Foram disponibilizadas ainda informações sobre a garantia de sigilo quanto à identificação dos respondentes, o número de perguntas do questionário (21) e informados os meios de contatos com a pesquisadora. Os convites por e-mail foram enviados entre os dias 15 e 18 de abril de 2014. O primeiro lembrete foi enviado entre os dias 5 e 8 de maio e o segundo e último lembrete entre os dias 28 e 30 de maio. 


\section{Análise do CV Lattes}

Nesta etapa foram coletadas informações sobre a formação acadêmica e foram quantificados os artigos publicados por estes em periódicos científicos nacionais e internacionais.

\section{Formação acadêmica.}

Foram coletadas informações referentes à modalidade de doutorado; local de realização e ano de conclusão. Apenas as modalidades doutorado pleno no Brasil e doutorado pleno no exterior foram consideradas. Como apenas oito pesquisadores da haviam realizado o doutorado sanduíche, estes casos foram classificados como doutorado no Brasil.

\section{Quantificação da produção científica.}

A quantificação das publicações foi feita por meio da contagem simples do número de artigos publicados, isto é, não foi levado em conta o número de autores ou a posição dos mesmos na lista de autores. Foi quantificado o número acumulado de artigos nacionais e internacionais publicados até o $10^{\circ}$ ano da carreira após o doutorado (primeiros 10 anos, $\mathrm{n}=249$ ) e o número acumulado de artigos publicados em periódicos nacionais e internacionais nos últimos 10 anos da carreira. Fazem parte deste grupo apenas os pesquisadores que concluíram o doutorado até $1993(\mathrm{n}=47)$, e que, portanto, têm os dois períodos da carreira: (primeiros 10 anos: 1994 - 2003; últimos 10 anos: 2004 - 2013). Foram consideradas publicações nacionais os artigos publicados em revistas sediadas no Brasil e internacionais os artigos publicados por revistas editadas em outros países, independente do idioma de publicação. A identificação dos periódicos 
científicos nacionais e internacionais foi feita por um juiz especialista na área de Ecologia. A separação entre publicação nacional e internacional é relevante para estudos sobre produção científica em países periféricos como o Brasil, em função de representarem duas orientações distintas na carreira: reconhecimento internacional ou desenvolvimento da pesquisa local (Miller et al., 2012).

\section{Caracterização}

Os participantes desta pesquisa são pesquisadores e docentes de nível superior, identificados como 'pesquisadores', com doutorado concluído no período de 1989 a 2002, atuantes em Instituições de Ensino Superior ou de Pesquisa no Brasil, identificadas como 'IES' com no mínimo dez anos de atuação profissional na área de Biodiversidade, cujos currículos estavam cadastrados na Plataforma Lattes.

Dos 249 pesquisadores, 135 são homens $(54,2 \%)$ e 114 são mulheres $(45,8 \%)$, distribuição sexual comparável a do grupo de pesquisadores para os quais o questionário foi enviado: 306 homens $(54,1 \%)$ e 260 mulheres $(45,9 \%)$.

Quanto ao local de realização do doutorado, $81,5 \%$ cursaram o doutorado no Brasil, nas seguintes universidades: Universidade de São Paulo - USP (20\%); Universidade Estadual de Campinas - UNICAMP (16\%); Universidade Federal de São Carlos - UFSCar (11\%) e Universidade Estadual de São Paulo - UNESP (9\%). As universidades: Universidade Federal do Rio de Janeiro - UFRJ, Universidade Federal do Paraná - UFPR, Universidade Estadual de Maringá - UEM e Universidade de Brasília UnB formaram, cada uma, menos de $5 \%$ dos pesquisadores da população estudada. Os demais pesquisadores estudaram nas seguintes universidades ou institutos de pesquisa: Fundação Universidade do Rio Grande - FURG; Instituto Nacional de Pesquisa da 
Amazônia - INPA; Pontifícia Universidade Católica do Rio Grande do Sul - PUC-RS; Universidade Estadual do Norte Fluminense - UENF; Universidade Federal Fluminense - UFF; Universidade Federal Rural do Rio de Janeiro - UFRRJ; Universidade Federal do Rio Grande do Sul - UFRGS; Universidade Federal do Ceará - UFC; Universidade Federal de Lavras - UFLA; Universidade Federal de Minas Gerais - UFMG; Universidade Federal do Pará - UFPA; Universidade Federal Rural de Pernambuco UFRPE e Universidade Federal de Viçosa - UFV.

Os pesquisadores que cursaram o doutorado no exterior $(18,5 \%)$ estudaram principalmente nos EUA (16); Alemanha e Inglaterra (9) e Escócia (7). Um pequeno número de pesquisadores estudou no Canadá; Argentina; Espanha; França e Suécia.

A idade média de conclusão do doutorado foi 35,7 anos, variando de 27 a 55 anos de idade. 85 pesquisadores concluíram o doutorado entre os anos de 1989 e 1995 e 164 pesquisadores concluíram entre 1996 e 2002.

Todos os pesquisadores trabalham em regime de dedicação exclusiva e 95\% atuam na pós-graduação. Quanto ao local de atuação profissional, as Instituições de Ensino ou de Pesquisa representadas por ao menos quatro pesquisadores, por região, são:

- Sudeste: USP, UNESP, UFMG, UFRJ, UENF, UNICAMP, UERJ, UFU e IBT;

- Sul: UFRGS UFPR, FURG, UEM e UNISINOS;

- Nordeste: UFBA, UFC, UFMA e UFRPE;

- Centro-Oeste: UNB, UFG e UFMS;

- Norte: INPA.

Os demais pesquisadores distribuem-se em outras 80 instituições de ensino ou pesquisa. 
Dos 249 pesquisadores, $96(38,6 \%)$ realizaram pós-doutorado e $113(45,4 \%)$ são bolsistas de Produtividade em Pesquisa do CNPq, nas categorias:

Nível $1-60(24,1 \%): 1 \mathrm{~A}=8 ; 1 \mathrm{~B}=17 ; 1 \mathrm{C}=9 ; 1 \mathrm{D}=26)$;

Nível 2 - $53(21,3 \%)$;

Não possuem bolsa - $136(54,6 \%)$.

Considerando os 10 primeiros anos após a conclusão do doutorado, 26,8\% dos pesquisadores não se casaram, a maior parte dos pesquisadores $(63,0 \%)$ é ou foi casado apenas uma vez, 6,9\% casaram-se duas vezes e apenas 3,3\% casaram-se três vezes. Quanto ao número de filhos, 32,8\% não tiveram filhos, 25,9\% tiveram um filho, 31,2\% tiveram dois filhos, $8,9 \%$ tiveram três filhos e apenas $1,2 \%$ tiveram quatro ou cinco filhos.

Quanto ao suporte educacional familiar, a maior parte dos pesquisadores revelou ter recebido supervisão pedagógica da mãe $(70,7 \%)$, do pai $(11,2 \%)$ ou de ambos os pais $(3,6 \%)$. Alguns dados ilustrativos do perfil dos pesquisadores da revelam que mais da metade $(57,4 \%)$ é proveniente de famílias onde algum membro possuía formação universitária. Apenas 14\% declararam não ter tido acesso a informações sobre ensino superior no período que antecedeu o ingresso na universidade. Com relação à experiência internacional, a maior parte dos pesquisadores $(52,2 \%)$ pertence a famílias sem qualquer contato com países estrangeiros e poucos $(10,8 \%)$ haviam residido no exterior. 


\section{Publicações.}

Os 249 pesquisadores publicaram 4.669 artigos nos primeiros 10 anos de suas carreiras. Porém, a distribuição dos artigos entre pesquisadores é muito desigual, variando de 0 a 112, com os $10 \%$ mais produtivos publicando $27,3 \%$ dos artigos (Figura $1)$.

A Tabela 1 mostra as médias de publicações de homens e mulheres por tipo de publicação (nacional e internacional).

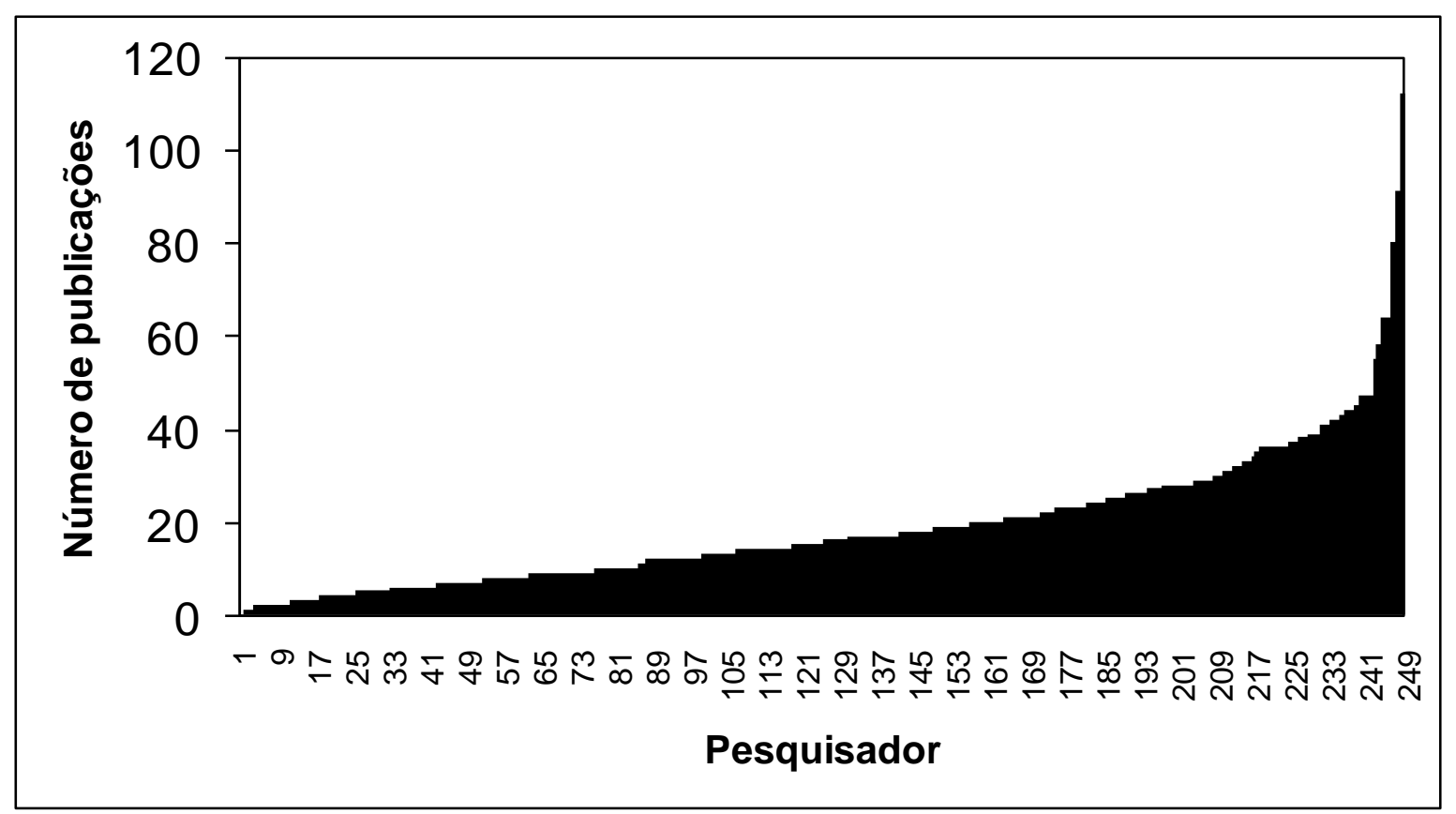

Figura 1. Número de artigos publicados pelos pesquisadores da área de Biodiversidade nos primeiros 10 anos após o doutorado. 
Tabela 1. Média ( \pm DP) do número de publicações nacionais, internacionais e total de publicações durante os primeiros 10 anos da carreira de pesquisadores brasileiros (homens, mulheres e total) da área de Biodiversidade.

\begin{tabular}{cccc}
\hline Tipo de & \multicolumn{3}{c}{ Grupo de pesquisadores } \\
\cline { 2 - 4 } publicação & $\begin{array}{c}\text { Homens } \\
(\mathbf{n}=\mathbf{1 3 5})\end{array}$ & $\begin{array}{c}\text { Mulheres } \\
(\mathbf{n}=\mathbf{1 1 4})\end{array}$ & $\begin{array}{c}\text { Total } \\
(\mathbf{n}=\mathbf{2 4 9})\end{array}$ \\
\hline Brasil & $11,3 \pm 8,7$ & $9,2 \pm 8,0$ & $10,4 \pm 8,4$ \\
Internacional & $9,8 \pm 11,3$ & $6,7 \pm 7,0$ & $8,4 \pm 9,7$ \\
Total & $21,1 \pm 16,9$ & $15,9 \pm 11,5$ & $18,7 \pm 14,9$ \\
\hline
\end{tabular}

\section{Variáveis excluídas}

Algumas das informações coletadas por meio do questionário foram excluídas das análises pelas seguintes razões:

(1) Escolaridade e Profissão do responsável pedagógico são variáveis relacionadas diretamente à variável "suporte educacional", que não se mostrou relevante como preditora de produção científica. Por esta razão, não considerei relevante investigar as duas variáveis relacionadas.

(2) As variáveis apresentações de trabalhos científicos durante o doutorado e orientação de alunos de iniciação científica tiveram resposta positiva de, respectivamente, $96 \%$ e $98 \%$ dos participantes e foram eliminadas devido à baixa variação.

As demais informações obtidas por meio do questionário foram tabuladas e analisadas descritiva e estatisticamente. 


\section{Análise}

\section{Seleção de modelos - conceitos teóricos.}

Modelos são simplificações da realidade utilizadas para descrever as relações entre variáveis em sistemas complexos. A seleção de modelos tem por objetivo identificar qual(is) modelo(s) melhor descreve(m) as relações entre as variáveis preditoras e a variável critério (Burnham \& Anderson, 2004).

As abordagens convencionais de seleção de modelos, baseadas em testes de hipóteses e no valor de "p" (Field, 2009; Zar, 1984) são adequadas para a análise de dados obtidos por meio de experimentos controlados ou com poucos parâmetros. Situação diferente é encontrada, no entanto, quando é necessário obter estimativas sobre a magnitude do efeito de variáveis potencialmente preditoras de um determinado processo e avaliar se este efeito é suficientemente importante para a inclusão da variável em um modelo preditivo (Mazerolle, 2006).

Um critério alternativo para a seleção de modelos foi desenvolvido por Hirotugu Akaike na década de 1970. Esse critério tem como base um conceito oriundo da Teoria da Informação, a distância de Kullback-Leibler, relacionada à medida da informação perdida na aproximação de um modelo qualquer ao "modelo verdadeiro" (Burnham \& Anderson, 2001). A seleção de modelos pelo Critério de Informação de Akaike (AIC) utiliza a razão de verossimilhança e o princípio da máxima verossimilhança para estimar a discrepância entre cada modelo e a "realidade". Nesta análise, diversos modelos são comparados em função das diferenças entre os índices de AIC (delta AIC - $\triangle \mathrm{AIC}$ ) atribuídos a cada um. O modelo selecionado como o melhor será aquele com o menor valor de $\triangle \mathrm{AIC}$, ou seja, aquele "menos distante" da realidade e, portanto, o que melhor 
explica o processo ou o sistema em questão, dentre os modelos analisados, considerando os dados disponíveis (Burnham, Anderson, \& Huyvaert, 2011).

Os valores individuais de $\triangle \mathrm{AIC}$ não são interpretáveis isoladamente, sendo utilizados apenas para a comparação entre modelos. O melhor modelo terá $\Delta \mathrm{AIC}=0$ e o valor de $\Delta$ AIC dos demais modelos fornece uma medida do poder de evidência relativo. A regra sugerida por Burnham e Anderson (2004) para a avaliação dos modelos é a seguinte: valores de $\Delta \mathrm{AIC} \leq 2$ sugerem que há forte evidência de suporte para o modelo. Valores de $\triangle \mathrm{AIC}$ entre 3 e 7 indicam que o modelo tem consideravelmente menos suporte e valores de $\triangle \mathrm{AIC} \geq 8$ indicam que o modelo é bastante improvável.

Em grande parte das pesquisas que utilizam AIC, o tamanho da amostra requer um ajuste relacionado ao aumento da penalização por excesso de variáveis - AICc. Burnham e Anderson (2002) propõem que se a relação entre o tamanho da amostra (n) e o número de variáveis no modelo $(\mathrm{K})$ for menor que $40(\mathrm{n} / \mathrm{K}<40)$, o ajuste AICc deverá ser utilizado. Uma vez que este ajuste é flexível, ou seja, AICc converge para AIC na medida em que o tamanho da amostra aumenta ou que o número de variáveis diminui, Burnham e Anderson (2002) recomendam que se use sempre AICc ao invés de AIC.

Outro ajuste no critério de AIC é aquele utilizado para a seleção de modelos que utilizam dados de contagem, que tipicamente apresentam problemas de super-dispersão e, portanto, não se conformam à distribuição normal. Nestes casos, o ajuste implica na utilização de uma estimativa de inflação da variância (parâmetro de dispersão). $\mathrm{O}$ critério de seleção de modelos ajustado pelo parâmetro de dispersão passa a ser denominado qAIC, em função do conceito de quasi-verossimilhança (Anderson, 2008). A distribuição de frequência da produtividade científica em qualquer área do 
conhecimento é reconhecidamente não normal (Lotka, 1926 citado em Solla Price, 1976), conforme verificado também nesta pesquisa (Figura 1).

Finalmente, vale enfatizar que o critério de AIC não é um teste de hipóteses e não utiliza o conceito de significância estatística (p). A seleção de modelos por meio do AIC tem como foco a magnitude da evidência ( $\triangle \mathrm{AIC}$ ), sendo uma medida da incerteza de cada modelo (Anderson, Burnham, \& Thompson, 2000; Anderson, Link, Johnson, \& Burnham, 2001; Burnham \& Anderson, 2002). Por esta razão, Anderson (2008), não recomenda misturar em uma mesma análise, evidências originárias da Teoria da Informação, com evidências obtidas por meio de Testes de Hipóteses.

A análise estatística utilizada nesta pesquisa foi a seleção de modelos por meio de modelos lineares generalizados (GLMs), usando o critério de Akaike (AIC) corrigido para amostras de tamanho pequeno (AICc) e dispersão dos dados (qAICc). Para cada conjunto de variáveis independentes, foram construídos modelos completos (contendo todas as variáveis) e modelos aninhados contendo as combinações destas variáveis. Cada grupo de modelos foi analisado separadamente para publicações nacionais, publicações internacionais e total de publicações. Para a seleção hierárquica dos modelos foram utilizados os valores de $\Delta \mathrm{qAICc}$, que mostram a diferença entre o modelo de maior suporte e os demais modelos e os respectivos graus de liberdade.

A estimativa e o erro padrão das variáveis dos melhores modelos são reportados, da mesma forma que em uma regressão linear, para estimar o efeito de cada variável no modelo. $\mathrm{O}$ valor da estimativa representa, nesta pesquisa, quantos artigos seriam publicados a mais ou a menos em função da contribuição de cada variável do modelo, ou seja, o quanto cada variável contribui para estimar a produção científica dos pesquisadores. Desta forma, quanto maior a estimativa, maior o efeito. O erro padrão 
mostra a variação desta estimativa, em função da amostra. Assim, quanto menor o erro padrão, maior a confiança no efeito estimado da variável (Field, 2009). Todas as análises foram conduzidas no pacote Tools for General Maximum Likelihood Estimation (bbmle), versão 1.0.17 no programa 'R', versão 3.0.3. 


\section{Capítulo 1 - Socialização familiar}

Características pessoais como o sexo e a idade e situações relacionadas à socialização familiar podem interferir na produção científica de um pesquisador. O contexto familiar (estado civil e filhos), também pode contribuir para afetar este comportamento. Assim, neste capítulo, apresento e discuto as relações encontradas entre os fatores pessoais e a socialização familiar e o seu papel sobre a produção científica. As variáveis analisadas são: sexo, idade na conclusão do doutorado, fase da carreira, número de casamentos, número de filhos, crises e origem familiar.

\section{Sexo, Idade e Família}

O tema "participação feminina na Ciência" foi discutido pela primeira vez em 1913 no livro "Women in Science", mas somente a partir dos anos de 1980, a pesquisa sobre diferenças entre os sexos na ciência tornou-se importante, sendo a menor produtividade científica das mulheres, um dos principais aspectos abordados na literatura sobre o tema (Leta, 2003). As diferenças entre homens e mulheres em relação à quantidade de publicações e ao número de citações recebidas são consistentes entre as várias áreas do conhecimento (Cole \& Zuckerman, 1984; Xie \& Shauman, 1998) e são comuns a diversos países (Olinto, 2011). Diferenças significativas foram encontradas entre pesquisadores das áreas de Ecologia e Biologia Evolutiva da Inglaterra e Austrália, com menor produtividade feminina desde o início da carreira (Symonds et al., 2006). Embora este padrão seja comum, as explicações para a menor produtividade feminina são complexas. 
Diferenças entre homens e mulheres em termos de produtividade científica podem ser moderadas pela idade com a qual o pesquisador conclui o doutorado, em função da associação com eventos relacionados à vida pessoal, como casamento e nascimento de filhos. Uma vez que o impacto destes eventos varia com o passar do tempo, a produtividade científica pode variar ao longo da carreira, afetando diferentemente homens e mulheres. Paradoxalmente, homens casados tendem a ser o grupo mais produtivo e mulheres solteiras o menos produtivo (Lee \& Bozeman, 2005). Mulheres casadas e com filhos pequenos tem $35 \%$ menos probabilidade de ingressar em uma carreira com perspectiva de estabilidade (tenure-track position) em comparação com homens na mesma situação, nos EUA. Dentre as que ingressam na carreira, a probabilidade de alcançar estabilidade é $27 \%$ menor em comparação com os homens (Editorial, 2010). Mulheres solteiras e sem filhos têm 16\% mais chance de obter um emprego do que homens nas mesmas condições, enquanto mulheres casadas com filhos pequenos têm mais dificuldade em aceitar empregos que envolvam deslocamento para outras cidades (Wolfinger, Mason \& Goulden, 2008). Mulheres com filhos pequenos têm $45 \%$ menos chance de assumir um cargo de líder de pesquisa em comparação com homens com filhos pequenos (69\%) (Editorial, 2010).

O maior tempo investido pelas mulheres em comparação com os homens, em atividades relacionadas às responsabilidades com a família, seria responsável pela maior dificuldade em obter estabilidade profissional na área de Neurociências (Barinaga, 1992). Mulheres encontram dificuldades em conciliar pesquisa acadêmica e maternidade tanto na Biologia quanto na Medicina (Adamo, 2013). No entanto, entre as médicas a taxa de abandono da carreira é muito pequena (NSERC, 2010), enquanto na carreira científica em Biologia, grande parte das mulheres abandona a carreira após o 
doutorado (Goulden, Mason \& Frasch, 2011; NSERC, 2010). A diferença entre as duas carreiras é que para as médicas, a faixa etária em que elas alcançam estabilidade na carreira coincide com o período ideal para iniciar uma família, em torno dos 30 anos (Wolfinger, Goulden, \& Mason, 2010). Já na Biologia, para uma cientista que concluiu o doutorado com 33 ou 34 anos (Jacobs \& Winslow, 2004), são necessários mais seis anos aproximadamente para adquirir estabilidade profissional. Desta forma, quando atingem a fase da carreira ideal para iniciar uma família, as mulheres já têm 40 anos aproximadamente (Wolfinger et al., 2010).

É possível que as dificuldades enfrentadas pelas mulheres no início da carreira científica, associadas à "janela de fertilidade” mais estreita e cuidados com filhos pequenos tenham um impacto negativo na sua produtividade científica inicial (Cole \& Cole, 1973). Sendo assim, se a baixa produtividade inicial feminina estiver associada aos cuidados com os filhos pequenos, então a produtividade observada no início da carreira não representaria o potencial real de produção das mulheres (Reskin, 1978) e a produção tenderia a aumentar ao longo da carreira na medida da diminuição destas demandas.

\section{Resposta ao estresse}

Homens e mulheres diferem na forma como lidam com o estresse. Situações estressantes encontradas na vida cotidiana como estresse financeiro, social, profissional, ambiental, familiar e relacionado aos filhos provocam impacto na saúde mental (Denton, Prus \& Walters, 2004), mas homens e mulheres são afetados de forma diferente em função de diferentes níveis de exposição e vulnerabilidade aos fatores estressantes (McDonough \& Strohschein, 2003). As mulheres tendem a ser mais 
susceptíveis ao estresse provocado por eventos relacionados à família e os homens, aos eventos relacionados ao trabalho (Conger et al., 1993).

Outra hipótese para explicar as diferenças entre os gêneros quanto às reações ao estresse referem-se à maior eloquência das mulheres quanto à expressão das emoções, criando uma falsa impressão de maior estresse (Nolen-Hoeksema, 1987). As emoções experimentadas por homens e mulheres em resposta ao estresse também são diferentes: homens sentem raiva direcionada a outras pessoas e as mulheres ficam aborrecidas consigo mesmas (Mirowsky \& Ross, 1995). As mulheres tendem ainda a considerar uma determinada situação como mais estressante, do que um homem consideraria (Ptacek, Smith \& Dodge, 1994). Com a idade, homens e mulheres respondem de forma menos intensa ao estresse (Nurullah, 2010).

\section{Origem familiar}

Um dos fatores que podem afetar a produtividade científica é a origem familiar, representada pelo suporte educacional, pelo conhecimento da família sobre o sistema de ensino superior e pela experiência internacional da família. O comportamento educativo da família pode afetar o desempenho de estudantes, em função das disposições cognitivas adquiridas no processo de socialização educacional familiar (Bourdieu \& Passeron, 1964). Esta socialização depende, entre outros fatores, da adesão, no âmbito da família, ao papel, tradicionalmente assumido pela mãe, de professor coadjuvante (Carvalho, 2000).

As práticas educativas adotadas por algumas famílias constituem-se em estratégias de mobilização escolar em função de um projeto de escolarização dos filhos e envolvem recursos humanos como tempo livre para acompanhamento e supervisão do 
trabalho escolar, assim como recursos materiais: livros, computador, etc (Carvalho, 2000). A mobilização escolar da família propiciaria a mobilização individual do estudante em relação à escola e ao conhecimento, um importante elemento constitutivo do sucesso escolar (Charlot, 1996). Esta mobilização familiar teria consequências duradouras no desempenho cognitivo em função da regularidade e organização das tarefas escolares e do cumprimento de regras, que dariam origem a estruturas cognitivas relacionadas à capacidade de organização e ordenamento de pensamentos, potencialmente desencadeadores de elementos favoráveis ao êxito acadêmico (Vianna, 2005).

As informações sobre oportunidades relacionadas a instituições de ensino superior no Brasil e principalmente no exterior circulam nos meios acadêmicos, nos Institutos de Pesquisa e entre estes e as agências e fundações relacionadas ao fomento à pesquisa. Para aqueles não relacionados a estes círculos, o acesso à informação relevante para a trajetória acadêmica depende de outras pessoas. Retomando a questão das trajetórias dos herdeiros e não-herdeiros apresentada na Revisão, nos casos de famílias que não dispunham de informações sobre o ensino superior e a carreira acadêmica, diversas estratégias de escolarização tiveram de ser utilizadas para que os filhos pudessem superar o vestibular, a graduação e o mestrado até fazer parte da pequena parcela da população brasileira que chega ao doutorado (Brito, 2004).

Embora a origem social (e econômica) não seja limitante para a realização do doutorado no exterior, os benefícios proporcionados por esta experiência são maiores quando já existe fluência no idioma estrangeiro e conhecimento sobre a cultura estrangeira proporcionada por viagens de estudo ou lazer e contato com familiares ou amigos em outros países. A experiência internacional prévia proporciona familiaridade 
com as regras e fatores informais que facilita a inserção na cultura acadêmica internacional (Brito, 2004). O domínio do idioma facilita a comunicação no meio científico, proporcionando um benefício adicional para a carreira (Meneguini \& Packer, 2007).

\section{Método}

Os métodos utilizados para a coleta de dados e as informações gerais sobre as análises estatísticas estão descritos na parte de Método (pg. 93). Para este capítulo, vale esclarecer que as variáveis: crises pessoais e familiares foram agrupadas, dando origem à variável "crise".

As respostas à pergunta: "em qual destas fases você experimentou/está experimentando mais conflitos entre demandas pessoais/familiares e demandas acadêmicas, foram transformadas na variável dicotômica conflitos $=1$ (experimentou conflito em qualquer fase do período considerado ou conflitos $=0$ (não experimentou conflitos).

\section{Resultados}

A seguir são apresentados os resultados das análises das variáveis relacionadas aos fatores individuais: sexo, idade na conclusão do doutorado, número de casamentos e número de filhos, crises, conflitos e origem familiar (suporte educacional, conhecimento sobre ensino superior e experiência internacional). Além disso, para um grupo de pesquisadores com pelo menos 20 anos de carreira, foi analisado o efeito da fase da carreira. As variáveis foram organizadas em grupos, para fins das análises, em função 
das associações naturais entre as mesmas. A variável sexo foi incluída em todos os grupos nos quais seria esperado encontrar diferenças entre homens e mulheres.

\section{Sexo e Idade.}

Os pesquisadores concluíram o doutorado com idade variando entre 27 e 55 anos, sendo que os homens concluíram em média um pouco mais jovens $(34,9 \pm 4,7$ anos, $\mathrm{n}=$ 114) do que as mulheres $(36,6 \pm 5,5$ anos, $n=135)$ (Figura 2$)$.

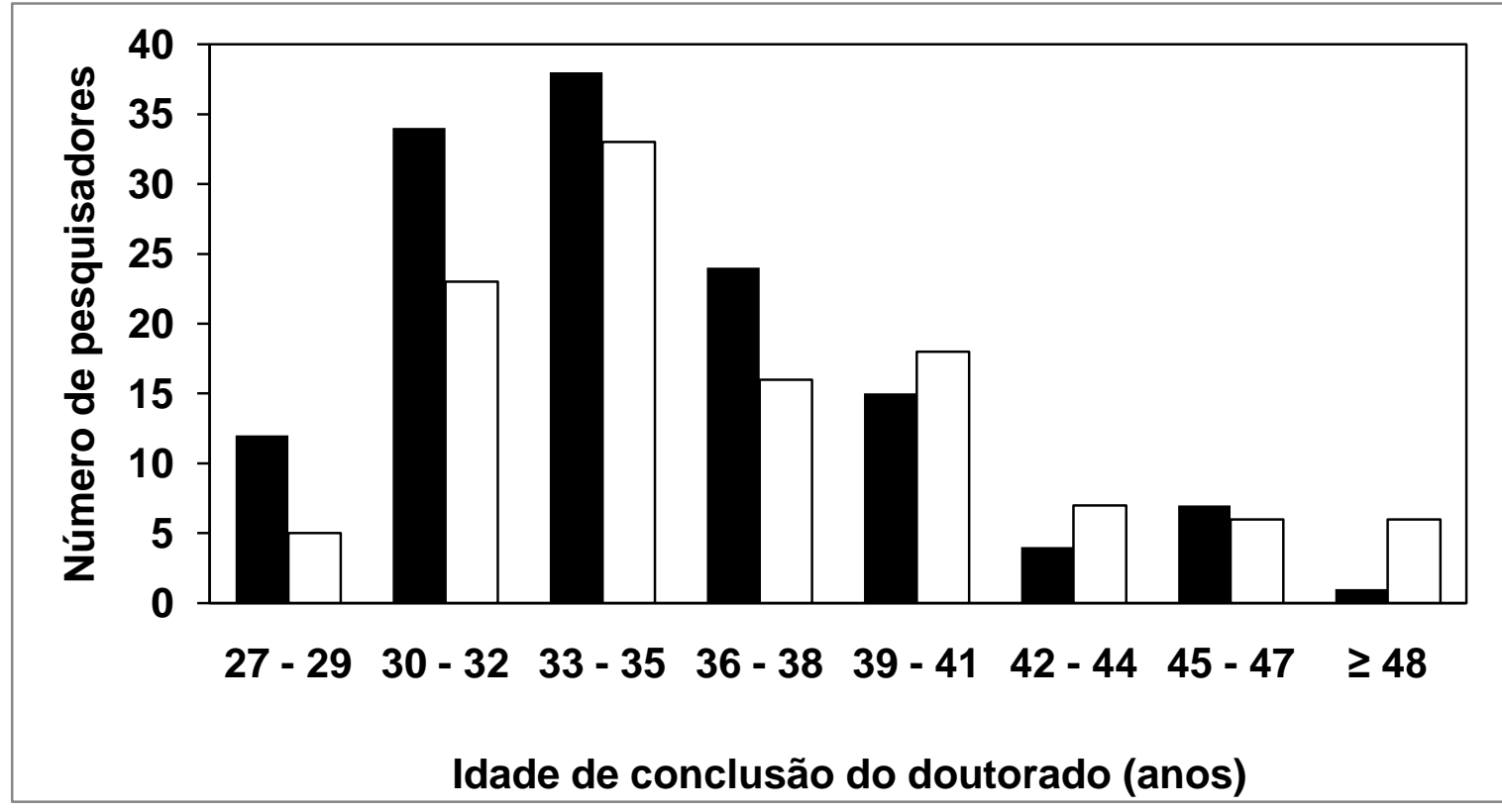

Figura 2. Idade de conclusão do doutorado (anos) de homens $(\mathrm{n}=135)$ (barras pretas) e mulheres $(\mathrm{n}=114)$ (barras brancas) da área de Biodiversidade.

Os resultados da análise estatística mostram que, para publicações nacionais, as variáveis sexo e idade e a interação entre estas duas variáveis foram incluídas no melhor modelo (Tabela 2). A análise dos coeficientes (Tabela 3) mostra que o maior efeito é da variável sexo (estimativa $=1,950)$. A variável idade, isoladamente, tem pouco poder de 
explicação (estimativa $=0,005)$ e considerando o valor do erro padrão $(\mathrm{EP})$, o efeito pode ser tanto positivo quanto negativo, uma vez que há sobreposição do zero. A interação entre idade e sexo foi uma das variáveis selecionadas no modelo, porém o seu efeito foi muito pequeno, mostrando diminuição da produção de homens do grupo dos que concluíram com mais idade (estimativa $=-0,050)($ Tabela 3 e Figura 3$)$.

Tabela 2. Variáveis dos modelos (sexo; idade; sexo:idade), quasiAIC, $\triangle \mathrm{AIC}$ e graus de liberdade das variáveis dos modelos mais ajustados $(\triangle \mathrm{AIC}<2)$ para predizer o número de publicações no Brasil (pubbr), internacionais (pubint) e total de publicações (pubtot) durante os 10 primeiros anos da carreira após a obtenção do doutorado, de pesquisadores brasileiros da área de Biodiversidade.

\begin{tabular}{ccccc}
\hline $\begin{array}{c}\text { Tipo de } \\
\text { publicação }\end{array}$ & Modelos & qAICc & $\Delta$ AIC & gl \\
\hline Brasil & pubbr $\sim$ sexo + idade + sexo:idade & 386,3 & 0,0 & 4 \\
& pubint $\sim$ sexo + idade + sexo:idade & 316,4 & 0,0 & 4 \\
Internacional & pubint $\sim$ sexo + idade & 317,6 & 1,2 & 3 \\
& & & & \\
& & & & \\
Total & pubtot $\sim$ sexo + idade + sexo:idade & 345,3 & 0,0 & 4 \\
& & & & \\
\hline
\end{tabular}


Tabela 3. Resultados do GLM com as estimativas das variáveis incluídas nos melhores modelos (Tabela 2) como preditoras do número de publicações no Brasil, internacionais e total de publicações durante os 10 primeiros anos da carreira após a obtenção do doutorado, de pesquisadores brasileiros da área de Biodiversidade.

\begin{tabular}{|c|c|c|}
\hline $\begin{array}{c}\text { Tipo de } \\
\text { publicação }\end{array}$ & Termo & Estimativa ( $( \pm$ EP) \\
\hline \multirow[t]{4}{*}{ Brasil } & (Intercepto) & $2,032 \pm 0,526$ \\
\hline & Sexo (Homem) & $1,951 \pm 0,744$ \\
\hline & Idade (Mais velho) & $0,005 \pm 0,014$ \\
\hline & Sexo (Homem):Idade (Mais velho) & $-0,050 \pm 0,021$ \\
\hline \multirow[t]{4}{*}{ Internacional } & (Intercepto) & $3,613 \pm 0,784$ \\
\hline & Sexo (Homem) & $2,186 \pm 1,065$ \\
\hline & Idade (Mais velho) & $-0,048 \pm 0,022$ \\
\hline & Sexo (Homem):Idade (Mais velho) & $-0,056 \pm 0,031$ \\
\hline \multirow[t]{4}{*}{ Total } & (Intercepto) & $3,328 \pm 0,505$ \\
\hline & Sexo (Homem) & $2,140 \pm 0,704$ \\
\hline & Idade (Mais velho) & $-0,015 \pm 0,014$ \\
\hline & Sexo (Homem):Idade (Mais velho) & $-0,055 \pm 0,020$ \\
\hline
\end{tabular}



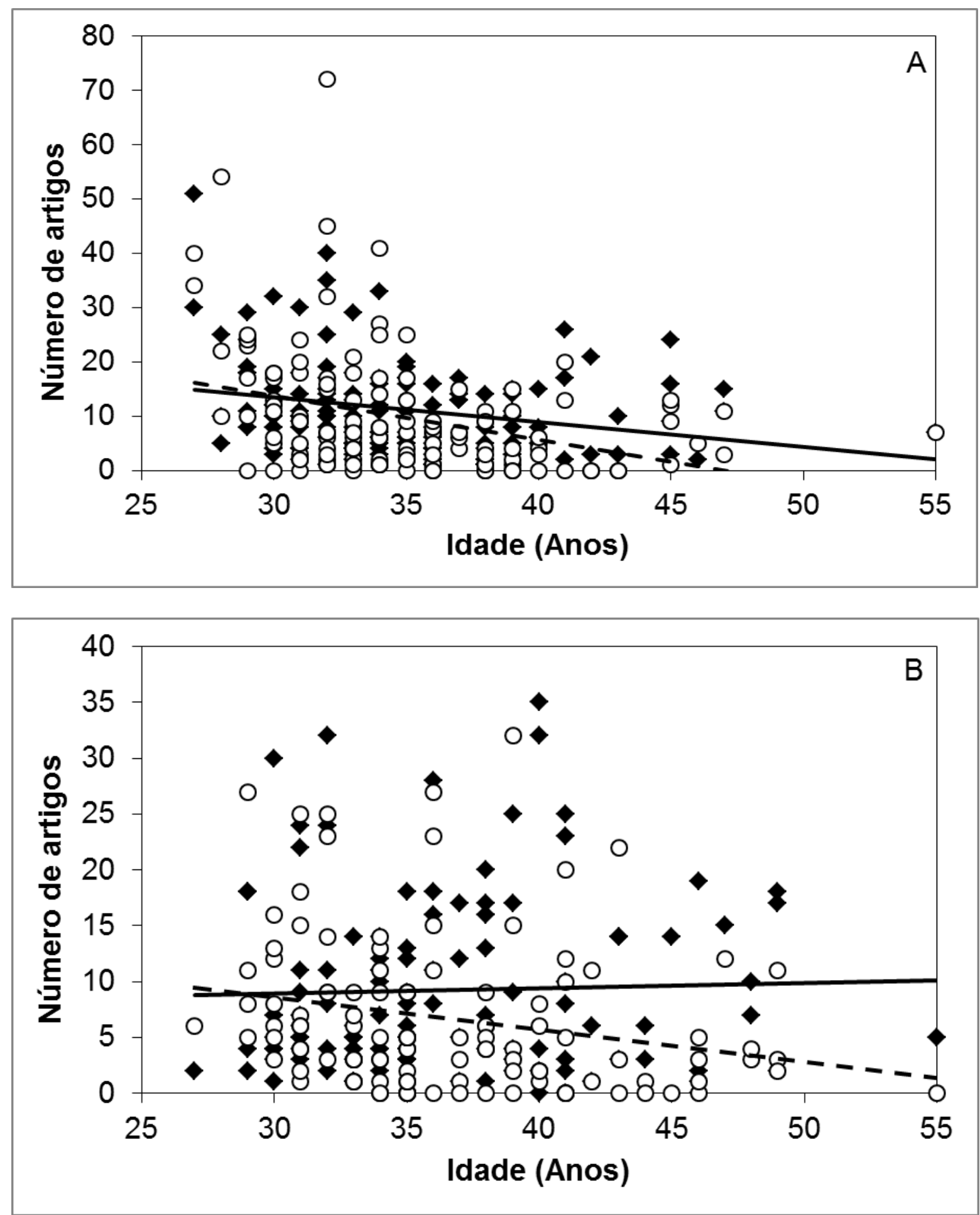

Figura 3. Número de artigos publicados por homens (A) e mulheres (B) nos primeiros 10 anos após a conclusão do doutorado em relação à idade de conclusão do doutorado. Losangos pretos e linhas contínuas representam artigos nacionais e círculos vazados e linhas tracejadas representam artigos internacionais. 
Em relação a publicações internacionais, mais uma vez as variáveis sexo e idade e a interação entre estas duas variáveis foram selecionadas no melhor modelo. As variáveis sexo e idade foram incluídas também no segundo melhor modelo (Tabela 1). A análise dos coeficientes (Tabela 3) mostra que o efeito da variável sexo é maior (estimativa $=2,186)$ em relação a publicações internacionais em comparação com o efeito desta variável nas publicações nacionais. O efeito da idade também é maior (estimativa $=-0,048)$, ou seja, a diferença em termos de publicação internacional entre o grupo mais jovem e mais velho é maior. A interação entre sexo e idade mostra que os homens (estimativa $=-0,056)$ do grupo dos que concluíram o doutorado mais velhos, produzem menos em comparação com o grupo das mulheres e dos homens mais jovens (Tabela 3).

Considerando o total de publicações, as mesmas variáveis e a interação entre elas foram selecionadas no melhor modelo (Tabela 2). O efeito do sexo (estimativa $=2,140$ ) é muito superior ao efeito da idade (estimativa $=-0,015)$ (Tabela 3$)$ e os homens (estimativa $=-0,055)$ que concluíram o doutorado mais velhos publicaram menos artigos em comparação com o grupo dos que concluíram mais jovem.

\section{Sexo e fase da carreira.}

As análises referentes à variável fase da carreira foram realizadas apenas com os dados dos 47 pesquisadores que possuíam ao menos 20 anos de atividade após a conclusão do doutorado. Foram comparados dois períodos: os primeiros 10 anos de carreira após o doutorado e os últimos 10 anos (2003 - 2012).

A maior diferença entre homens e mulheres foi encontrada em termos de publicação em periódicos nacionais nos primeiros 10 anos da carreira (estimativa $=$ 
0,702) (Tabela 4), período no qual os homens publicaram o dobro do que foi publicado pelas mulheres (Tabela 5). Nos últimos 10 anos da carreira, a diferença entre os sexos diminuiu (estimativa $=0,279)$ (Tabela 4 ) e os homens publicaram apenas $27 \%$ a mais que as mulheres (Tabela 5).

A análise da produção de artigos internacionais mostrou que a diferença entre homens e mulheres foi pequena nos primeiros 10 anos (estimativa $=0,022 \pm 0,339$ ) $\mathrm{e}$ esta diferença aumentou pouco nos últimos 10 anos (estimativa $=0,177 \pm 0,300$ ). No entanto, como a diferença é pequena (Tabelas 3 e 4) e em ambos os casos houve sobreposição do zero, não houve diferença estatística, mas apenas uma tendência de maior produção masculina.

Homens e mulheres apresentaram aumento na produção de artigos nacionais e internacionais nos últimos 10 anos da carreira, em comparação com os primeiros 10 anos (Tabela 5). O acréscimo em produção científica total foi mais acentuado para os homens, principalmente devido ao aumento do número de artigos internacionais. Para as mulheres, o aumento na produção científica total foi devido principalmente ao aumento do número de artigos nacionais (Tabela 5). 
Tabela 4. Resultados do GLM com as estimativas da variável sexo como preditora do número de publicações no Brasil, internacionais e total de publicações durante os 10 primeiros anos após a obtenção do doutorado, e durante os 10 últimos anos da carreira de pesquisadores brasileiros da área de Biodiversidade.

\begin{tabular}{|c|c|c|c|}
\hline $\begin{array}{c}\text { Tipo de } \\
\text { publicação }\end{array}$ & Período & Termo & Estimativa ( \pm EP) \\
\hline \multirow[t]{4}{*}{ Brasil } & Primeiros & (Intercepto) & $1,619 \pm 0,214$ \\
\hline & 10 anos & Sexo (Homem) & $0,702 \pm 0,252$ \\
\hline & Últimos & (Intercepto) & $2,691 \pm 0,204$ \\
\hline & 10 anos & Sexo (Homem) & $0,279 \pm 0,256$ \\
\hline \multirow[t]{4}{*}{ Internacional } & Primeiros & (Intercepto) & $1,924 \pm 0,256$ \\
\hline & 10 anos & Sexo (Homem) & $0,022 \pm 0,339$ \\
\hline & Últimos & (Intercepto) & $2,674 \pm 0,234$ \\
\hline & 10 anos & Sexo (Homem) & $0,177 \pm 0,300$ \\
\hline \multirow[t]{4}{*}{ Total } & Primeiros & (Intercepto) & $2,477 \pm 0,198$ \\
\hline & 10 anos & Sexo (Homem) & $0,368 \pm 0,245$ \\
\hline & Últimos & (Intercepto) & $3,376 \pm 0,188$ \\
\hline & 10 anos & Sexo (Homem) & $0,230 \pm 0,239$ \\
\hline
\end{tabular}


Tabela 5. Média ( \pm EP) do número de publicações em revistas brasileiras, internacionais e total de publicações durante os primeiros 10 anos da carreira e durante os 10 últimos anos de pesquisadores (homens e mulheres) brasileiros da área de Biodiversidade.

\begin{tabular}{ccccc}
\hline Tipo de & \multicolumn{2}{c}{ Homens $(\mathbf{n}=\mathbf{2 7})$} & \multicolumn{2}{c}{ Mulheres $(\mathbf{n}=\mathbf{2 0})$} \\
\cline { 2 - 5 } publicação & Primeiros & Últimos & Primeiros & Últimos \\
\hline Brasil & $10,2 \pm 1,4$ & $18,8 \pm 3,3$ & $5,1 \pm 1,0$ & $14,8 \pm 2,5$ \\
Internacional & $6,7 \pm 1,8$ & $16,7 \pm 3,6$ & $6,9 \pm 1,3$ & $14,5 \pm 2,8$ \\
Total & $16,9 \pm 2,8$ & $35,4 \pm 6,3$ & $11,9 \pm 1,6$ & $29,3 \pm 3,9$
\end{tabular}

\section{Sexo, casamento e filhos.}

O número de casamentos no período considerado (do início do doutorado até o $10^{\circ}$ ano de carreira após a conclusão do doutorado) variou entre 0 e 6 (Figura 4). O número de filhos neste período variou de 0 a 5 (Figura 5). Para fins de análise foi criado um índice que considera o número de filhos e o número de anos com filhos no período considerado. Um ano com um filho equivale a um ano/filho. A variação do número de filhos considerando este índice foi de 0 a 70.

Independente do sexo, as variáveis casamento ou presença/ausência de filhos não contribuíram para explicar a produção científica. A única variável relevante, ou seja, a variável incluída nos modelos com maior suporte foi sexo (Tabela 6), em relação a todos os tipos de publicação: nacional (estimativa $=0,204)$, internacional (estimativa $=$ $0,392)$ ou total (estimativa $=0,287)$ (Tabela 7). Os segundos melhores modelos incluíram filhos (Tabela 6), mas os efeitos do número de filhos foram desconsiderados, uma vez que foram muito pequenos e com sobreposição do zero, quando considerado o erro padrão (Tabela 7). 


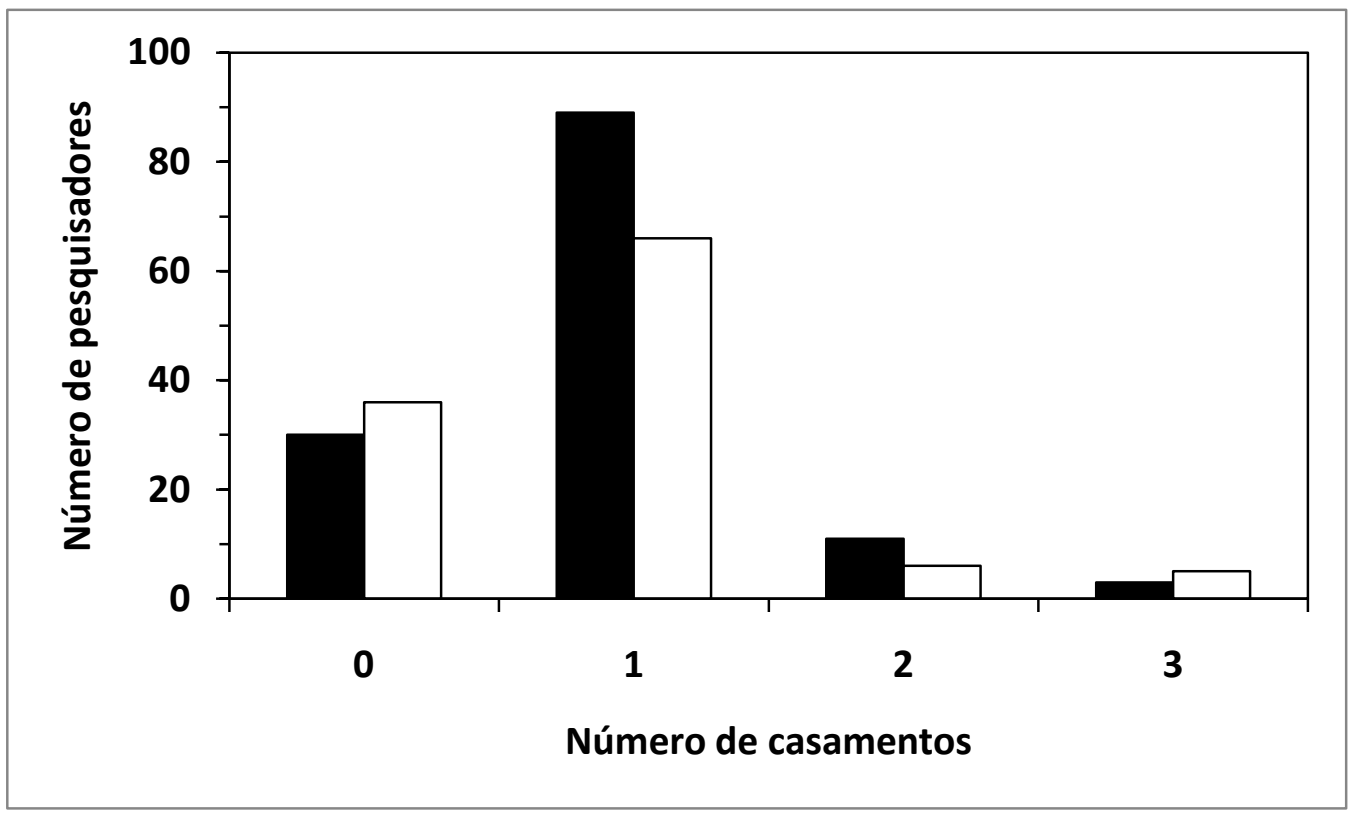

Figura 4. Número de casamentos de homens (barras pretas) e mulheres (barras brancas) nos primeiros 10 anos após a conclusão do doutorado.

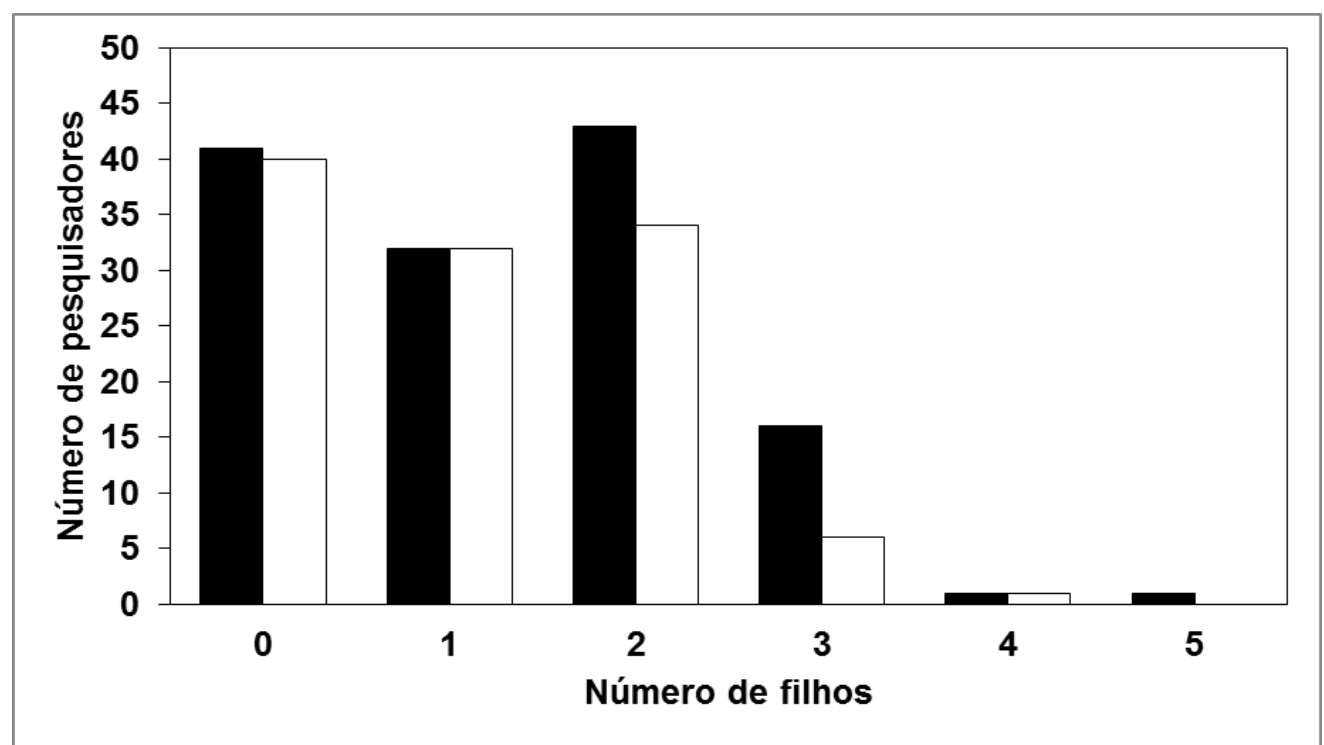

Figura 5. Número de filhos de homens (barras pretas) e mulheres (barras brancas) até os primeiros 10 anos após a conclusão do doutorado. 
Tabela 6. Variáveis dos modelos (sexo; casamento; filhos; sexo:casamento; sexo:filhos), quasiAIC, $\triangle \mathrm{AIC}$ e graus de liberdade das variáveis dos modelos mais ajustados $(\triangle \mathrm{AIC}$ <) para predizer o número de publicações no Brasil (pubbr), internacionais (pubint) e total de publicações (pubtot) durante os 10 primeiros anos da carreira após a obtenção do doutorado, de pesquisadores brasileiros da área de Biodiversidade.

\begin{tabular}{ccccc}
\hline $\begin{array}{c}\text { Tipo de } \\
\text { publicação }\end{array}$ & Modelos & qAICc & $\Delta$ AIC & gl \\
\hline Brasil & pubbr $\sim$ sexo & 375,0 & 0,0 & 2 \\
& pubbr $\sim$ sexo + filhos & 376,7 & 1,7 & 3 \\
& pubbr $\sim$ modelo nulo & 377,7 & 1,7 & 1 \\
Internacional & pubint $\sim$ sexo & 290,7 & 0,0 & 2 \\
& pubint $\sim$ sexo + filhos & 292,7 & 2,0 & 3 \\
& & & & \\
Total & pubtot $\sim$ sexo & 323,9 & 0,0 & 2 \\
& pubtot $\sim$ sexo + filhos & 325,7 & 1,8 & 3 \\
\hline
\end{tabular}


Tabela 7. Resultados do GLM com as estimativas das variáveis incluídas nos melhores modelos (Tabela 6) como preditoras do número de publicações no Brasil, internacionais e total de publicações durante os 10 primeiros anos da carreira após a obtenção do doutorado, de pesquisadores brasileiros da área de Biodiversidade.

\begin{tabular}{|c|c|c|}
\hline $\begin{array}{c}\text { Tipo de } \\
\text { publicação }\end{array}$ & Termo & Estimativa ( \pm EP) \\
\hline \multirow[t]{3}{*}{ Brasil } & (Intercepto) & $2,253 \pm 0,093$ \\
\hline & Sexo (Homem) & $0,204 \pm 0,104$ \\
\hline & Filhos (Sim) & $-0,002 \pm 0,004$ \\
\hline \multirow[t]{3}{*}{ Internacional } & (Intercepto) & $1,909 \pm 0,133$ \\
\hline & Sexo (Homem) & $0,392 \pm 0,146$ \\
\hline & Filhos (Sim) & $-0,001 \pm 0,005$ \\
\hline \multirow[t]{3}{*}{ Total } & (Intercepto) & $2,788 \pm 0,090$ \\
\hline & Sexo (Homem) & $0,287 \pm 0,100$ \\
\hline & Filhos (Sim) & $-0,002 \pm 0,004$ \\
\hline
\end{tabular}

\section{Sexo, crises e conflitos.}

O número de crises ( 0 a 8 ) foi quantificado em relação ao período que vai do início do doutorado até o $10^{\circ}$ ano de carreira após a conclusão do doutorado (Figura 6). 


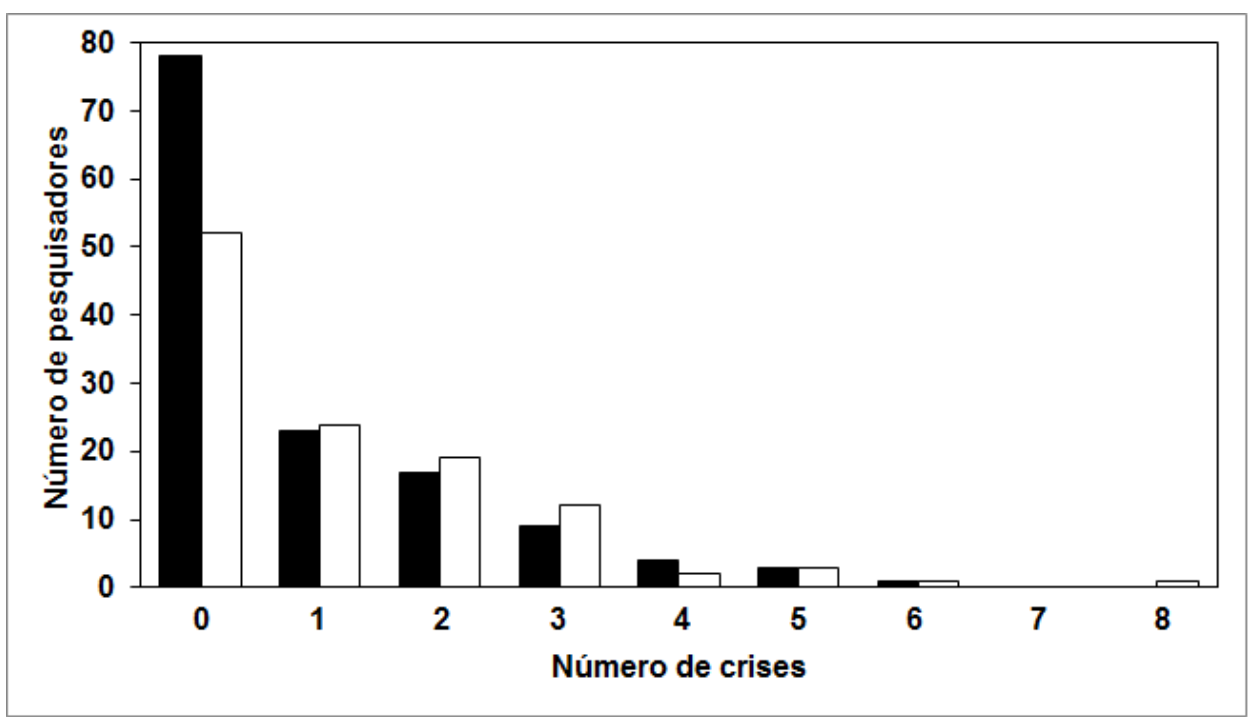

Figura 6. Número de crises de homens (barras pretas) e mulheres (barras brancas) durante os primeiros 10 anos após a conclusão do doutorado.

A seleção de modelos mostrou que as variáveis sexo e crise foram incluídas nos melhores modelos para os três tipos de publicação (Tabela 8). O efeito das crises foi sempre negativo, mas pequeno: publicação nacional (estimativa $=-0,067$ ); publicação internacional (estimativa $=-0,094)$ e total de publicações $($ estimativa $=-0,078)($ Tabela 9). Para publicações nacionais e internacionais, a variável conflito apareceu apenas em modelos com pouco suporte (Tabela 8). A interação entre sexo e crises esteve presente em modelos de baixo suporte para todos os três tipos de publicação (Tabela 8). A Tabela 10 mostra, como tendência, que os homens que relataram ter experimentado crises e conflitos são mais produtivos em comparação com os homens nas demais condições. Entre as mulheres, o grupo que relatou ter vivenciado crises e conflitos é o menos produtivo em comparação com as mulheres nas demais condições.

De acordo com a seleção de modelos, o efeito cumulativo de crises e conflitos foi fraco. Para confirmar este resultado, apresento as médias de artigos publicados para quatro grupos: (1) com conflitos e crises; (2) com conflitos e sem crises; (3) sem 
conflitos e com crises e (4) sem conflitos e crises (Tabela 10). Estes dados revelam a tendência de homens publicarem mais quando experimentam conflitos e crises e de mulheres publicarem menos nestas mesmas condições. Apesar destas tendências, a semelhança entre as médias e os erros padrão relativamente altos suportam a não inclusão destas variáveis nos melhores modelos. 
Tabela 8. Variáveis dos modelos (sexo; crises; conflitos; sexo:crises; sexo:conflitos), quasiAIC, $\triangle \mathrm{AIC}$ e graus de liberdade das variáveis dos modelos mais ajustados $(\triangle \mathrm{AIC}$ 2) para predizer o número de publicações no Brasil (pubbr), internacionais (pubint) e total de publicações (pubtot) durante os 10 primeiros anos da carreira após a obtenção do doutorado, de pesquisadores brasileiros da área de Biodiversidade.

\begin{tabular}{|c|c|c|c|c|}
\hline $\begin{array}{c}\text { Tipo de } \\
\text { publicacão }\end{array}$ & Modelos & qAICc & $\triangle \mathrm{AIC}$ & gl \\
\hline \multirow[t]{6}{*}{ Brasil } & pubbr $\sim$ sexo + crises & 375,9 & 0,0 & 3 \\
\hline & pubbr $\sim$ sexo & 376,9 & 1,0 & 2 \\
\hline & pubbr $\sim$ crises & 376,9 & 1,0 & 2 \\
\hline & pubbr $\sim$ sexo + crises + sexo:crises & 377,2 & 1,3 & 4 \\
\hline & pubbr $\sim$ sexo + crises + conflitos & 377,5 & 1,6 & 4 \\
\hline & pubbr $\sim$ sexo + conflitos & 377,6 & 1,7 & 3 \\
\hline \multirow[t]{4}{*}{ Internacional } & pubint $\sim$ sexo + crises & 294,3 & 0,0 & 3 \\
\hline & pubint $\sim$ sexo & 295,2 & 0,9 & 2 \\
\hline & pubint $\sim$ sexo + crises + conflitos & 295,9 & 1,6 & 4 \\
\hline & pubint $\sim$ sexo + crises + sexo:crises & 296,1 & 1,8 & 4 \\
\hline \multirow[t]{2}{*}{ Total } & pubtot $\sim$ sexo + crises & 320,6 & 0,0 & 3 \\
\hline & pubtot $\sim$ sexo + crises + sexo:crises & 322,6 & 2,0 & 4 \\
\hline
\end{tabular}


Tabela 9. Resultados do GLM com as estimativas das variáveis incluídas nos melhores modelos (Tabela 8) como preditoras do número de publicações no Brasil, internacionais e total de publicações durante os 10 primeiros anos da carreira após a obtenção do doutorado, de pesquisadores brasileiros da área de Biodiversidade.

\begin{tabular}{|c|c|c|}
\hline Tipo de publicação & Termo & Estimativa $( \pm$ EP $)$ \\
\hline \multirow[t]{3}{*}{ Brasil } & (Intercepto) & $2,298 \pm 0,090$ \\
\hline & Sexo (Homem) & $0,182 \pm 0,104$ \\
\hline & Crises (Sim) & $-0,067 \pm 0,039$ \\
\hline \multirow[t]{3}{*}{ Internacional } & (Intercepto) & $1,999 \pm 0,128$ \\
\hline & Sexo (Homem) & $0,365 \pm 0,146$ \\
\hline & Crises (Sim) & $-0,094 \pm 0,056$ \\
\hline \multirow[t]{3}{*}{ Total } & (Intercepto) & $2,854 \pm 0,087$ \\
\hline & Sexo (Homem) & $0,263 \pm 0,100$ \\
\hline & Crises (Sim) & $-0,078 \pm 0,038$ \\
\hline
\end{tabular}


Tabela 10. Média ( \pm EP) do número de publicações em revistas brasileiras, internacionais e total de publicações durante os primeiros 10 anos da carreira de pesquisadores brasileiros da área de Biodiversidade, em relação às variáveis conflitos e crises.

\begin{tabular}{|c|c|c|c|c|c|c|c|}
\hline \multirow{3}{*}{$\begin{array}{c}\text { Tipo } \\
\text { de } \\
\text { publicação } \\
\end{array}$} & \multirow{3}{*}{ Crises } & \multicolumn{3}{|c|}{ Homens } & \multicolumn{3}{|c|}{ Mulheres } \\
\hline & & \multicolumn{3}{|c|}{ Conflitos } & \multicolumn{3}{|c|}{ Conflitos } \\
\hline & & Sim & Não & Total & Sim & Não & Total \\
\hline \multirow[t]{6}{*}{ Brasil } & Sim & $12,9 \pm 1,7$ & $11,2 \pm 2,1$ & $12,2 \pm 1,3$ & $7,9 \pm 1,0$ & $9,9 \pm 2,3$ & $8,4 \pm 0,9$ \\
\hline & & $(n=33)$ & $(n=24)$ & $(n=57)$ & $(n=47)$ & $(n=15)$ & $(\mathrm{n}=62)$ \\
\hline & Não & $9,0 \pm 1,2$ & $11,7 \pm 1,2$ & $10,6 \pm 0,9$ & $9,6 \pm 1,7$ & $10,8 \pm 1,7$ & $10,3 \pm 1,2$ \\
\hline & & $(\mathrm{n}=31)$ & $(n=47)$ & $(\mathrm{n}=78)$ & $(\mathrm{n}=22)$ & $(\mathrm{n}=30)$ & $(\mathrm{n}=52)$ \\
\hline & Total & $11,0 \pm 1,1$ & $11,5 \pm 1,0$ & $11,3 \pm 0,8$ & $8,4 \pm 0,9$ & $10,5 \pm 1,4$ & $9,2 \pm 0,7$ \\
\hline & & $(n=64)$ & $(\mathrm{n}=71)$ & $(\mathrm{n}=135)$ & $(\mathrm{n}=69)$ & $(n=45)$ & $(\mathrm{n}=114)$ \\
\hline \multirow[t]{6}{*}{ Internacional } & Sim & $10,9 \pm 1,8$ & $9,5 \pm 2,0$ & $10,3 \pm 1,3$ & $5,4 \pm 1,0$ & $6,7 \pm 1,0$ & $5,7 \pm 0,8$ \\
\hline & & $(n=33)$ & $(n=24)$ & $(n=57)$ & $(n=47)$ & $(\mathrm{n}=15)$ & $(n=62)$ \\
\hline & Não & $10,0 \pm 1,8$ & $9,2 \pm 2,0$ & $9,5 \pm 1,4$ & $8,2 \pm 1,9$ & $7,5 \pm 1,3$ & $7,8 \pm 1,1$ \\
\hline & & $(\mathrm{n}=31)$ & $(n=47)$ & $(n=78)$ & $(\mathrm{n}=22)$ & $(\mathrm{n}=30)$ & $(n=52)$ \\
\hline & Total & $10,5 \pm 1,3$ & $9,3 \pm 1,5$ & $9,9 \pm 1,0$ & $6,3 \pm 0,9$ & $7,2 \pm 0,9$ & $6,7 \pm 0,7$ \\
\hline & & $(n=64)$ & $(\mathrm{n}=71)$ & $(n=135)$ & $(n=69)$ & $(n=45)$ & $(\mathrm{n}=114)$ \\
\hline \multirow[t]{6}{*}{ Total } & Sim & $23,8 \pm 3,1$ & $20,7 \pm 3,8$ & $22,5 \pm 2,4$ & $13,3 \pm 1,4$ & $16,5 \pm 2,6$ & $14,1 \pm 1,3$ \\
\hline & & $(\mathrm{n}=33)$ & $(n=24)$ & $(\mathrm{n}=57)$ & $(n=47)$ & $(n=15)$ & $(n=62)$ \\
\hline & Não & $19,0 \pm 2,1$ & $20,9 \pm 2,7$ & $20,1 \pm 1,8$ & $17,9 \pm 2,8$ & $18,3 \pm 1,4$ & $18,1 \pm 1,8$ \\
\hline & & $(\mathrm{n}=31)$ & $(n=47)$ & $(\mathrm{n}=78)$ & $(\mathrm{n}=22)$ & $(\mathrm{n}=30)$ & $(\mathrm{n}=52)$ \\
\hline & Total & $21,5 \pm 1,9$ & $20,8 \pm 2,2$ & $21,1 \pm 1,5$ & $14,8 \pm 1,3$ & $17,7 \pm 1,8$ & $15,9 \pm 1,1$ \\
\hline & & $(n=64)$ & $(n=71)$ & $(\mathrm{n}=135)$ & $(n=69)$ & $(n=45)$ & $(\mathrm{n}=114)$ \\
\hline
\end{tabular}




\section{Origem familiar.}

Para analisar o efeito da origem familiar, as variáveis suporte educacional familiar, conhecimento sobre ensino superior, experiência internacional da família e sexo foram analisadas em conjunto. $\mathrm{O}$ suporte educacional familiar, representado pela pessoa que prestava apoio pedagógico revelou que a maioria dos pesquisadores recebia suporte dos próprios pais; alguns não recebiam qualquer tipo de suporte e um número muito reduzido recebia suporte educacional de outros familiares (Figura 7).

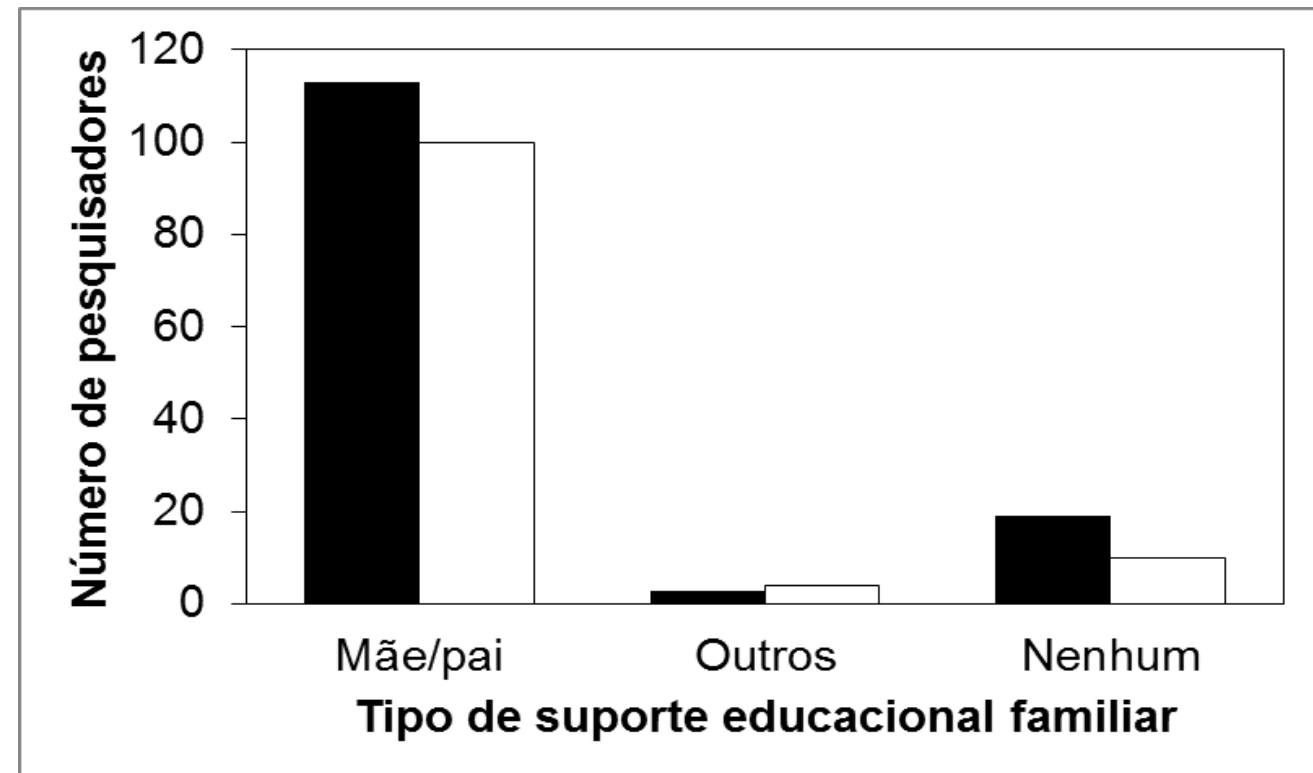

Figura 7. Tipo de suporte educacional familiar de pesquisadores homens (barras pretas) e mulheres (barras brancas) da área de Biodiversidade.

Com relação ao conhecimento sobre ensino superior, a maioria dos pesquisadores veio de famílias nas quais algum membro possuía formação universitária. Os demais pesquisadores se distribuíram nas seguintes categorias: pessoas próximas com formação universitária; família sem formação universitária, mas com informações sobre ensino 
superior; família sem formação universitária e ausência de informações sobre ensino superior (Figura 8).

Em relação à experiência internacional da família, a maioria dos pesquisadores veio de famílias sem qualquer experiência internacional. As categorias relacionadas à experiência internacional são: residência temporária no exterior; viagens para o exterior e pessoas próximas vivendo no exterior (Figura 9).

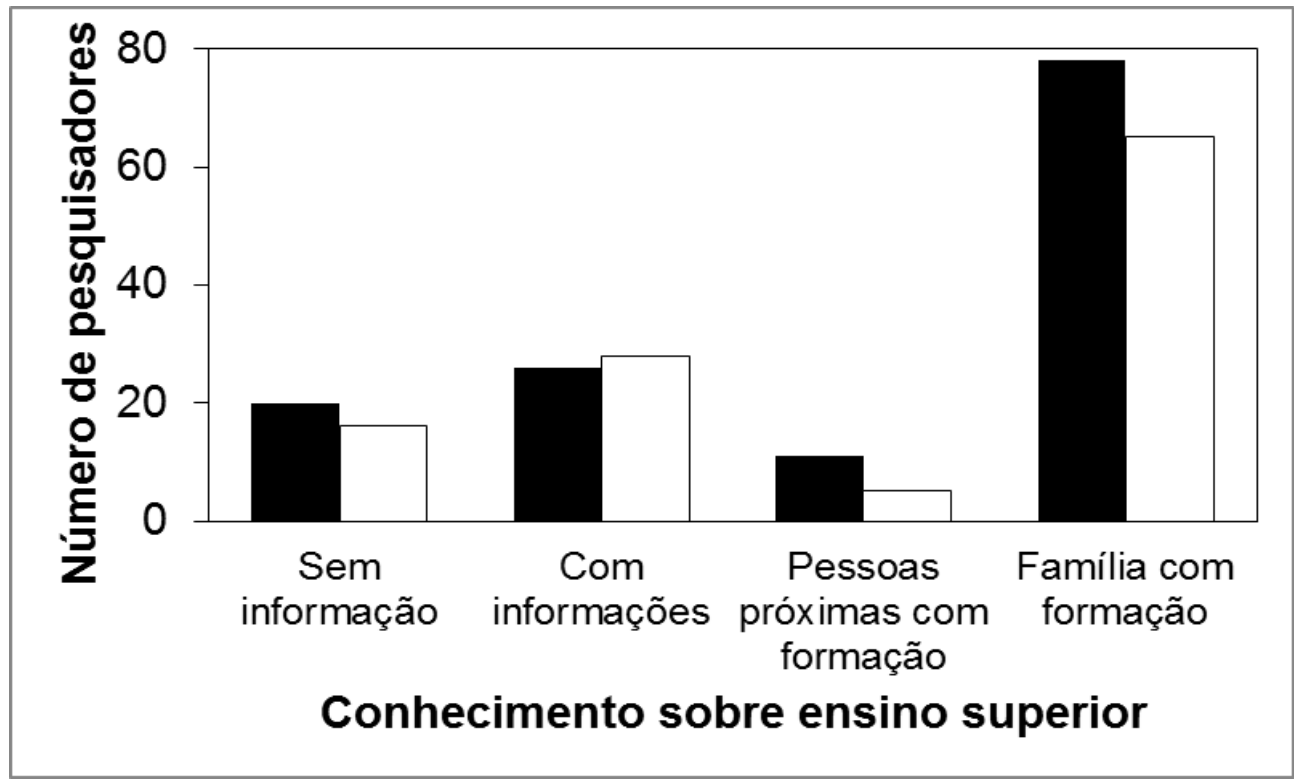

Figura 8. Conhecimento sobre ensino superior de pesquisadores homens (barras pretas) e mulheres (barras brancas) da área de Biodiversidade. 


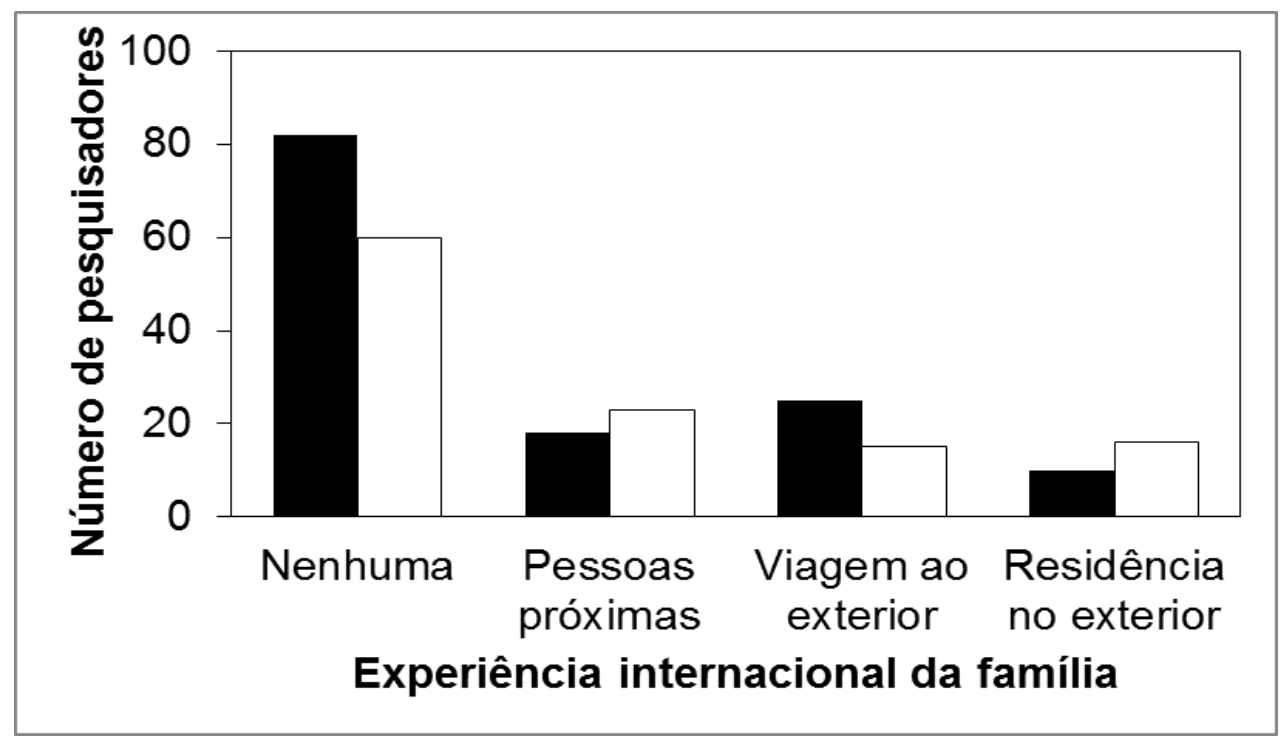

Figura 9. Experiência internacional da família de pesquisadores homens (barras pretas) e mulheres (barras brancas) da área de Biodiversidade.

As análises estatísticas mostraram que apenas a variável sexo foi incluída nos melhores modelos para publicações nacionais e total de publicações (Tabela 11) $($ nacional - estimativa $=0,162 ;$ total - estimativa $=0,284)($ Tabela 12$)$. A variável experiência internacional da família foi incluída em alguns dos modelos para explicar public ação nacional, mas uma vez que o modelo nulo estava entre os modelos selecionados, os demais modelos têm suporte questionável (Tabela 11). A análise dos coeficientes revela que o efeito de residência no exterior e pessoas próximas no exterior é negativo sobre o número de artigos nacionais (Tabela 12).

Em relação à publicação de artigos internacionais, as variáveis sexo e suporte educacional familiar foram incluídas no melhor modelo (Tabela 11). O efeito da variável sexo mostrou-se relevante (estimativa $=0,391$ ). Com relação ao suporte familiar, os pesquisadores que receberam suporte educacional de outros familiares (estimativa $=-1,300)$ e aqueles que não receberam suporte educacional familiar 
(estimativa $=-0,205)$ tiveram tendência a publicar menos (Tabela 12), mas o erro padrão foi grande, com sobreposição do zero. Além disso, o tamanho da população referente a estas variáveis é pequeno, especialmente em relação a suporte educacional de outros familiares $(\mathrm{n}=3$ ) (Tabela 13), o que torna este resultado pouco confiável. A variável conhecimento sobre ensino superior não foi incluída nos melhores modelos para nenhum dos três tipos de publicação e, portanto, não foi considerada relevante. Em resumo, nenhuma das três variáveis relacionadas à origem familiar mostrou ter influência de maneira consistente e importante sobre a produção científica.

Tabela 11. Variáveis dos modelos (sexo; suporte educacional familiar; conhecimento sobre ensino superior; experiência internacional da família; sexo:suporte educacional familiar), quasiAIC, $\triangle \mathrm{AIC}$ e graus de liberdade dos modelos mais ajustados $(\Delta \mathrm{AIC}<2)$ para predizer o número de publicações no Brasil (pubbr), internacionais (pubint) e total de publicações (pubtot) durante os 10 primeiros anos da carreira após a obtenção do doutorado, de pesquisadores brasileiros da área de Biodiversidade.

$\begin{array}{cccc}\text { pubbr } \sim \text { sexo } & 379,7 & 0,0 & 2 \\ \text { pubbr } \sim \text { sexo + experiência } & 380,0 & 0,3 & 5 \\ \text { pubbr } \sim \text { experiência internacional } & 380,3 & 0,6 & 4 \\ \text { pubbr } \sim \text { modelo nulo } & 381,5 & 1,8 & 1\end{array}$

Internacional

pubint $\sim$ sexo + suporte educacional

303,5

0,0

4

pubint $\sim$ sexo

$304,3 \quad 0,8 \quad 2$

Total

pubtot $\sim \operatorname{sexo}$

$320,3 \quad 0,0$ 
Tabela 12. Resultados do GLM com as estimativas das variáveis incluídas nos melhores modelos (Tabela 11) como preditoras do número de publicações no Brasil, internacionais e total de publicações durante os 10 primeiros anos da carreira após a obtenção do doutorado, de pesquisadores brasileiros da área de Biodiversidade.

\begin{tabular}{|c|c|c|}
\hline $\begin{array}{c}\text { Tipo de } \\
\text { publicação }\end{array}$ & Termo & $\operatorname{Estimativa(\pm ~EP)~}$ \\
\hline \multirow[t]{5}{*}{ Brasil } & (Intercepto) & $2,314 \pm 0,091$ \\
\hline & Sexo (Homem) & $0,162 \pm 0,104$ \\
\hline & Experiência internacional (2) & $-0,248 \pm 0,153$ \\
\hline & Experiência internacional (3) & $0,009 \pm 0,137$ \\
\hline & Experiência internacional (4) & $-0,364 \pm 0,197$ \\
\hline \multirow[t]{4}{*}{ Internacional } & (Intercepto) & $1,940 \pm 0,117$ \\
\hline & Sexo (Homem) & $0,391 \pm 0,145$ \\
\hline & Suporte educacional (Outros familiares) & $-1,300 \pm 0,798$ \\
\hline & Suporte educacional (Nenhum) & $-0,205 \pm 0,229$ \\
\hline \multirow[t]{2}{*}{ Total } & (Intercepto) & $2,767 \pm 0,079$ \\
\hline & Sexo (Homem) & $0,284 \pm 0,100$ \\
\hline
\end{tabular}

Os valores médios do número de artigos publicados associados aos valores altos dos erros padrão demonstram não haver um padrão claro de influência do suporte educacional familiar (Tabela 13), do conhecimento sobre ensino superior (Tabela 14) e da experiência internacional da família (Tabela 15) sobre a produtividade científica dos pesquisadores. 
Tabela 13. Média ( \pm EP) do número de publicações em revistas brasileiras, internacionais e total de publicações durante os primeiros 10 anos da carreira de pesquisadores brasileiros da área de Biodiversidade, em relação ao tipo de suporte educacional.

\begin{tabular}{|c|c|c|c|c|}
\hline \multirow{2}{*}{$\begin{array}{c}\text { Tipo de } \\
\text { publicação }\end{array}$} & \multirow[b]{2}{*}{ Sexo } & \multicolumn{3}{|c|}{ Tipo de Suporte Educacional } \\
\hline & & 1 (pai/mãe) & $\begin{array}{c}2 \text { (outros } \\
\text { familiares) }\end{array}$ & 3 (nenhum) \\
\hline \multirow[t]{3}{*}{ Brasil } & Homens & $\begin{array}{l}11,3 \pm 0,8 \\
(\mathrm{n}=113)\end{array}$ & $\begin{array}{c}11,3 \pm 1,3 \\
(\mathrm{n}=3)\end{array}$ & $\begin{array}{c}11,3 \pm 2,2 \\
(n=19)\end{array}$ \\
\hline & Mulheres & $\begin{array}{l}9,0 \pm 0,8 \\
(\mathrm{n}=100)\end{array}$ & $\begin{array}{c}14,3 \pm 7,9 \\
(n=4)\end{array}$ & $\begin{array}{l}9,8 \pm 2,5 \\
(n=10)\end{array}$ \\
\hline & Total & $\begin{array}{l}10,2 \pm 0,6 \\
(\mathrm{n}=213)\end{array}$ & $\begin{array}{c}13,0 \pm 4,3 \\
(n=7)\end{array}$ & $\begin{array}{c}10,8 \pm 1,6 \\
(\mathrm{n}=29)\end{array}$ \\
\hline \multirow[t]{3}{*}{ Internacional } & Homens & $\begin{array}{l}10,5 \pm 1,1 \\
(\mathrm{n}=113)\end{array}$ & $\begin{array}{c}1,3 \pm 0,7 \\
(\mathrm{n}=3)\end{array}$ & $\begin{array}{l}7,2 \pm 1,6 \\
(\mathrm{n}=19)\end{array}$ \\
\hline & Mulheres & $6,7 \pm 0,7$ & $3,0 \pm 2,7$ & $7,8 \pm 2,2$ \\
\hline & Total & $\begin{array}{l}(\mathrm{n}=100) \\
8,7 \pm 0,7 \\
(\mathrm{n}=213)\end{array}$ & $\begin{array}{c}(\mathrm{n}=4) \\
2,3 \pm 1,5 \\
(\mathrm{n}=7)\end{array}$ & $\begin{array}{l}(\mathrm{n}=10) \\
7,4 \pm 1,1 \\
(\mathrm{n}=29)\end{array}$ \\
\hline \multirow[t]{3}{*}{ Total } & Homens & $\begin{array}{l}21,8 \pm 1,7 \\
(n=113)\end{array}$ & $\begin{array}{c}12,7 \pm 1,8 \\
(n=3)\end{array}$ & $\begin{array}{c}18,5 \pm 2,9 \\
(\mathrm{n}=19)\end{array}$ \\
\hline & Mulheres & $\begin{array}{l}15,7 \pm 1,1 \\
(\mathrm{n}=100)\end{array}$ & $\begin{array}{c}17,3 \pm 8,9 \\
(n=4)\end{array}$ & $\begin{array}{c}17,7 \pm 3,9 \\
(\mathrm{n}=10)\end{array}$ \\
\hline & Total & $\begin{array}{l}18,9 \pm 1,1 \\
(n=213)\end{array}$ & $\begin{array}{c}15,3 \pm 4,9 \\
(n=7)\end{array}$ & $\begin{array}{c}18,2 \pm 2,3 \\
(n=29)\end{array}$ \\
\hline
\end{tabular}


Tabela 14. Média ( \pm EP) do número de publicações em revistas brasileiras, internacionais e total de publicações durante os primeiros 10 anos da carreira de pesquisadores brasileiros da área de Biodiversidade, em relação ao conhecimento sobre ensino superior ( 1 = não havia este tipo de informação; 2 = sem formação universitária, mas com informações sobre ensino superior; 3 = pessoas próximas com formação universitária; 4 = família com formação universitária).

\begin{tabular}{ccccc}
\hline $\begin{array}{c}\text { Tipo de } \\
\text { publicação }\end{array}$ & \multicolumn{5}{c}{ Conhecimento sobre ensino superior } \\
\cline { 2 - 5 } & $\mathbf{1}$ & $\mathbf{2}$ & $\mathbf{3}$ & $\mathbf{4}$ \\
& $(\mathbf{n}=\mathbf{3 6})$ & $(\mathbf{n}=\mathbf{5 4})$ & $(\mathbf{n}=\mathbf{1 6})$ & $(\mathbf{n}=\mathbf{1 4 3})$ \\
\hline Brasil & $10,9 \pm 1,6$ & $10,6 \pm 1,1$ & $7,8 \pm 1,5$ & $10,4 \pm 0,7$ \\
Internacional & $8,8 \pm 2,3$ & $7,9 \pm 1,2$ & $7,9 \pm 2,1$ & $8,5 \pm 0,7$ \\
Total & $19,7 \pm 3,6$ & $18,5 \pm 1,8$ & $15,7 \pm 2,9$ & $18,9 \pm 1,6$ \\
\hline
\end{tabular}

Tabela 15. Média ( \pm EP) do número de publicações em revistas brasileiras, internacionais e total de publicações durante os primeiros 10 anos da carreira de pesquisadores brasileiros da área de Biodiversidade, em relação à experiência internacional da família $(1$ = nenhuma experiência internacional; 2 = pessoas próximas vivendo no exterior; 3 = viagens para o exterior; 4 = residência temporária no exterior).

\begin{tabular}{ccccc}
\hline Tipo de & \multicolumn{5}{c}{ Experiência internacional da família } \\
\cline { 2 - 5 } publicação & $\mathbf{1}$ & $\mathbf{2}$ & $\mathbf{3}$ & $\mathbf{4}$ \\
& & & & \\
& $(\mathbf{n}=\mathbf{1 4 2})$ & $(\mathbf{n}=\mathbf{4 1})$ & $(\mathbf{n}=\mathbf{4 0})$ & $(\mathbf{n}=\mathbf{2 6})$ \\
\hline Brasil & $11,1 \pm 0,7$ & $8,5 \pm 0,8$ & $11,3 \pm 1,5$ & $7,5 \pm 1,6$ \\
Internacional & $8,3 \pm 0,9$ & $8,5 \pm 1,1$ & $7,9 \pm 1,3$ & $9,3 \pm 1,8$ \\
Total & $19,5 \pm 1,3$ & $17,0 \pm 1,6$ & $19,2 \pm 2,5$ & $16,8 \pm 2,9$ \\
\end{tabular}




\section{Discussão}

Os resultados apontam que as pesquisadoras da área de Biodiversidade publicam menos que seus colegas do sexo masculino, resultado semelhante ao relatado por Symonds et al. (2006) e Olinto (2011). A diferença entre homens e mulheres em termos do número de artigos publicados mostrou-se a mais relevante para explicar produção científica tanto em termos de artigos nacionais quanto internacionais, em diversos contextos e interagindo com diversas outras variáveis. A partir da revisão da literatura sobre as diferenças entre os sexos em termos de produção científica, ficou claro que diversas variáveis como: idade, estado civil e filhos moderam a relação entre sexo e produção científica. Em função da "janela de fertilidade feminina", a idade está intimamente relacionada com a maternidade, que em geral, também envolve casamento. Por esta razão, as variáveis: idade, casamento e filhos foram consideradas possíveis moderadoras do efeito do sexo sobre a produção científica e foram analisadas nesta pesquisa.

Os efeitos da idade sobre a produção científica de homens e mulheres foram analisados tanto em termos da idade de conclusão do doutorado quanto da comparação entre diferentes fases da carreira. As análises estatísticas mostraram que o sexo foi mais relevante que a idade para explicar produção científica nacional e internacional e que os pesquisadores de ambos os sexos que concluíram o doutorado com mais idade produziram menos, em comparação com os que concluíram com menos idade. Quando apenas publicações internacionais são consideradas, as diferenças entre homens e mulheres e entre grupos de idade são maiores. Para os homens, o efeito negativo de haver concluído o doutorado com mais idade é mais evidente do que para as mulheres e mais acentuado quando consideradas as publicações internacionais. 
Em termos da idade de conclusão do doutorado, foi identificada uma tendência de maior produção de artigos nacionais entre as mulheres que concluíram o doutorado com mais idade, em comparação com os homens do mesmo grupo etário. Estes resultados estariam de acordo com o esperado, uma vez que mulheres nesta faixa etária teriam filhos mais crescidos, o que facilitaria a conciliação entre maternidade e carreira científica, como sugerido por Adamo (2013). Em termos de produção de artigos internacionais, as mulheres que concluíram com mais idade tiveram produção inferior a dos homens, contrariando a tendência de efeito positivo da idade sobre a produção científica das mulheres.

Diversas razões podem estar associadas à relação entre conclusão do doutorado com mais idade e menor produção científica. Pessoas mais velhas, que talvez já trabalhassem, podem ter tido dificuldade em conciliar estudos e trabalho durante o doutorado, o que pode ter contribuído tanto para o atraso na conclusão do curso quanto para a menor produção no início da carreira. As associações entre sexo e idade e seu efeito sobre a produção científica revelam uma redução da diferença entre os sexos em função da idade de conclusão do doutorado. Uma vez que homens e mulheres estão igualmente sujeitos aos fatores que contribuiriam para o atraso na conclusão do curso, uma explicação pode estar relacionada ao efeito da diminuição da demanda com filhos pequenos, o que pode gerar aumento da produção científica das mulheres e a consequente diminuição da diferença em relação aos homens.

Estudos sobre a influência dos filhos sobre a produção científica mostram resultados contraditórios. O efeito negativo dos filhos sobre a produtividade científica de homens e mulheres (Cole, 1979; Hargens, McCann, \& Reskin, 1978) é intuitivo e facilmente compreensível, principalmente levando-se em conta o número de crianças 
(Long, 1990) e o fator idade, ou seja, quanto mais novas as crianças, mais negativo o efeito (Kyvik \& Teigen, 1996). Entretanto, alguns estudos revelam que os filhos não teriam qualquer influência sobre a produtividade científica de homens e mulheres (Hamovitch \& Morgenstern, 1977; Leahey, 2006). A explicação para o resultado de estudos que mostram aumento da produtividade das mulheres em função dos filhos (Fox \& Faver, 1985; Nakhaie, 2002) é menos intuitiva. Algumas explicações baseiam-se na associação entre características pessoais favoráveis tanto ao cuidado com filhos, quanto à maior produtividade científica: organização, energia e força de vontade (Cole \& Zuckerman, 1987; Fox \& Faver, 1985, Kyvik, 1990). Deste modo, mulheres mais organizadas poderiam ser mais capazes de conciliar as responsabilidades com crianças e com a condução de pesquisas, em comparação com as demais mulheres (Stack, 2004). Este resultado, no entanto, pode ser um artifício resultante da antecipação da pesquisadora gestante, que intensificaria sua produção para compensar o período de ausência ou de menor atividade científica no futuro (Hunter \& Leahey, 2010).

Com relação ao casamento, os resultados também apontam para mais de uma direção. O casamento é considerado, por alguns autores, uma condição favorável em termos de produção científica, principalmente para os homens (Long, 1990), mas também para as mulheres (Hartley \& Dobele, 2009). Outros autores encontraram um efeito negativo do casamento para a produção científica das mulheres (Ogbogu, 2013).

Principalmente entre casais onde ambos têm uma atividade profissional, condição frequentemente encontrada na sociedade brasileira desde algumas décadas, a conciliação entre família e trabalho costuma ser causadora de conflitos, principalmente em profissões muito exigentes, como a acadêmica, na qual o custo das demandas profissionais é particularmente negativo para as mulheres (Matias \& Fontaine, 2012). 
Um reflexo disso é o grande número de mulheres com doutorado que não exercem atividades compatíveis com sua formação, como exemplificado pelas doutoras que atuam como professoras de ensino médio (CGEE, 2010), provavelmente em função da dificuldade em conciliar carreira científica e família.

Alguns fatores de ordem pessoal que podem impactar a produção científica estão relacionados com situações de crises pessoais ou profissionais causadoras de estresse psicológico (Denton et al., 2004). Características tais como otimismo; auto estima elevada; resiliência psicológica e o apoio da família, amigos e colegas (Jonas \& Lebherz, 2008) podem responder por diferenças na forma de lidar com o estresse provocado por crises e conflitos familiares e profissionais. Neste estudo, a produção científica dos pesquisadores não foi afetada pela ocorrência de crises e conflitos, o que pode estar relacionado ao fato dos pesquisadores da população serem aqueles que, por possuírem recursos para lidar com o estresse, foram capazes de superar as situações de crises e conflitos, se manter na carreira acadêmica e continuar publicando artigos.

A origem familiar pode ter impacto sobre o futuro acadêmico de estudantes (Vianna, 2005), em função da mobilização de recursos materiais, como o tempo dedicado a ajudar com tarefas escolares (Carvalho, 2000) ou recursos simbólicos, como o conhecimento da família sobre o sistema de ensino superior do país ou a experiência internacional proporcionada por viagens ao exterior ou contato com estrangeiros. A mobilização familiar pode ter efeitos sobre aspectos cognitivos e psicológicos que poderiam impactar o desempenho acadêmico futuro (Charlot, 1996). Ao contrário do esperado, as variáveis relacionadas à origem familiar não se mostraram relevantes para explicar produção científica. Uma hipótese para esta ausência de efeito pode ser o fato do mesmo ter sido "diluído" em etapas anteriores da trajetória dos pesquisadores, como 
na seleção daqueles que ingressaram na universidade ou os que optaram por uma formação no exterior. Outra explicação é que as eventuais diferenças entre os pesquisadores relacionadas com a origem familiar, já teriam sido sanadas e niveladas durante as diferentes etapas da formação acadêmica.

\section{Conclusão}

A principal variável relacionada às diferenças em produção científica entre os pesquisadores é o sexo, resultado esperado considerando a revisão da literatura (ver introdução). O papel central da variável sexo quando analisada em conjunto com outras variáveis mostra que variáveis associadas à maternidade, como: idade, estado civil e filhos, comumente apontadas como responsáveis pelas diferenças entre os sexos, não foram relevantes, nesta pesquisa, para explicar as diferenças em termos de produção científica. Do mesmo modo, variáveis relacionadas com o estresse: crises (pessoais e profissionais) e conflitos (entre demandas pessoais e profissionais) também não foram capazes de predizer produção científica, mesmo considerando seu efeito diferencial sobre os sexos. Indicadores relacionados à mobilização da família em função da educação dos filhos foram analisados como causas potenciais das diferenças entre os pesquisadores e mais uma vez, nenhum mostrou-se relevante para explicar produção científica.

Uma vez que casamento, filhos, estresse ou origem familiar não explicam por que as mulheres publicam menos que os homens, é preciso buscar outras explicações para esta diferença. As mulheres são uma parte importante da força de trabalho dedicada à pesquisa científica em todos os países e é imprescindível entender por que, sendo 
igualmente capazes, tendo acesso a formação acadêmica da mesma qualidade e ocupando posições semelhantes profissionalmente, apresentam produção diferente.

Pesquisas sobre diferenças entre os sexos na área do esporte podem trazer contribuições para a compreensão das razões do menor desempenho das mulheres na ciência. Embora o esporte seja associado com atividades de recreação e lazer, para os atletas de alto nível, o esporte é uma carreira sujeita a muita pressão, na qual os atletas são submetidos a grande número de fatores causadores de estresse (Schaal et al., 2011). A predisposição genética, a personalidade, a dedicação, a motivação e a resiliência psicológica são características associadas aos atletas que conseguem alcançar a condição de elite. Apesar desta combinação de características, as pressões a que estão submetidos têm impactos que afetam diferentemente o desempenho de atletas do sexo masculino e feminino (Schaal et al., 2011).

A crescente participação das mulheres entre atletas de elite levou ao aumento do número de estudos sobre diferenças entre os sexos no esporte. Os resultados de alguns destes estudos (McLean \& Anderson, 2009; Schaal et al., 2011; Zalta \& Chambless, 2012) apontam para a maior susceptibilidade das mulheres às pressões da carreira e para a diminuição do desempenho delas em função da maior incidência de transtornos de ansiedade generalizada - TAG. A explicação para a alta incidência de TAG entre as atletas em esportes estéticos estaria relacionada à forma de mensurar o desempenho. Para estas atletas, a dependência do julgamento de juízes, treinadores ou colegas de equipe, para a determinação da qualidade do desempenho, geraria um sentimento de obrigação de "desempenho perfeito", que por sua vez provocaria grande pressão psicológica (Schaal et al., 2011). 


\section{Capítulo 2 - Socialização Acadêmica}

Ainda sobre socialização, neste capítulo serão discutidos aspectos relacionados à socialização acadêmica, como o papel da colaboração científica com o orientador de doutorado e o local de doutorado (Brasil ou exterior), sobre a produção científica dos pesquisadores de ambos os sexos, a partir da hipótese da vantagem cumulativa (Cole \& Cole, 1973).

A orientação acadêmica é considerada o aspecto central da formação de novos pesquisadores na pós-graduação (Krebs, 1967; Long \& McGinnis, 1985). A relação entre orientador e orientando é definida como "o relacionamento dinâmico, mútuo, profissional e pessoal entre o orientador acadêmico e o estudante" (L.M. Ferreira, Furtado, \& Silveira, 2009). O orientador é visto como o "outro significativo" ao longo do doutorado e a orientação acadêmica costuma envolver desde o interesse pelo bem estar do estudante, o apoio para lidar com a ansiedade e a ajuda no estabelecimento de contatos com outros membros da comunidade acadêmico-científica (Bargar \& MaioChamberlain, 1983). A orientação acadêmica envolve três aspectos principais: apoio psicossocial, orientação relacionada à carreira e colaboração em pesquisa. Destas, a colaboração entre orientador e orientando foi o melhor preditor da produtividade dos estudantes quatro anos após o início do doutorado (Paglis et al., 2006).

A colaboração em pesquisa é a ação mais importante que um orientador pode exercer em benefício da carreira de seus orientandos, e esta tem relação direta com seu próprio desempenho científico (Long \& McGinnis, 1985). Quanto mais produtivo o orientador e quanto mais reconhecida é a sua pesquisa, mais benéfica será a colaboração do ponto de vista da formação do estudante (Long \& McGinnis, 1985). A colaboração 
que se traduz em co-autoria de artigos é responsável direta pela produtividade científica dos doutores recém-formados (Green, 1991; Reskin, 1978). Por meio da colaboração com o orientador, o estudante participa ativamente do processo da pesquisa e aprende não só as normas da ciência, mas o conhecimento tácito de como a ciência é feita (Long \& McGinnis, 1985

A produtividade científica inicial é considerada um dos melhores indicadores de produtividade ao longo da carreira do pesquisador. A influência do orientador sobre a produtividade pré-doutoral dos doutorandos dá início a um processo de vantagem cumulativa que se inicia com a colaboração durante o doutorado e cujos efeitos diretos e indiretos persistem e influenciam a produtividade pós-doutoral (Lightfield, 1971) por meio do estabelecimento de um padrão de produtividade que tende a se manter ao longo da carreira (Creswell, 1985). Ao contrário, aqueles que começam a carreira produzindo pouco, tendem a manter este padrão durante a vida profissional (Cole \& Cole, 1967). Embora inicialmente a colaboração entre estudante e orientador seja uma parceria desigual que tende a diminuir na medida em que o orientando adquire independência científica, seus efeitos continuam a exercer influência ao longo da carreira profissional do futuro pesquisador (Long \& McGinnis, 1985).

Os doutorandos podem ser socializados para a pesquisa científica em programas de pós-graduação em seu país ou no exterior. As políticas públicas de estímulo à inserção dos estudantes brasileiros na comunidade científica internacional tem sido uma oportunidade para acompanhar o progresso científico internacional e são elementoschave de inserção do Brasil nas redes internacionais de Ciência e Tecnologia, tanto em função do aprendizado do conhecimento codificado, mas igualmente pela absorção dos conhecimentos tácitos incorporados nos parceiros estrangeiros (Velho, 2001). O 
intercâmbio acadêmico internacional tem sido associado com aumento da produtividade científica em função da integração dos estudantes em redes científicas internacionais e da cooperação entre pesquisadores de diferentes países (Jin et al., 2007).

Outra função importante do intercâmbio internacional é o aprendizado de um idioma estrangeiro, principalmente no caso de países de língua inglesa, idioma mais utilizado atualmente no discurso científico. O domínio das habilidades de comunicação em inglês permite a publicação de artigos em periódicos de prestígio, cuja exigência da qualidade da redação em inglês é dificilmente superada por aqueles que não dominam o uso do idioma (Meneguini \& Packer, 2007). Desta forma, o treinamento internacional, especialmente de longa duração, pode trazer um benefício adicional para a carreira científica.

\section{Método}

Os métodos utilizados estão descritos na parte de Método (pg. 93).

\section{Resultados}

A maior parte dos pesquisadores realizou o doutorado no país (Figura 10) e publicou artigos em colaboração com seus orientadores (Figura 11). 


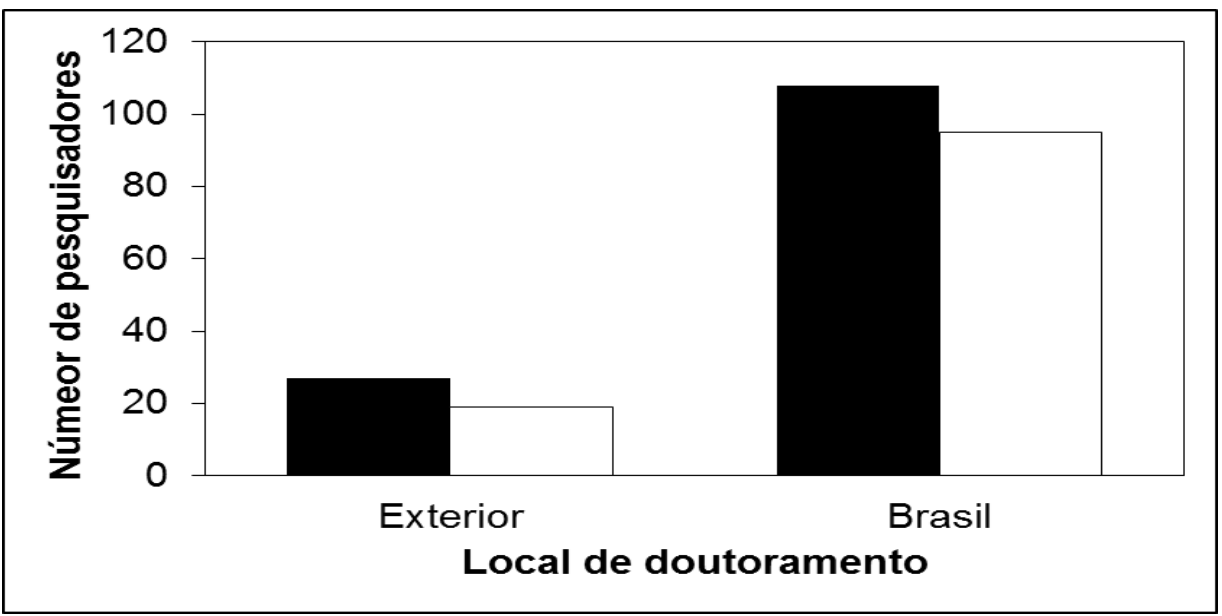

Figura 10. Local de doutorado de pesquisadores homens (barras pretas) e mulheres (barras brancas) da área de Biodiversidade.

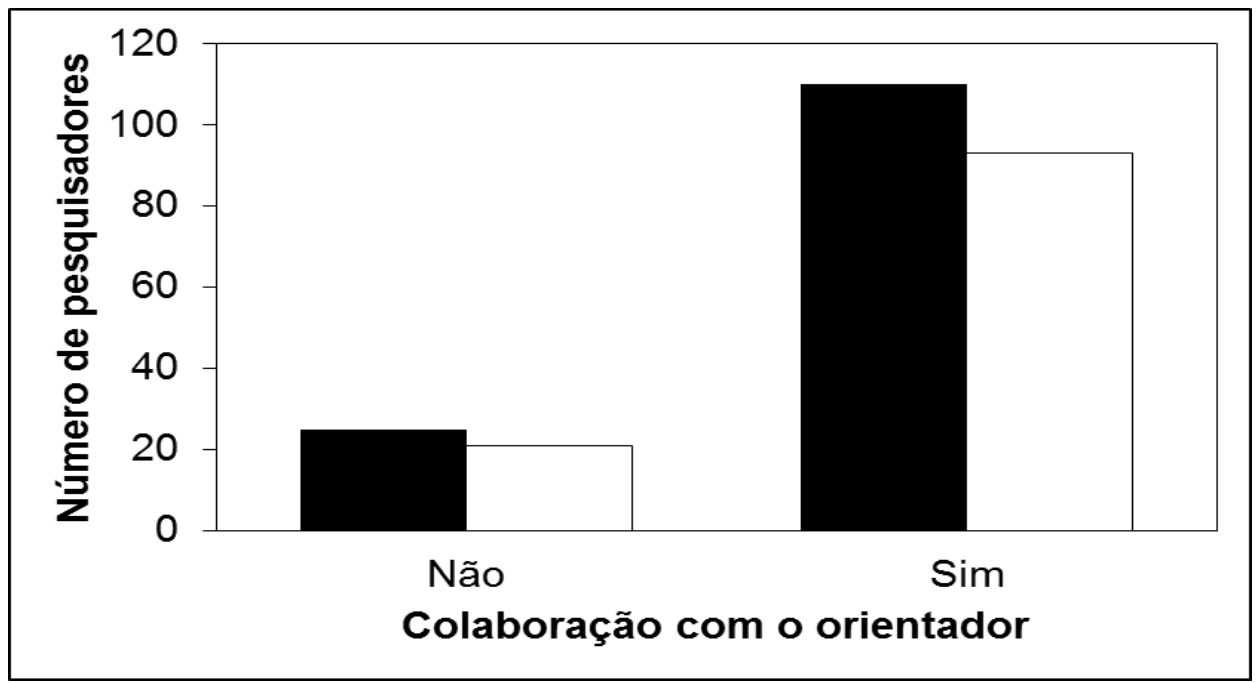

Figura 11. Colaboração com o orientador por pesquisadores homens (barras pretas) e mulheres (barras brancas) da área de Biodiversidade.

Sexo e publicação em colaboração com o orientador foram as variáveis incluídas no modelo com maior suporte (Tabela 16), e o efeito de ambas as variáveis foi importante para predizer o número de publicações em periódicos nacionais (Tabela 17). A variável com maior efeito sobre o número de publicações nacionais foi colaboração 
com o orientador (estimativa $=0,555)($ Tabela 17). Como esperado, os homens publicaram mais do que as mulheres em periódicos nacionais (estimativa $=0,201) \mathrm{e}$ aqueles que colaboraram com seus orientadores publicaram mais artigos em periódicos nacionais, independente do local de doutorado (Tabela 18). No segundo e no terceiro modelos, as variáveis local de doutorado e a interação entre as variáveis local e colaboração foram incluídas, mas uma vez que as estimativas tiveram valor baixo e erro padrão elevado, o efeito desta variável não foi considerado relevante.

Com relação às publicações em periódicos internacionais, as variáveis sexo, colaboração com o orientador e local de doutorado foram incluídas no modelo de maior suporte (Tabela 16). Colaboração com o orientador foi a variável que mais contribuiu (estimativa $=0,512$ ) para o aumento do número de publicações em periódicos internacionais (Tabela 17), principalmente entre as mulheres. Os homens publicaram mais do que as mulheres (estimativa $=0,371$ ) e, como esperado, os pesquisadores que fizeram o doutorado no Brasil publicaram menos artigos em periódicos internacionais em comparação com os que estudaram no exterior (estimativa $=-0,379$ ) (Tabela 17). No geral, os homens que cursaram o doutorado no exterior e colaboraram com os respectivos orientadores são os mais produtivos (média $=25,5$ artigos em 10 anos, Tabela 18). A interação entre as variáveis local de doutorado e colaboração foi incluída no segundo e no terceiro melhores modelos (Tabela 16).

Tanto sexo quanto colaboração com o orientador foram incluídas no modelo com maior suporte (Tabela 16), e o efeito de ambas predisse o total de publicações (Tabela 17). No entanto, colaboração com o orientador teve um efeito maior (estimativa $=$ 0,521) sobre o número de publicações do que sexo (estimativa $=0,285)$. Local de doutorado apareceu no segundo melhor modelo, mas contribuiu pouco para explicar o 
número total de artigos (Tabela 17). Em geral, homens que colaboraram com seus orientadores são os pesquisadores que possuem mais publicações (Tabela 18).

Tabela 16. Variáveis dos modelos (sexo; colaboração com orientador - colab; local do doutorado - local), quasiAIC, $\triangle \mathrm{AIC}$ e graus de liberdade dos modelos mais ajustados para prever o número de publicações no Brasil (pubbr), internacionais (pubint) e total de publicações (pubtot) durante os primeiros 10 anos após obtenção do doutorado de pesquisadores brasileiros da área de Biodiversidade.

\begin{tabular}{|c|c|c|c|c|}
\hline $\begin{array}{c}\text { Tipo de } \\
\text { publicação }\end{array}$ & Modelos & qAICc & $\triangle \mathrm{AIC}$ & gl \\
\hline \multirow[t]{4}{*}{ Brasil } & pubbr $\sim$ sexo + colab & 378,0 & 0,0 & 3 \\
\hline & pubbr $\sim$ sexo + colab + local:colab & 378,3 & 0,3 & 4 \\
\hline & pubbr $\sim$ sexo + colab + local & 378,6 & 0,6 & 4 \\
\hline & pubbr $\sim$ colab & 379,9 & 1,9 & 2 \\
\hline \multirow[t]{3}{*}{ Internacional } & pubint $\sim$ sexo + colab + local & 298,7 & 0,0 & 4 \\
\hline & pubint $\sim$ sexo + colab + local:colab & 298,9 & 0,2 & 4 \\
\hline & pubint $\sim$ sexo + colab + local + local:colab & 300,7 & 2,0 & 5 \\
\hline \multirow[t]{3}{*}{ Total } & pubtot $\sim$ sexo + colab & 325,6 & 0,0 & 3 \\
\hline & pubtot $\sim$ sexo + colab + local & 326,0 & 1,4 & 4 \\
\hline & pubtot $\sim$ sexo + colab + local:colab & 327,1 & 1,5 & 4 \\
\hline
\end{tabular}


Tabela 17. Resultados do GLM com as estimativas das variáveis incluídas no melhor modelo (Tabela 16) como preditoras do número de publicações no Brasil, internacionais e total de publicações durante os 10 primeiros anos da carreira após a obtenção do doutorado, de pesquisadores brasileiros da área de Biodiversidade.

\begin{tabular}{|c|c|c|}
\hline $\begin{array}{c}\text { Tipo de } \\
\text { publicação }\end{array}$ & Termo & Estimativa ( \pm EP) \\
\hline \multirow[t]{3}{*}{ Brasil } & (Intercepto) & $1,751 \pm 0,159$ \\
\hline & Colaboração com orientador (Sim) & $0,555 \pm 0,156$ \\
\hline & Sexo (Homem) & $0,201 \pm 0,102$ \\
\hline \multirow[t]{4}{*}{ Internacional } & (Intercepto) & $1,773 \pm 0,243$ \\
\hline & Colaboração com orientador (Sim) & $0,512 \pm 0,210$ \\
\hline & Local de obtenção do doutorado (Brasil) & $-0,379 \pm 0,160$ \\
\hline & Sexo (Homem) & $0,371 \pm 0,143$ \\
\hline \multirow[t]{3}{*}{ Total } & (Intercepto) & $2,324 \pm 0,150$ \\
\hline & Colaboração com orientador (Sim) & $0,521 \pm 0,146$ \\
\hline & Sexo (Homem) & $0,285 \pm 0,097$ \\
\hline
\end{tabular}


Tabela 18. Média ( \pm EP) do número de publicações em revistas brasileiras, internacionais e total de publicações durante os primeiros 10 anos da carreira de pesquisadores brasileiros da área de Biodiversidade, em relação ao local de doutoramento (Brasil vs. exterior) e colaboração com o orientador (Sim ou não).

\begin{tabular}{|c|c|c|c|c|c|c|c|}
\hline \multirow[t]{2}{*}{ Local } & \multirow{2}{*}{$\begin{array}{c}\text { Colaboração } \\
\text { com } \\
\text { orientador }\end{array}$} & \multicolumn{3}{|c|}{ Homens } & \multicolumn{3}{|c|}{ Mulheres } \\
\hline & & Brasil & Internacional & Total & Brasil & Internacional & Total \\
\hline Brasil & Sim & $\begin{array}{c}12,6 \pm 1,0 \\
(n=88)\end{array}$ & $\begin{array}{l}9,5 \pm 1,3 \\
(n=88)\end{array}$ & $\begin{array}{c}22,0 \pm 1,9 \\
(\mathrm{n}=88)\end{array}$ & $\begin{array}{r}10,5 \pm 0,9 \\
(n=81)\end{array}$ & $\begin{array}{r}7,0 \pm 0,8 \\
(n=81)\end{array}$ & $\begin{array}{r}17,4 \pm 1,2 \\
(\mathrm{n}=81)\end{array}$ \\
\hline & Não & $\begin{array}{l}7,1 \pm 0,9 \\
(n=20)\end{array}$ & $\begin{array}{l}7,1 \pm 1,6 \\
(n=20)\end{array}$ & $\begin{array}{c}14,2 \pm 2,1 \\
(\mathrm{n}=20)\end{array}$ & $\begin{array}{r}5,6 \pm 2,2 \\
(n=14)\end{array}$ & $\begin{array}{r}2,7 \pm 0,8 \\
(n=14)\end{array}$ & $\begin{array}{r}8,4 \pm 2,8 \\
(n=14)\end{array}$ \\
\hline & Total & $\begin{array}{l}11,5 \pm 0,8 \\
(n=108)\end{array}$ & $\begin{array}{l}9,0 \pm 1,1 \\
(\mathrm{n}=108)\end{array}$ & $\begin{array}{l}20,6 \pm 1,6 \\
(n=108)\end{array}$ & $\begin{array}{r}9,7 \pm 0,8 \\
(n=95)\end{array}$ & $\begin{array}{r}6,3 \pm 0,7 \\
(n=95)\end{array}$ & $\begin{array}{r}16,1 \pm 1,2 \\
(n=95)\end{array}$ \\
\hline Exterior & Sim & $\begin{array}{c}11,0 \pm 1,9 \\
(\mathrm{n}=22)\end{array}$ & $\begin{array}{c}14,5 \pm 2,5 \\
(\mathrm{n}=22)\end{array}$ & $\begin{array}{c}25,5 \pm 3,6 \\
(\mathrm{n}=22)\end{array}$ & $\begin{array}{r}7,4 \pm 2,1 \\
(n=12)\end{array}$ & $\begin{array}{r}9,8 \pm 2,4 \\
(\mathrm{n}=12)\end{array}$ & $\begin{array}{r}17,3 \pm 4,1 \\
(\mathrm{n}=12)\end{array}$ \\
\hline & Não & $\begin{array}{c}7,6 \pm 2,9 \\
(n=5)\end{array}$ & $\begin{array}{c}7,2 \pm 2,7 \\
(n=5)\end{array}$ & $\begin{array}{c}14,8 \pm 5,3 \\
(n=5)\end{array}$ & $\begin{array}{c}5,6 \pm 2,2 \\
(n=7)\end{array}$ & $\begin{array}{c}5,9 \pm 1,6 \\
(n=7)\end{array}$ & $\begin{array}{c}11,4 \pm 2,6 \\
(n=7)\end{array}$ \\
\hline & Total & $\begin{array}{c}10,3 \pm 1,6 \\
(n=27)\end{array}$ & $\begin{array}{l}13,2 \pm 2,1 \\
(n=27)\end{array}$ & $\begin{array}{c}23,5 \pm 3,1 \\
(n=27)\end{array}$ & $\begin{array}{l}6,7 \pm 1,6 \\
(n=19)\end{array}$ & $\begin{array}{r}8,4 \pm 1,6 \\
(n=19)\end{array}$ & $\begin{array}{r}15,1 \pm 2,8 \\
(n=19)\end{array}$ \\
\hline Total & & $\begin{array}{c}11,3 \pm 0,8 \\
(n=135)\end{array}$ & $\begin{array}{l}9,9 \pm 1,0 \\
(n=135)\end{array}$ & $\begin{array}{l}21,1 \pm 1,5 \\
(n=135)\end{array}$ & $\begin{array}{l}9,2 \pm 0,7 \\
(n=114)\end{array}$ & $\begin{array}{l}6,7 \pm 0,7 \\
(n=114)\end{array}$ & $\begin{array}{r}15,9 \pm 1,1 \\
(\mathrm{n}=114)\end{array}$ \\
\hline
\end{tabular}




\section{Discussão}

Os resultados encontrados nesta pesquisa corroboram a hipótese da vantagem cumulativa, uma vez que os pesquisadores de ambos os sexos que colaboraram com seus orientadores foram mais produtivos nos primeiros 10 anos de carreira, como sugerido por Long e McGinnis, (1985). As influências positivas do orientador de doutorado sobre a produção científica e a carreira dos doutorandos são evidentes. Os orientadores apresentam aos estudantes não só o conhecimento técnico, mas também a cultura e o conhecimento tácito tradicional de uma área específica do conhecimento. Por meio do processo de colaboração, os orientadores compartilham com seus estudantes, muitas das qualidades que fazem com que eles próprios sejam produtivos, o que pode levar os estudantes a serem igualmente produtivos desde o início de suas carreiras (Hilmer \& Hilmer, 2007). Alta produção científica no início da carreira pode estabelecer um padrão a ser seguido ao longo da carreira, sendo, portanto, um bom preditor de produtividade científica (Cole \& Cole, 1973; Lightfield, 1971).

A colaboração como um fator isolado, no entanto, não pode explicar produção científica, especialmente para as mulheres e particularmente nos primeiros 10 anos da carreira. Os resultados desta pesquisa, semelhantes aos encontrados na literatura, mostram que as mulheres tendem a publicar menos que os homens (Leta \& Batista, 2009; Parker et al., 2010; Symonds et al., 2006). Diversas explicações para as diferenças entre os sexos em termos de produção científica foram discutidos no capítulo anterior. Uma explicação alternativa para a menor produção científica das mulheres seria o critério quantitativo usado para a comparação. Se os critérios usados fossem corrigidos para incluir o efeito da qualidade das publicações, os resultados poderiam ser diferentes, uma vez que as mulheres tenderiam a publicar menos artigos, porém com 
maior impacto (Borrego et al., 2010; Symonds et al., 2006). Nesta pesquisa, a publicação em periódicos internacionais pode ser considerada um indicador de qualidade, uma vez que na área de Biodiversidade, estes artigos têm fator de impacto maior que os artigos publicados em periódicos nacionais. No entanto, os resultados mostraram que os homens publicaram mais artigos em periódicos internacionais, o que contradiz esta hipótese.

O doutorado realizado no exterior foi importante como fator responsável pelo aumento do número de publicações internacionais, resultado que contradiz algumas pesquisas anteriores. Por exemplo, na área de Ciências Biológicas, a produtividade científica dos pesquisadores que realizaram o doutorado no Brasil foi 56\% mais elevada em comparação com a produtividade dos que estudaram no exterior (Roos et al., 2014). $\mathrm{Na}$ área de Bioquímica, o país onde foi realizado o doutorado não teve influência sobre o número ou o impacto dos artigos publicados após o doutorado (De Meis \& Longo, 1990). Embora alguns estudos mostrem que o alto investimento das agências de fomento brasileiras no financiamento de estudantes no exterior não retorne na forma de aumento da produtividade científica (Meneguini, 1991), os resultados da presente pesquisa mostram que os pesquisadores que cursaram o doutorado no exterior publicaram mais artigos em periódicos internacionais. Com relação à publicação em periódicos nacionais, no entanto, este efeito não foi identificado.

As diferenças nos resultados encontrados na presente pesquisa, em comparação com outros estudos sobre o efeito do doutorado no exterior sobre a produção científica, pode ser consequência da falta de controle, nestes estudos, em relação ao tipo de publicação, se nacional ou internacional e à proporção de mulheres e homens na população estudada. A importância da distinção entre publicação nacional e 
internacional está relacionada ao papel do doutorado realizado em países de língua inglesa sobre a produção de artigos internacionais, em sua maioria publicados em inglês. A proporção de homens e mulheres terá reflexos nos resultados, em função das diferenças no padrão de publicação de homens e mulheres.

Considerando a importância da colaboração científica como variável preditora de produção científica, e sua prevalência em relação à variável sexo, é razoável supor que a colaboração com o orientador seja um caminho para diminuir as diferenças de produção científica entre homens e mulheres.

\section{Conclusão}

Os resultados apontam para algumas questões relevantes que podem ter impacto sobre a produção científica nacional: (1) A ênfase a ser dada pelos orientadores para as publicações em colaboração com seus doutorandos, de modo a dar início ao processo de vantagem cumulativa, cujo impacto poderá proporcionar um aumento duradouro na produção científica dos novos pesquisadores, ao longo de suas carreiras; (2) o impacto positivo do treinamento científico no exterior sobre a produção científica internacional; e (3) a importância da compreensão sobre as razões para a menor produção científica das mulheres, que compõem grande parte do corpo discente e docente dos programas de doutorado no país.

Outra contribuição desta pesquisa é revelar a importância de controlar os efeitos do sexo e do tipo de publicação (nacional ou internacional) nas avaliações de produtividade entre pesquisadores treinados no Brasil ou no exterior. Pesquisas mostrando que o investimento na formação de doutores no exterior não retorna na forma de aumento da produção científica podem ser enviesadas em função da proporção de 
homens e mulheres e em relação à proporção de doutores formados no Brasil e no exterior. Características particulares de cada área do conhecimento também podem contribuir para explicar os resultados encontrados em diferentes pesquisas. Respostas sobre o impacto da formação de doutores no exterior devem levar em conta a participação relativa de homens e mulheres. Além disso, levar em conta a qualidade dos programas de doutorado onde os pesquisadores foram treinados tanto no Brasil quanto no exterior também pode ajudar no entendimento das diferenças em produtividade científica. 


\section{Capítulo 3 - Carreira}

Este capítulo apresenta e discute os fatores relacionados às atividades desenvolvidas ao longo da carreira do pesquisador que melhor explicam produção científica: os tipos de colaboração científica (local, doméstica e internacional) e a orientação de alunos de mestrado e doutorado.

Estudos sobre carreira são geralmente encontrados no âmbito de pesquisas sobre psicologia organizacional e do trabalho (Oliveira, Lima, \& Borges-Andrade, 1999; Ambiel \& Noronha, 2012); gestão de carreira (Lacombe, \& Chu, 2006); ou teorias sobre comportamento no trabalho (Frese \& Zapf, 1994). Na presente pesquisa, os aspectos da carreira do pesquisador destacados no parágrafo anterior não estão alinhados com estas abordagens teóricas, sendo apresentados como variáveis relevantes na construção de um modelo geral de predição de produção científica no contexto brasileiro.

O local de trabalho, seja uma Instituição de Ensino Superior ou um Instituto de Pesquisa, é a organização formal onde é desenvolvida a pesquisa científica. Estas instituições são responsáveis pelo salário dos pesquisadores e pela infraestrutura para a realização de pesquisas (Mallon, Duberley, \& Cohen, 2005). No entanto, apesar de pertencerem a uma determinada organização acadêmica ou de pesquisa, os pesquisadores fazem parte de uma comunidade científica que ultrapassa a organização (Kaulisch \& Enders, 2005). O papel da comunidade científica, frequentemente negligenciado em função da importância atribuída ao contexto organizacional da pesquisa científica (Laudel \& Gläser, 2008), está relacionado à definição da identidade do pesquisador e ao conjunto de diretrizes e normas da produção científica (Gläser, 2001). A comunidade científica confere a reputação necessária para que o pesquisador 
seja contratado pela organização que, por sua vez, irá prover os recursos que garantem a mobilidade dos pesquisadores na comunidade científica, uma vez que muitas vezes, o pesquisador está mais atento ao que os seus pares estão fazendo em outros países do que ao que estão fazendo seus colegas da mesma universidade (Kaulisch \& Enders, 2005). Por esta razão, a mobilidade, principalmente a participação em eventos científicos internacionais é altamente correlacionada com a produtividade científica (Teodorescu, 2000) em função do aumento das oportunidades de colaboração entre os cientistas (Katz \& Martin, 1997).

A colaboração científica é um processo social complexo (Sonnenwald, 2007) que envolve um conjunto de pesquisadores em função da produção de conhecimento científico (Katz \& Martin, 1997). A crescente especialização dos cientistas a partir do século XX deu origem a uma situação onde os especialistas em um mesmo tema encontravam-se apenas em conferências e outros fóruns científicos e trocavam informações e artigos impressos por meio do correio (Gresham, 1994). A partir do acesso a computadores, do advento da internet e do uso de e-mail, a comunicação entre pesquisadores do mundo inteiro vem sendo enormemente facilitada, em função do uso de e-mail para trocar informações, estabelecer parcerias, debater questões científicas, compartilhar ideias e socializar (Koku, Nazer, \& Wellman, 2000).

A facilidade de comunicação levou ao aumento da colaboração entre pesquisadores de um mesmo país ou de diferentes países em função da diminuição dos custos de coordenação das pesquisas (Bordons, Gomez, Fernández, Zulueta, \& Méndez 1996; Koku et al., 2000). Para alguns autores, porém, as possibilidades de comunicação e o uso da internet são apenas facilitadores da colaboração, já que a maioria dos trabalhos em colaboração inicia-se face a face e apenas continua pela internet (Laudel, 
2001). Outros autores consideram que diferenças culturais e problemas relacionados à segurança da informação são um problema associado ao uso de e-mail na comunicação entre cientistas (Walsh \& Hong, 2003).

Diversos estudos têm revelado aumento da colaboração entre cientistas (Beaver, 2001; Glänzel, 2001; Wagner \& Leydesdorff, 2005a, 2005b). No entanto, bases bibliométricas utilizam como indicador de colaboração, a co-autoria de artigos, negligenciando outras dimensões importantes da colaboração entre pesquisadores (Duque et al., 2005). Nesta pesquisa, o indicador de colaboração utilizado foi o autorelato dos pesquisadores sobre a colaboração em três níveis: local (com pesquisadores da mesma instituição); doméstica (com pesquisadores de outras instituições de ensino ou pesquisa no Brasil) e internacional (com pesquisadores que atuam em outros países).

A colaboração científica pode ter impactos em todas as etapas da produção científica e pode ocorrer desde a concepção de um problema de pesquisa; durante a coleta de dados ou na análise dos mesmos ou na elaboração do artigo que relata os resultados da pesquisa (Katz \& Martin, 1997). A tendência ao trabalho em colaboração é justificada por fatores tais como a necessidade de dividir custos de equipamentos, de se relacionar com pesquisadores de outros campos do conhecimento em estudos interdisciplinares, a ampliação do acesso a financiamentos, e o desejo de aumentar a bagagem acadêmica e de conhecer novas metodologias e desenvolver habilidades por meio do contato com quem tem mais experiência (Vanz \& Stumpf, 2010). A transferência de conhecimentos e habilidades é um dos maiores benefícios da colaboração (Katz \& Martin, 1997).

A interdisciplinaridade da ciência atual é outro dos motivos que levam à colaboração científica. O conhecimento individual de cada pesquisador é socializado 
entre o grupo quando diferentes pontos de vista são discutidos, gerando novas perspectivas, possibilitando o aprendizado e estimulando a criatividade, principalmente quando os colaboradores são de áreas diferentes (Katz \& Martin, 1997). O grau de colaboração varia em função da modalidade de pesquisa, se teórica ou experimental, se básica ou aplicada, em função da maior ou menor necessidade de instrumentação complexa para sua realização. A colaboração varia ainda em função da área, sendo maior nas ciências naturais e exatas do que nas ciências humanas (Soares, Souza, \& Moura, 2010).

Apesar da ampliação do acesso à internet ter sido responsável pelo aumento da possibilidade de colaboração, a proximidade física e social entre os pesquisadores aumenta a probabilidade de colaboração (Katz \& Martin, 1997). O status acadêmico do pesquisador também afeta a probabilidade de colaboração entre pesquisadores. Quanto mais elevado o status acadêmico, mais e maior acesso a recursos de pesquisa e maior a probabilidade de colaborar com parceiros estrangeiros em redes de colaboração científica internacional, principalmente nas áreas de geociências, astronomia, biologia e física, em função da necessidade de compartilhar equipamentos de pesquisa de custo elevado ou de dados de pesquisa específicos de determinados países (Thorsteinsdóttir, 2000).

O aumento da colaboração entre pesquisadores, mediada pela facilidade de comunicação, vem sendo associada ao aumento da produtividade científica (Lee \& Bozeman, 2005). No entanto, em países em desenvolvimento, onde o processo de produção do conhecimento pode ser diferente daquele encontrado nos países desenvolvidos, esta associação entre colaboração e produtividade científica não foi encontrada (Duque et al., 2005; Shrum, 2005). Este "paradoxo da produtividade" seria 
gerado pela falta de correspondência entre o investimento em tecnologias de informação e comunicação e o aumento em colaboração e produtividade científica (Duque et al., 2005).

Os efeitos da colaboração sobre a produção científica variam entre os países. A associação entre colaboração científica internacional e aumento da produtividade científica (Katz \& Martin, 1997; Lee \& Bozeman, 2005) em geral se baseia em pesquisas com cientistas estadunidenses. Os resultados de estudos com pesquisadores africanos e indianos mostraram que a colaboração não foi consistentemente relacionada com aumento de produtividade, podendo inclusive ser motivo de diminuição da produção científica, em função de problemas contextuais e de questões relacionadas à transmissão e segurança da informação (Duque et al., 2005).

Quando a colaboração envolve a co-autoria em publicações, a chance de aceitação do artigo submetido aumenta devido ao grau de competência dos autores (Katz \& Martin, 1997). Além disso, quanto maior o número de autores, maior a divulgação do trabalho e maior a possibilidade de citações (Persson, Glänzel \& Danell, 2004). No Brasil, as avaliações constantes das agências financiadoras podem constituir um fator que impulsiona a colaboração e a co-autoria. A pressão exercida sobre os pesquisadores para publicarem cada vez mais faz da co-autoria um meio para aumentar o número total de publicações de cada pesquisador (Packer \& Meneghini, 2006). A visibilidade da colaboração internacional pode ser verificada por meio das citações. Dos artigos brasileiros com mais de 100 citações na base Web of Science entre os anos de 1994 e 2003, 84,3\% eram fruto de parcerias com outros países (Packer \& Meneghini, 2007). Porém, em um estudo sobre colaboração científica internacional com base no ISI entre 1999 e 2003, o Brasil ostentava o menor percentual de publicações com pelo menos um 
parceiro internacional em comparação com países latino-americanos como Argentina, Chile, México e Venezuela (Glänzel, Leta \& Thijs, 2006).

Embora a colaboração científica tenha mais chance de ocorrer entre pesquisadores de mesmo status acadêmico do que entre aqueles que mantêm diferenças significativas neste aspecto, uma exceção é feita quando se trata da colaboração, assimétrica, entre o professor e seus orientandos (Katz \& Martin, 1997). Os diferentes aspectos deste tipo de colaboração têm sido objeto de considerável interesse de pesquisas (Green \& Bauer, 1995; Luna \& Cullen, 1998; Paglis et al., 2006; Scandura, 1992), cujos resultados costumam enfatizar os benefícios para ambos os envolvidos (Schlosser, Lyons, Talleyrand, Kim, \& Johnson, 2011). Do ponto de vista do orientador, a motivação para a colaboração científica com os orientandos envolve o estímulo e a satisfação na formação da nova geração de pesquisadores, a oportunidade de atualização, a habilidade de atrair novos colaboradores para projetos atuais e futuros, o crescimento do grupo de pesquisa (L. M. Ferreira et al., 2009) e o aumento da produtividade científica (Schlosser et al., 2011). Entretanto, este tipo de colaboração pode significar diminuição da produção do orientador em função do tempo e energia envolvidos na colaboração com pesquisadores menos experientes (Lee \& Bozeman, 2005).

\section{Método}

Os métodos utilizados para a coleta de dados são descritos na parte de Método (pg. 93). 


\section{Resultados}

\section{Colaboração.}

O número de publicações em periódicos nacionais e internacionais nos primeiros 10 anos da carreira dos pesquisadores em função de sua participação em colaborações locais (com parceiros da mesma instituição), domésticas (com parceiros de outras instituições de ensino ou pesquisa no Brasil) e internacionais (com parceiros de instituições estrangeiras) pode ser visto na Tabela 19. As colaborações não são mutuamente exclusivas, portanto o número total de participantes que relataram cada tipo de colaboração é superior ao número total de participantes.

Tabela 19. Média ( \pm EP) do número de publicações em revistas brasileiras e internacionais e número total de publicações durante os primeiros 10 anos da carreira de pesquisadores brasileiros da área de Biodiversidade em relação ao tipo de colaboração.

\begin{tabular}{cccc}
\hline $\begin{array}{c}\text { Tipo de } \\
\text { publicação }\end{array}$ & \multicolumn{3}{c}{ Tipo de colaboração* } \\
\cline { 2 - 4 } & Local & Doméstica & Internacional \\
& $(\mathbf{n}=\mathbf{1 9 9 )}$ & $(\mathbf{n}=\mathbf{2 2 1})$ & $\mathbf{( n = 1 2 9 )}$ \\
\hline Brasil & $11,0 \pm 0,6$ & $10,9 \pm 0,6$ & $11,6 \pm 0,8$ \\
Internacional & $9,1 \pm 0,7$ & $9,0 \pm 0,7$ & $11,3 \pm 1,0$ \\
Total & $20,1 \pm 1,1$ & $19,9 \pm 1,0$ & $22,8 \pm 1,5$ \\
\hline * Como apenas dois pesquisadores informaram que não realizaram colaboraçães, a categoria \\
“sem colaboração” não foi quantificada.
\end{tabular}

Em termos de publicações nacionais, os dois melhores modelos tiveram suporte muito semelhante $(\triangle \mathrm{AIC}=0$ e 0,1$)($ Tabela 20$)$ e incluíram as duas modalidades de 
colaboração nacional (Tabela 20), sendo a colaboração doméstica, de maior efeito (estimativa $=0,481$ ) do que a local (estimativa $=0,326$ ) sobre a produção de artigos nacionais (Tabela 21). A variável colaboração internacional, que apareceu apenas no segundo melhor modelo, contribuiu pouco para explicar a produção de artigos nacionais $($ estimativa $=0,146)($ Tabela 21$)$.

Quanto aos artigos internacionais foram incluídas no melhor modelo as variáveis colaboração doméstica (Tabela 20) (estimativa $=0,704)$ e colaboração internacional $($ estimativa $=0,655)($ Tabela 21$)$, sendo ambas igualmente importantes para explicar produção de artigos em periódicos internacionais (Tabela 21).

No melhor modelo para o total de publicações, todas as variáveis foram incluídas (Tabela 20), mas o efeito da colaboração doméstica foi maior (estimativa $=0,567$ ) do que o efeito da colaboração internacional (estimativa $=0,365)$ ou local (estimativa $=$ 0,295) (Tabela 21). 
Tabela 20. Variáveis dos modelos (colaboração local - local; colaboração doméstica domest; colaboração internacional - inter), quasiAIC, $\triangle \mathrm{AIC}$ e graus de liberdade das variáveis dos melhores modelos para predizer o número de publicações no Brasil (pubbr), internacionais (pubint) e total (pubtot) durante os primeiros 10 anos da carreira de pesquisadores brasileiros da área de Biodiversidade.

\begin{tabular}{ccccc}
\hline $\begin{array}{c}\text { Tipo de } \\
\text { publicação }\end{array}$ & Modelos & qAICc & $\Delta$ AIC & gl \\
\hline Brasil & pubbr $\sim$ local + domest & 386,0 & 0,0 & 3 \\
& pubbr $\sim$ local + domest + inter & 386,1 & 0,1 & 4 \\
Internacional & pubint $\sim$ domest + inter & 309,6 & 0,0 & 3 \\
& pubint $\sim$ local + domest + inter & 309,9 & 0,3 & 4 \\
& \\
& pubtot $\sim$ local + domest + inter & 337,6 & 0,0 & 4 \\
\hline
\end{tabular}


Tabela 21. Resultados do GLM com as estimativas das variáveis incluídas nos melhores modelos (Tabela 20) como preditoras do número de publicações no Brasil, internacionais e total de publicações durante os 10 primeiros anos da carreira após a obtenção do doutorado, de pesquisadores brasileiros da área de Biodiversidade.

\begin{tabular}{|c|c|c|}
\hline Tipo de publicação & Termo & Estimativa ( \pm EP) \\
\hline \multirow[t]{4}{*}{ Brasil } & (Intercepto) & $1,550 \pm 0,220$ \\
\hline & Doméstica & $0,481 \pm 0,197$ \\
\hline & Local & $0,326 \pm 0,143$ \\
\hline & Internacional & $0,146 \pm 0,104$ \\
\hline \multirow[t]{4}{*}{ Internacional } & (Intercepto) & $0,870 \pm 0,332$ \\
\hline & Doméstica & $0,704 \pm 0,307$ \\
\hline & Internacional & $0,655 \pm 0,147$ \\
\hline & Local & $0,251 \pm 0,194$ \\
\hline \multirow[t]{4}{*}{ Total } & (Intercepto) & $1,957 \pm 0,215$ \\
\hline & Doméstica & $0,567 \pm 0,195$ \\
\hline & Internacional & $0,365 \pm 0,098$ \\
\hline & Local & $0,295 \pm 0,134$ \\
\hline
\end{tabular}




\section{Colaboração internacional e publicação internacional.}

Para avaliar se a produção de artigos internacionais é afetada pelas oportunidades de contato com pesquisadores de outros países, foi analisado o papel das variáveis participação em eventos científicos no exterior e colaboração internacional. A análise estatística mostrou que tanto colaboração no exterior quanto participação em eventos científicos no exterior foram incluídas no melhor modelo (Tabela 22), mas que a colaboração com parceiros do exterior teve um efeito muito maior (estimativa $=0,696$ ) do que a participação em eventos no exterior (estimativa $=0,104)($ Tabela 23), na publicação de artigos internacionais. A comparação entre as médias do número de artigos internacionais dos pesquisadores que participaram ou não de eventos científicos internacionais e colaboram ou não com parceiros no exterior mostra que os pesquisadores que mais publicam (11,8 artigos) são aqueles que participam de eventos no exterior e colaboram com parceiros no exterior (Tabela 24).

Tabela 22. Variáveis dos modelos (participação em eventos científicos no exterior eventos; colaboração com universidades no exterior - colab; eventos:colab), quasiAIC, $\triangle \mathrm{AIC}$ e graus de liberdade das variáveis dos melhores modelos para predizer o número de publicações internacionais (pubint) durante os primeiros 10 anos da carreira de pesquisadores brasileiros da área de Biodiversidade.

\begin{tabular}{lccc}
\hline Modelos & qAICc & $\Delta$ AIC & gl \\
\hline pubint $\sim$ eventos + colab & 302,5 & 0,0 & 3 \\
pubint $\sim$ colab & 303,0 & 0,5 & 2 \\
pubint $\sim$ eventos + colab + eventos:colab & 304,3 & 1,8 & 4 \\
\hline
\end{tabular}


Tabela 23. Resultados do GLM com as estimativas das variáveis incluídas no melhor modelo (Tabela 22) como preditoras do número de publicações no Brasil, internacionais e total de publicações durante os primeiros 10 anos da carreira após a obtenção do doutorado, de pesquisadores brasileiros da área de Biodiversidade.

\begin{tabular}{cc}
\hline Termo & Estimativa ( \pm EP) \\
\hline (Intercepto) & $1,439 \pm 0,188$ \\
Colaborações no exterior (colab) & $0,696 \pm 0,150$ \\
Eventos no exterior (eventos) & $0,104 \pm 0,064$ \\
\hline
\end{tabular}

Tabela 24. Média ( \pm EP) do número de publicações em revistas internacionais durante os primeiros 10 anos da carreira de pesquisadores brasileiros da área de Biodiversidade em relação a colaborações internacionais e participação em congressos no exterior.

\begin{tabular}{cccc}
\hline $\begin{array}{c}\text { Colaborações } \\
\text { internacionais }\end{array}$ & \multicolumn{2}{c}{ Participação em congressos no exterior } \\
\cline { 2 - 4 } & Sim & Não & Total \\
\hline Sim & $11,8 \pm 1,1$ & $5,5 \pm 0,8$ & $11,3 \pm 1,0$ \\
Não & $(\mathrm{n}=118)$ & $(\mathrm{n}=11)$ & $(\mathrm{n}=129)$ \\
& $5,8 \pm 0,7$ & $4,0 \pm 1,0$ & $5,3 \pm 0,6$ \\
Total & $(\mathrm{n}=87)$ & $(\mathrm{n}=33)$ & $(\mathrm{n}=120)$ \\
& $9,3 \pm 0,7$ & $4,4 \pm 0,8$ & $8,4 \pm 0,6$ \\
& $(\mathrm{n}=205)$ & $(\mathrm{n}=44)$ & $(\mathrm{n}=249)$ \\
& & & \\
\hline
\end{tabular}




\section{Colaboração ao longo da carreira.}

O efeito da colaboração ao longo da carreira foi avaliado por meio da comparação entre os 10 primeiros e os 10 últimos anos dos 47 pesquisadores com ao menos 20 anos de carreira.

\section{Primeiros 10 anos.}

Nos primeiros 10 anos, a colaboração tem um grande efeito sobre a produção de artigos, uma vez que os melhores modelos para explicar todos os tipos de publicações são aqueles que envolvem colaboração, em comparação com o modelo nulo (Tabela 25). Este padrão se repetiu para o total de publicações. Quando analisados os efeitos do número de colaborações, foi encontrado um efeito aditivo, ou seja, quanto mais colaborações, maior o efeito sobre todos os tipos de publicação (Tabela 26). 
Tabela 25. Modelos totais e nulos, quasiAIC, $\triangle \mathrm{AIC}$ e graus de liberdade do efeito do número de colaborações (1, 2, e 3 tipos de instituições) para predizer o número de publicações no Brasil, internacionais e total de publicações durante os primeiros 10 anos da carreira de pesquisadores da área de Biodiversidade.

\begin{tabular}{ccccc}
\hline $\begin{array}{c}\text { Tipo de } \\
\text { publicação }\end{array}$ & Modelos & qAICc & $\Delta$ AIC & gl \\
\hline Brasil & Número de colaborações & 377,9 & 0,0 & 3 \\
& Nulo & 387,4 & 9,5 & 1 \\
Internacional & Número de colaborações & 299,6 & 0,0 & 3 \\
& Nulo & 332,8 & 33,2 & 1 \\
Total & Número de colaborações & 329,1 & 0,0 & 3 \\
& Nulo & 362,3 & 33,2 & 1 \\
\hline
\end{tabular}


Tabela 26. Resultados do GLM com as estimativas das variáveis incluídas nos melhores modelos (Tabela 25) como preditoras do número de publicações no Brasil, internacionais e total de publicações durante os primeiros 10 anos da carreira após a obtenção do doutorado, de pesquisadores brasileiros da área de Biodiversidade.

\begin{tabular}{ccc}
\hline $\begin{array}{c}\text { Tipo de } \\
\text { publicação }\end{array}$ & Termo & Estimativa ( \pm EP) \\
\hline Brasil & (Intercepto) & $2,06 \pm 0,12$ \\
& Duas colaborações & $0,19 \pm 0,15$ \\
Tnternacional & (Intercepto) & $0,46 \pm 0,14$ \\
& Duas colaborações & $1,59 \pm 0,18$ \\
Total & Três colaborações & $0,17 \pm 0,23$ \\
& (Intercepto) & $0,91 \pm 0,20$ \\
& Duas colaborações & $2,55 \pm 0,12$ \\
& Três colaborações & $0,18 \pm 0,15$ \\
& & $0,66 \pm 0,13$ \\
\hline
\end{tabular}

\section{Últimos 10 anos.}

$\mathrm{Na}$ análise referente aos últimos 10 anos, os modelos com colaboração foram incluídos como melhores, em comparação com os modelos nulos (Tabela 27). No entanto, as diferenças entre modelos com e sem colaboração foram menores em comparação com os resultados encontrados para os primeiros 10 anos (Tabela 25). Além disso, para publicações nacionais, a diferença entre o modelo nulo e o modelo de colaborações é muito pequena $(\Delta \mathrm{AIC}=0,200$; Tabela 27$)$, revelando pouca influência das colaborações. A análise do efeito do número de colaborações, de forma semelhante 
ao encontrado em relação aos primeiros 10 anos, também mostra um efeito aditivo. No entanto, como o tamanho da população para esta análise foi pequeno $(1$ colaboração $=$ 16 pesquisadores; 2 colaborações $=14 ; 3$ colaborações $=16$ ) e o erro padrão foi grande (Tabela 28), os efeitos só foram conclusivos para o efeito cumulativo de três colaborações.

Tabela 27. Modelos totais e nulos, quasiAIC, $\triangle \mathrm{AIC}$ e graus de liberdade do efeito do número de colaborações (1, 2, e 3 tipos de colaborações) para predizer o número de publicações no Brasil, internacionais e total de publicações durante os últimos 10 anos da carreira de pesquisadores da área de Biodiversidade.

\begin{tabular}{ccccc}
\hline $\begin{array}{c}\text { Tipo de } \\
\text { publicação }\end{array}$ & Modelos & qAICc & $\Delta$ AIC & gl \\
\hline Brasil & Número de colaborações & 56,4 & 0,0 & 3 \\
& Nulo & 56,6 & 0,2 & 1 \\
Internacional & Número de colaborações & 55,5 & 0,0 & 3 \\
& Nulo & 58,9 & 3,4 & 1 \\
Total & Número de colaborações & 52,4 & 0,0 & 3 \\
& Nulo & 55,7 & 3,3 & 1 \\
\hline
\end{tabular}


Tabela 28. Resultados do GLM com as estimativas das variáveis incluídas nos melhores modelos (Tabela 27) como preditoras do número de publicações no Brasil, internacionais e total de publicações durante os últimos 10 anos da carreira após a obtenção do doutorado, de pesquisadores brasileiros da área de Biodiversidade.

\begin{tabular}{ccc}
\hline $\begin{array}{c}\text { Tipo de } \\
\text { publicação }\end{array}$ & Termo & Estimativa $( \pm \mathbf{E P})$ \\
\hline Brasil & (Intercepto) & $2,53 \pm 0,24$ \\
& Duas colaborações & $0,26 \pm 0,33$ \\
Três colaborações & $0,60 \pm 0,30$ \\
Internacional & (Intercepto) & $2,58 \pm 0,25$ \\
& Duas colaborações & $-0,28 \pm 0,39$ \\
Total & Três colaborações & $0,59 \pm 0,31$ \\
& (Intercepto) & $3,25 \pm 0,20$ \\
& Duas colaborações & $0,02 \pm 0,30$ \\
& Três colaborações & $0,59 \pm 0,25$ \\
\hline
\end{tabular}

\section{Colaborações assimétricas - orientador/aluno.}

A seleção de modelos referente às variáveis orientação de mestrado e doutorado mostra que para publicações nacionais, quatro modelos tiveram grande suporte, sendo que o melhor modelo incluiu as variáveis orientação de mestrado e orientação de doutorado (Tabela 29). Considerando que a diferença entre os 4 melhores modelos foi pequena $(\triangle \mathrm{AIC} \leq 0,7)$ reporto os valores das estimativas para o modelo completo, com sexo, mestrado e doutorado. $\mathrm{O}$ efeito da orientação de doutorado (estimativa $=0,470)$ 
foi maior do que a de mestrado $(0,314)$ e que do sexo (estimativa $=0,117)($ Tabela 30$)$.

Em termos do número de publicações, os pesquisadores que orientaram alunos de mestrado e de doutorado publicaram mais do que o dobro de artigos nacionais em comparação com aqueles que não orientaram alunos de mestrado ou de doutorado (Tabela 31).

Quanto às publicações internacionais, as variáveis selecionadas no melhor modelo foram sexo e orientação de doutorado (Tabela 29). O efeito da orientação de doutorado foi elevada (estimativa $=1,072)$, enquanto o efeito do sexo foi menor (estimativa $=$ 0,252) (Tabela 30). O impacto da orientação de mestrado, presente no segundo melhor modelo foi baixo e muito variável, não sendo considerado importante (Tabela 30). Em termos de número de publicações, no entanto, os pesquisadores que orientaram tanto alunos de mestrado quanto de doutorado publicaram mais do que o triplo de artigos internacionais em comparação com aqueles que não orientaram nenhum dos dois tipos de alunos (Tabela 31).

Os resultados do total de publicações foram semelhantes aos encontrados para publicações internacionais, mostrando que as variáveis orientação de doutorado e sexo foram selecionadas (Tabela 29), mas que o efeito da orientação de doutorado (estimativa $=0,716)$ foi muito superior ao efeito do sexo (estimativa $=0,177)$. O papel da orientação de mestrado também revelou ser importante, estando presente no segundo melhor modelo, com efeito (estimativa $=0,256)$ superior ao do sexo (Tabela 30$)$.

A Tabela 31 mostra a produção científica dos pesquisadores em relação à orientação de alunos de mestrado e doutorado. Os pesquisadores que orientaram tanto mestrado quanto doutorado têm o melhor resultado em termos de publicação nacional e este efeito é ainda maior quanto às publicações internacionais. A orientação apenas no 
nível de mestrado resulta em menor produção internacional, não sendo o efeito tão grande para a produção nacional. Não foi possível analisar os dados referentes aos pesquisadores que orientaram apenas no nível de doutorado sem ter orientado mestrado, uma vez que apenas um pesquisador relatou esta condição.

Tabela 29. Variáveis dos modelos (sexo; orientação de estudantes de mestrado - mestre; orientação de estudantes de doutorado - doutor), quasiAIC, $\triangle \mathrm{AIC}$ e graus de liberdade das variáveis dos melhores modelos para predizer o número de publicações no Brasil (pubbr), internacionais (pubint) e total de publicações (pubtot) durante os primeiros 10 anos da carreira de pesquisadores brasileiros da área de Biodiversidade.

\begin{tabular}{ccccc}
\hline $\begin{array}{c}\text { Tipo de } \\
\text { publicação }\end{array}$ & Modelos & qAICc & $\Delta$ AIC & gl \\
\hline Brasil & pubbr $\sim$ doutor + mestre & 388,3 & 0,0 & 3 \\
& pubbr $\sim$ doutor & 388,6 & 0,3 & 2 \\
& pubbr $\sim$ sexo + doutor & 389,0 & 0,7 & 3 \\
& pubbr $\sim$ sexo + doutor + mestre & 389,0 & 0,7 & 4 \\
Internacional & pubint $\sim$ sexo + doutor & 330,3 & 0,0 & 3 \\
& pubint $\sim$ sexo + doutor + mestre & 332,1 & 1,8 & 4 \\
& pubint $\sim$ doutor & 332,3 & 2,0 & 2 \\
& & & & \\
Total & pubtot $\sim$ sexo + doutor & 361,3 & 0,0 & 3 \\
& pubtot $\sim$ sexo + doutor + mestre & 361,8 & 0,5 & 4 \\
\hline
\end{tabular}


Tabela 30. Resultados do GLM com as estimativas das variáveis incluídas nos modelos completos (Tabela 29) como preditoras do número de publicações no Brasil, internacionais e total de publicações durante os 10 primeiros anos da carreira após a obtenção do doutorado, de pesquisadores brasileiros da área de Biodiversidade.

\begin{tabular}{|c|c|c|}
\hline Tipo de & Termo & Estimativa ( $( \pm$ EP) \\
\hline \multirow[t]{4}{*}{ Brasil } & (Intercepto) & $1,679 \pm 0,209$ \\
\hline & Doutorado & $0,470 \pm 0,113$ \\
\hline & Mestrado & $0,314 \pm 0,226$ \\
\hline & Sexo(Homem) & $0,117 \pm 0,100$ \\
\hline \multirow[t]{4}{*}{ Internacional } & (Intercepto) & $1,073 \pm 0,307$ \\
\hline & Doutorado & $1,072 \pm 0,169$ \\
\hline & Sexo(Homem) & $0,252 \pm 0,129$ \\
\hline & Mestrado & $0,163 \pm 0,331$ \\
\hline \multirow[t]{4}{*}{ Total } & (Intercepto) & $2,113 \pm 0,193$ \\
\hline & Doutorado & $0,716 \pm 0,105$ \\
\hline & Mestrado & $0,256 \pm 0,209$ \\
\hline & Sexo(Homem) & $0,177 \pm 0,087$ \\
\hline
\end{tabular}


Tabela 31. Média ( \pm EP) do número de publicações em revistas brasileiras e internacionais durante os primeiros 10 anos da carreira de pesquisadores brasileiros da área de Biodiversidade em relação à orientação de alunos de mestrado e de doutorado.

\begin{tabular}{|c|c|c|c|c|}
\hline \multirow{2}{*}{$\begin{array}{c}\text { Tipo de } \\
\text { publicação }\end{array}$} & \multirow[t]{2}{*}{ Mestrado } & \multicolumn{3}{|c|}{ Doutorado } \\
\hline & & Sim & Não & Total \\
\hline \multirow[t]{3}{*}{ Brasil } & Sim & $\begin{array}{l}12,7 \pm 0,7 \\
(\mathrm{n}=143)\end{array}$ & $\begin{array}{l}7,7 \pm 0,8 \\
(\mathrm{n}=81)\end{array}$ & $\begin{array}{l}10,9 \pm 0,6 \\
(n=224)\end{array}$ \\
\hline & Não & $*$ & $\begin{array}{l}5,9 \pm 1,1 \\
(n=24)\end{array}$ & $\begin{array}{l}5,7 \pm 1,0 \\
(n=25)\end{array}$ \\
\hline & Total & $\begin{array}{l}12,6 \pm 0,7 \\
(n=144)\end{array}$ & $\begin{array}{l}7,3 \pm 0,6 \\
(\mathrm{n}=105)\end{array}$ & $\begin{array}{l}10,4 \pm 0,5 \\
(n=249)\end{array}$ \\
\hline \multirow[t]{3}{*}{ Internacional } & Sim & $\begin{array}{l}11,8 \pm 0,9 \\
(n=143)\end{array}$ & $\begin{array}{l}3,9 \pm 0,5 \\
(n=81)\end{array}$ & $\begin{array}{l}8,9 \pm 0,7 \\
(n=224)\end{array}$ \\
\hline & Não & $*$ & $\begin{array}{l}3,5 \pm 0,8 \\
(n=24)\end{array}$ & $\begin{array}{l}3,5 \pm 0,7 \\
(\mathrm{n}=25)\end{array}$ \\
\hline & Total & $\begin{array}{l}11,8 \pm 0,9 \\
(n=144)\end{array}$ & $\begin{array}{l}3,8 \pm 0,4 \\
(\mathrm{n}=105)\end{array}$ & $\begin{array}{l}8,4 \pm 0,6 \\
(n=249)\end{array}$ \\
\hline \multirow[t]{3}{*}{ Total } & Sim & $\begin{array}{r}24,5 \pm 1,4 \\
(\mathrm{n}=143)\end{array}$ & $\begin{array}{c}11,5 \pm 0,8 \\
(\mathrm{n}=81)\end{array}$ & $\begin{array}{l}19,8 \pm 1,0 \\
(n=224)\end{array}$ \\
\hline & Não & * & $\begin{array}{l}9,4 \pm 1,6 \\
(n=24)\end{array}$ & $\begin{array}{l}9,2 \pm 1,5 \\
(\mathrm{n}=25)\end{array}$ \\
\hline & Total & $\begin{array}{r}24,4 \pm 1,4 \\
(\mathrm{n}=144)\end{array}$ & $\begin{array}{l}11,0 \pm 0,7 \\
(\mathrm{n}=105)\end{array}$ & $\begin{array}{l}18,8 \pm 0,9 \\
(n=249)\end{array}$ \\
\hline
\end{tabular}

* Como apenas um pesquisador orientou estudante de doutorado, mas não orientou de mestrado, esta categoria não foi quantificada. 


\section{Discussão}

Os resultados mostraram que a colaboração entre cientistas é um fator importante na organização do trabalho científico no Brasil, que se reflete no aumento da produção de artigos. Os resultados encontrados nesta pesquisa corroboram a tendência de primazia da colaboração doméstica no crescimento da produção científica brasileira, em todas as áreas do conhecimento (Sidone, Haddad, \& Mena-Chalco, 2014). Apesar do presente estudo não ter utilizado dados de co-autoria propriamente, a relação direta entre colaboração e produção de artigos (Sonnenwald, 2007) permite a comparação com os dados de Sidone e colaboradores (2013). Segundo estes autores, o número de artigos em co-autorias passou de 547.249 no triênio 1992-1994 para 9.445.399 no triênio 20072009, crescimento devido principalmente ao aumento na colaboração doméstica, que passou de 229.439 para 8.408.125.

A relação entre tipo de colaboração e tipo de produção mostrou que as colaborações entre pesquisadores brasileiros tiveram maior efeito sobre as publicações em periódicos nacionais e as colaborações entre pesquisadores brasileiros e pesquisadores de outros países afetaram principalmente a produção de artigos em periódicos internacionais. Estes resultados podem ser o reflexo de duas estratégias distintas de produção. A primeira estratégia, semelhante ao padrão de produção dos pesquisadores da Índia, envolve pesquisadores de países em desenvolvimento que desfrutam de um sistema científico nacional bem desenvolvido, mas que estão relativamente isolados das redes de pesquisa internacionais (Duque et al., 2005). Estes pesquisadores têm como foco a produção nacional e evitam problemas relacionados à participação em redes internacionais, como barreiras linguísticas, dificuldades de transmissão de informação e de mobilidade. A segunda estratégia é semelhante a dos 
países desenvolvidos e deve ser resultante das diversas práticas de internacionalização, como a realização de doutorado no exterior e a participação em eventos científicos no exterior. Estas práticas proporcionam aos pesquisadores de países periféricos, oportunidades para o estabelecimento de colaborações científicas com parceiros de países cientificamente mais avançados, afetando positivamente a colaboração internacional e consequentemente, a produção de artigos em periódicos internacionais (Duque et al., 2005). A associação encontrada entre participação em eventos científicos internacionais e aumento da produção científica internacional corrobora os achados de Teodorescu (2000), principalmente em relação aos pesquisadores mais jovens. Segundo este autor, participar de eventos científicos proporciona oportunidades para encontros e conversas informais entre colegas que podem levar à colaboração na produção de artigos (Sonnenwald, 2007), um importante preditor de produtividade científica (Beaver, 2001; Blackburn et al., 1978; Thorsteinsdóttir, 2000). O efeito da participação em eventos científicos poderia ser comparado ao efeito exercido pelos estímulos compartilhados pelos indivíduos de um mesmo grupo social de trabalho (Coelho Junior \& Borges-Andrade, 2011). Como os pesquisadores, em geral, têm poucas oportunidades de encontros presenciais com membros da comunidade científica da qual fazem parte, os eventos científicos seriam uma oportunidade de compartilhamento de estímulos cujos efeitos poderiam impactar os padrões de comportamento, neste caso, a produção científica dos pesquisadores.

Na análise temporal, o maior efeito da colaboração científica no início da carreira pode refletir uma fase em que o pesquisador procura parceiros tanto em função de suprir limitações teóricas ou metodológicas, quanto pela necessidade de obter os recursos materiais para a realização da pesquisa, uma vez que ainda não acumulou capital 
científico suficiente para obter verbas que permitam desenvolver sua pesquisa de forma autônoma. O pesquisador pode ainda precisar publicar em associação com outros em busca de aumentar a probabilidade de aceitação do manuscrito para publicação ou aumentar as chances de citação do artigo publicado (Katz \& Martin, 1997). Estes resultados podem estar relacionados com o interesse em aquisição de maior visibilidade de cientistas de menor status acadêmico (Lin, 1999), tendo como motivação a probabilidade de aumento da produtividade científica (Wagner \& Leydesdorff, 2005b).

Foi possível identificar uma tendência de diminuição da importância da colaboração, principalmente em relação à publicação de artigos nacionais, embora o reduzido número de pesquisadores com ao menos 20 anos de carreira $(n=47)$, tenha dificultado a análise temporal. Este resultado pode estar relacionado à maior autonomia adquirida, ao capital científico acumulado e conseqüentemente, à menor demanda por associações com parceiros para a realização de pesquisa.

Nesta pesquisa, o indicador de colaboração utilizado foi a auto-declaração dos pesquisadores em relação à participação em diferentes tipos de colaboração. Uma vantagem deste indicador, em comparação ao uso da co-autoria de artigos, é a inclusão de atividades de colaboração que não resultaram em publicação, uma vez que nem toda colaboração resulta em artigo e nem toda co-autoria indica colaboração (Lima, Velho \& Faria, 2007). O produto final de uma colaboração científica pode incluir, além de publicações, a socialização de estudantes na pesquisa científica acadêmica, o que pode influenciar positivamente sua formação como pesquisador.

Do ponto de vista do orientador, a colaboração com o orientando é uma colaboração assimétrica, na qual ele tem um papel de tutor. Na orientação de mestrandos, a parceria entre orientador e estudante é muito desigual e o papel do 
orientador reflete mais o modelo mestre/aprendiz do que o modelo de parceria. No que se refere à orientação de doutorado, em função do recorte temporal desta pesquisa, que analisa os primeiros 10 anos de carreira do pesquisador e considerando que usualmente é necessário orientar uma ou duas dissertações de mestrado antes de iniciar a orientação de uma tese de doutorado, é preciso observar que os primeiros doutorandos orientados estariam concluindo suas teses, no mínimo, seis anos após o início da carreira de seus orientadores e os primeiros artigos em colaboração com estes seriam publicados a partir do sexto ou sétimo ano após o início da carreira do orientador. Portanto, o efeito da orientação de doutorado sobre a produção científica dos pesquisadores, nesta pesquisa, deve ser considerado não como um fator que explicaria a produção, mas como uma consequência da produção. Pesquisadores produtivos atraem mais alunos de doutorado. Portanto, a diferença encontrada entre sexos na orientação de alunos de mestrado e doutorado pode estar refletindo a diferença em termos de produção científica dos orientadores.

\section{Conclusão}

Os pesquisadores brasileiros da área de Biodiversidade trabalham em colaboração com outros cientistas do Brasil ou do exterior, seguindo a tendência mundial de ciência mais colaborativa do que competitiva (Thorsteinsdóttir, 2000). A colaboração que se dá entre pesquisadores no Brasil proporciona perspectivas diferentes da colaboração internacional, mas independentemente do tipo de colaboração, os resultados apontam para as vantagens do trabalho colaborativo. O efeito positivo da colaboração científica na carreira de um pesquisador gera um círculo virtuoso de produção científica. $\mathrm{O}$ pesquisador que começou a carreira publicando um ou dois artigos em colaboração com 
o seu orientador poderá buscar outras colaborações ao longo da carreira, o que contribui para aumentar sua produção e capital científico, que por sua vez aumenta as chances de buscar recursos para realizar pesquisa e participar de eventos no exterior, gerando mais colaborações e publicações. 


\section{Limitações do Estudo}

Assim como em qualquer pesquisa, há algumas limitações neste estudo. O fato dos pesquisadores pertencerem a uma única área do conhecimento pode tornar a pesquisa pouco generalizável. No entanto, é difícil comparar produção científica entre pesquisadores de áreas diferentes, em função de características peculiares das áreas, como o tempo médio para a obtenção dos dados que darão origem a uma publicação, por exemplo. O recorte temporal também pode representar uma limitação, uma vez que pesquisadores que concluíram o doutorado em 2002 podem ter sido submetidos a condições, demandas e critérios de seleção bastante diferentes dos pesquisadores que se doutoraram em 1989, tornando a população heterogênea neste aspecto. Porém, ao limitar o recorte a um período de 13 anos (1989-2002), tentou-se amenizar quaisquer diferenças existentes.

Outra limitação deste estudo foi o uso de um indicador quantitativo de produção científica. A justificativa para esta escolha, apresentada em outra parte do texto representa uma limitação, uma vez que o uso de medidas de impacto, como o número de citações dos artigos publicados poderia ter gerado resultados diferentes dos aqui encontrados. Vale ressaltar que na quantificação do número de artigos, não foi levado em conta o número de autores ou a posição dos mesmos na lista de autores. Porém, devido à grande escala temporal da data de publicação dos artigos (1990 a 2012), o uso de número de citações ou do fator de impacto das revistas torna-se difícil de ser controlado ou padronizado.

A medida de colaboração utilizada foi o auto-relato, ou seja, os pesquisadores indicaram o(s) tipo(s) de colaboração científica estabelecida(s) com seus pares. Não foi 
realizada nenhuma tentativa de verificação das colaborações relatadas por meio de seu produto, as co-autorias.

As diferenças de qualidade entre os Programas de Pós-Graduação onde os pesquisadores concluíram o doutorado ou onde atuam profissionalmente não foram consideradas nesta pesquisa. A obtenção desta informação apresenta dificuldades em função da amplitude do período de conclusão do doutorado considerado e da variação entre os países quanto à avaliação da qualidade dos Programas de Pós-Graduação.

Por fim, esta pesquisa poderia ter capturado aspectos importantes para explicar a produção científica se tivessem sido realizadas entrevistas com os pesquisadores. Um indicador do potencial deste recurso é a riqueza dos relatos de alguns dos respondentes. Entretanto, esta abordagem apresenta dificuldades logísticas que limitariam o tamanho da população estudada. 


\section{Conclusão Geral}

O objetivo estabelecido para esta pesquisa foi o de identificar os preditores de produtividade científica, conforme apresentado na Figura 12. Os resultados mostraram que sexo e colaboração científica são as variáveis que melhor predizem produção científica entre pesquisadores brasileiros da área de Biodiversidade. A colaboração científica que impacta na produção acontece tanto durante a formação acadêmica, quando ocorre entre orientador e orientando, quanto ao longo da carreira, em função das interações entre pares. Sendo assim, uma característica pessoal, o sexo, e suas prováveis implicações relacionadas à socialização de gênero tanto no âmbito familiar quanto acadêmico, teve um efeito muito importante como preditor de produção científica. Com relação à carreira científica, a colaboração com outros pesquisadores, desde a coautoria de artigos com o orientador, ou a colaboração (relatada) com outros pesquisadores e com os orientandos, também foram importantes fatores que contribuíram para explicar produtividade científica.

Em termos de artigos nacionais, as principais variáveis preditoras foram sexo e colaboração nacional. A maior produção de artigos internacionais foi encontrada entre os pesquisadores do sexo masculino, que colaboraram com seus orientadores, cursaram o doutorado no exterior, participaram de eventos científicos no exterior e colaboraram com pesquisadores de universidades estrangeiras.

Em resumo, a contribuição desta pesquisa para a construção de um modelo preditivo de produção científica está na confirmação das evidências identificadas em outros estudos, quanto às diferenças entre os sexos em termos de produção científica e na importância de todas as formas de colaboração entre pesquisadores. 

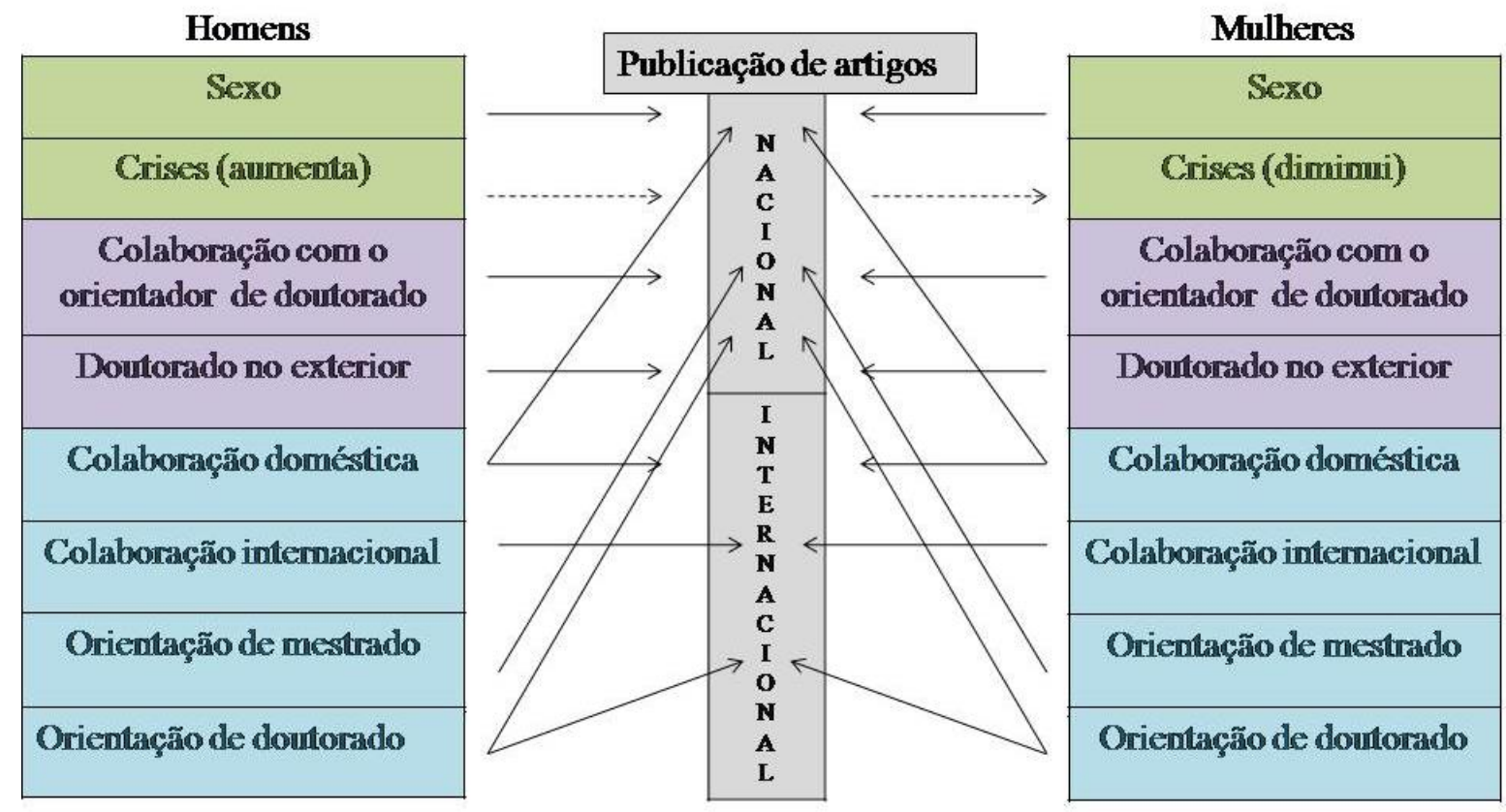

Figura 12. Modelo sintético das variáveis que afetam a publicação de artigos em periódicos nacionais e internacionais de pesquisadores brasileiros (de ambos os sexos) da área de Biodiversidade. As setas que não tocam a coluna central indicam efeito indiscriminado das variáveis sobre ambos os tipos de publicação. A seta tracejada indica um efeito fraco, mas cuja tendência aponta para uma diferença entre homens e mulheres. As cores indicam os diferentes grupos de variáveis: verde (fatores humanos); roxo (fatores associados à formação acadêmica); e azul (fatores associados à carreira).

A importância da colaboração científica como preditor de produção científica aponta para o acerto das políticas públicas voltadas para a intensificação da colaboração em pesquisa, tanto no nível nacional quanto, principalmente, no nível internacional. No Brasil, o investimento em mobilidade de docentes e estudantes por meio do apoio à formação de parcerias científicas entre diferentes países e pela concessão de bolsas e auxílios para o intercâmbio acadêmico de estudantes brasileiros no exterior fazem parte dos esforços para a internacionalização da pesquisa científica realizada nas 
universidades e institutos de pesquisa brasileiros. É possível que o doutorado no exterior seja o fator responsável por desencadear a postura 'globalizada', que se mostrou relevante para explicar a maior produção de artigos internacionais, evidenciando o efeito da fluência de um idioma estrangeiro e a familiaridade com a forma de fazer ciência no âmbito internacional. Entretanto, o reconhecimento do papel da colaboração científica internacional no crescimento da qualidade da produção científica não deve ofuscar a importância da colaboração doméstica, principalmente em países emergentes, onde o crescimento da produção científica está fortemente vinculado à colaboração nacional (Leta \& Chaimovichk, 2002; Royal Society, 2011).

A colaboração dos mestrandos e doutorandos com seus orientadores revelou-se como um importante preditor de produção científica. Este resultado aponta para a importância deste tipo de colaboração na formação de novos pesquisadores e na relevância da inclusão das atividades de orientação acadêmica nas avaliações da pósgraduação, como fator associado ao aumento da produção científica acadêmica e à crescente melhora da qualidade da pós-graduação no Brasil.

Os resultados desta pesquisa mostraram as diferenças em produtividade científica entre homens e mulheres, quase consistentemente desfavoráveis para as últimas. Este resultado, embora esperado, soa como um alerta. Se ambos os sexos são igualmente beneficiados pelas políticas de governo de incentivo à ciência e se estamos formando número comparável de pesquisadores de ambos os sexos, o caminho para aumentar a produção científica nacional deve passar, necessariamente, pelo esclarecimento dos fatores que detém o grande contingente feminino de alcançar o seu potencial científico.

Uma hipótese para explicar as diferenças entre os sexos em produtividade científica baseia-se nas diferenças entre os sexos encontradas também entre atletas de 
elite. De acordo com a descrição de especialistas em medicina e epidemiologia do esporte, para alcançar sucesso internacional, atletas de elite realizam um esforço colossal não apenas físico, mas também mental, em uma carreira sujeita a muita pressão, repleta de fatores estressantes e circunstâncias adversas (Schaal et al., 2011). De acordo com estes autores, a ansiedade generalizada foi a patologia mais prevalente entre os atletas, sendo as mulheres $56 \%$ mais susceptíveis que os homens. Atletas de elite e pesquisadores são submetidos a muita pressão para alcançar e manter alto desempenho em suas respectivas carreiras e dependem constantemente da avaliação de treinadores, juris e colegas de equipe, no caso de atletas. No caso de pesquisadores, a pressão é exercida pelos revisores dos artigos, pelos editores das revistas e pelas agências financiadoras das pesquisas. O sentimento de "falta de controle" sobre o resultado final e sobre outros aspectos da carreira, relatado por ginastas de elite (Kerr \& Goss, 1997), também foi apontado pelos participantes da presente pesquisa em depoimentos espontâneos sobre crises pessoais e profissionais durante a carreira científica.

Algumas explicações para a predominância de desordens relacionadas à ansiedade entre as mulheres, não só no âmbito esportivo, mas na população em geral, estariam relacionadas a diferenças entre os sexos em reatividade ao estresse provocado pela ação de um neurohormônio regulado pelo estrogênio (Schaal et al., 2011) e pelo papel dos processos de socialização de gênero; aprendizagem dos papéis sexuais; normas sociais; e agentes socializadores. Estes mecanismos, biológicos ou sociais, seriam responsáveis pelas diferenças entre os sexos em relação à ansiedade e a percepção de competência e controle (McLean \& Anderson, 2009; Zalta \& Chambless, 2012), com consequências 
sobre o comportamento de publicação de artigos, principalmente em periódicos internacionais, onde o nível de exigência é maior.

Os modelos selecionados nas análises mostraram as variáveis que melhor explicam produção científica. Este resultado, resumido na Figura 12, aponta para algumas direções: (1) a importância de buscar explicações para as diferenças de produção científica entre os sexos. Algumas tentativas de explicação foram feitas nesta pesquisa, mas serão necessárias investigações mais detalhadas para alcançar a compreensão de suas causas; (2) a ênfase a ser dada à parceria científica entre orientador e orientando; (3) a relevância da experiência acadêmica no exterior para alavancar a produção científica internacional, e (4) a importância da colaboração científica doméstica e internacional no aumento da produção científica nacional e internacional, respectivamente. 


\section{Referências}

Acker, S. (1992). New perspectives on an old problem: the position of women academics in British higher education. Higher Education, 24, 57-75.

Adamo, S. A. (2013). Attrition of women in the biological sciences: workload, motherhood, and other explanations revisited. BioScience, 63(1), 43-48.

Ambiel, R. A. M., \& Noronha, A. P. P. (2012). Autoeficácia para Escolha Profissional: Teoria, Pesquisas e Avaliação. Psicologia em Pesquisa, 6(02), 171-178.

Anderson, D. R. (2008). Model based inference in the Life Sciences. A Primer on evidence. New York: Springer.

Anderson, D. R., Burnham, K. P., \& Thompson, W. L. (2000). Null hypothesis testing: problems, prevalence, and an alternative. Journal of Wildlife Management, 64, 912923.

Anderson, D. R., Link, W. A., Johnson, D. H., \& Burnham, K. P. (2001). Suggestions for presenting the results of data analysis. Journal of Wildlife Management, 65(3), 373-378.

Antony, J. S. (2002). Reexamining doctoral student socialization and professional development: moving beyond the congruence and assimilation orientation. In J. C., Smart, \& W. G., Tierney (Eds.), Higher Education: Handbook of Theory and Research (pp. 349-380) (Vol. 17). New York, NY: Agathon Press.

Austin, A. E. (2002). Preparing the next generation of faculty: graduate school as socialization to the academic career. The Journal of Higher Education, 73, 94-121.

Bakar, D. (2012). Socialization of science - The acquisition of skills and values. Momentum, 1, 1-7. 
Balbachevsky, E. (2007). Carreira e contexto institucional no sistema de ensino superior brasileiro - Dossiê. Sociologias, 17, 158-188.

Bargar, R. R., \& Maio-Chamberlain, J. (1983). Advisor and advisee issues in doctoral education. The Journal of Higher Education, 54, 407-432.

Barinaga, M. (1992). Profile of a field: Neuroscience - the pipeline is leaking. Science, $255,1366-1367$.

Beaver, D. (2001). Reflections on scientific collaboration (and its study): past, present, and future. Scientometrics, 52(3), 365-377.

Beiguelman, B. (1998). Reflexões sobre a pós-graduação brasileira. In M. Palatnik, P. Arruda, J. Leta, F. Leite, \& L. De Meis (Orgs.), A Pós-graduação no Brasil (pp. 33-48). Rio de Janeiro: Editora UFRJ.

Blackburn, R. T., Behymer, C. E., \& Hall, D. E. (1978). Research note: correlates of faculty publications. Sociology of Education, 51, 132-141.

Bordons, M., Gomez, I., Fernández, M. T., Zulueta, M. A., \& Méndez, A. (1996). Local, domestic and international scientific collaboration in Biomedical research. Scientometrics, 37(2), 279-295.

Borges-Andrade, J. E. (1994). Preditores individuais e ambientais da produção do pesquisador. Revista de Administração, 29(4), 73-87.

Borrego, A., Barrios, M., Villarroya, A., \& Ollé, C. (2010). Scientific output and impact of postdoctoral scientists: a gender perspective. Scientometrics, 83(1), 93-101.

Bourdieu, P., \& Passeron, J. C. (1964). Les Héritiers: les étudiants et la culture. Paris: Les Éditions de Minuit.

Brasil. (2000). Enfrentar e vencer desafios. Brasília: Ministério da Educação. 
Brasil. (2011). Decreto $n^{o}$ 7642, que institui o Programa Ciência sem Fronteiras. Diário Oficial da União, Brasília, 14 de dez. 2011, seção 1, p. 10.

Brickman, W. W. (1950). International education. In W. S. Monroe (Ed.). Encyclopedia of Educational Research (pp. 617-627). New York, NY: Macmillan.

Brito, A. X. (2004). Habitus de herdeiro, habitus escolar. Os sentidos da internacionalização nas trajetórias dos estudantes brasileiros. In A. M. F. Almeida, L. Canedo, A. Garcia, \& A. Bittencourt (Eds.). Circulação Internacional e Formação Intelectual das Elites Brasileiras (pp. 85-104). Campinas: Editora Unicamp.

Bronstein, P., Rothblum, E. D., \& Solomon, S. E. (1993). Ivy halls and glass walls: barriers to academic careers for women and ethnic minorities. New Directions for Teaching and Learning, 53, 17-31.

Burnham, K. P., \& Anderson, D. R. (2002). Model selection and multimodel inference: A practical information-theoretic approach ( $2^{\mathrm{a}}$ ed.). New York: Springer.

Burnham, K. P., \& Anderson, D. R. (2004). Multimodal inference: understanding AIC and BIC in model selection. Sociological Methods Research, 33, 261-304.

Burnham, K. P., \& Anderson, D. R., (2001). Kullback-Leibler information as a basis for strong inference in ecological studies. Wildlife Research, 28, 111-119.

Burnham, K. P., Anderson, D. R., \& Huyvaert, K. P. (2011). AIC model selection and multimodel inference in behavioral ecology: some background, observations, and comparisons. Behavioral Ecology and Sociobiology, 65(1), 23-35.

Campbell, R. A. (2003). Preparing the next generation of scientists: the social process of managing students. Social Studies of Science, 33(6), 897-927. 
CAPES. (2013). Documento de área 2013. Área de avaliação Biodiversidade.

Recuperado em 27 de setembro de 2013 de

http://www.capes.gov.br/images/stories/download/avaliacaotrienal/Docs_de_area/B iodiversidade_doc_area_e_comiss\%C3\%A3o_block.pdf.

Carayol, N., \& Matt, M. (2006). Individual and collective determinants of academic scientist's productivity. Information Economics and Policy, 18, 55-72.

Carvalho, I. M. M. (2002). Trajetórias de formação e projetos de pesquisa: Uma comparação entre as diferentes áreas. In J. Velloso (Org.), Formação no País ou no Exterior? Doutores na Pós-Graduação de Excelência. Um Estudo na Bioquímica, Engenharia Elétrica, Física e Química no País (pp. 193-200). Brasília: CAPES.

Carvalho, M. E. P. (2000). Relações entre família e escola e suas implicações de gênero. Cardernos de Pesquisa, 110, 143-155.

Castro, C. M. (1985). Há produção científica no Brasil? Ciência e Cultura, 37(7), 165187.

Ceci, S. J., \& Williams, W. M. (2011). Understanding current causes of women's underrepresentation in science. Proceedings of the National Academy of Sciences, 108(8), 3157-3162.

CGEE (2010). Doutores 2010: Estudos da demografia da base técnico-científica brasileira. Brasília: Centro de Gestão e Estudos Estratégicos.

Charlot, B. (1996). Relação com o saber e com a escola entre estudantes de periferia. Cadernos de Pesquisa, 97, 47-63 (trad. Neide Luiza de Rezende).

Coelho Junior, F. A., \& Borges-Andrade, J. E. (2011). Efeitos de variáveis individuais e contextuais sobre desempenho individual no trabalho. Estudos de Psicologia, 16(2), 111-120. 
Cole, J. R., \& Cole, S. (1967). Scientific output and recognition: a study in the operation of the reward system in science. American Sociological Review, 32, 377-390.

Cole, J. R., \& Cole, S. (1973). Social stratification in science. Chicago: The University of Chicago Press.

Cole, J. R., \& Zuckerman, H. (1984). The productivity puzzle: persistence and change in patterns of publication of men and women scientists. Advances in Motivation and Achievement, 2, 217-258.

Cole, J. R., \& Zuckerman, H. (1987). Marriage, motherhood and research performance in science. Scientific American, 256(2), 119-125.

Cole, S. (1979). Age and scientific performance. American Journal of Sociology, 84, 958-977.

Coleman, J. S. (1988). Social capital in the creation of human capital. The American Journal of Sociology, 94, 95-120.

Conger, R. W., Lorenz, E. O., Elder, G. H., Simons, R. L., \& Ge, X. (1993). Husband and wife differences in response to undesirable life events. Journal of Health and Social Behavior, 34(1), 71-88.

Creswell, J. W. (1985). Faculty research performance - Lessons from the Sciences and the Social Sciences (ASHE-ERIC Higher Education Report 4). Washington, DC: Association for the Study of Higher Education.

Cury, C. R. J. (2004). Qualificação pós-graduada no exterior. In A. M. Almeida, L. Canedo, A. Garcia, \& A. Bittencourt (Org.), Circulação Internacional e Formação Intelectual das Elites Brasileiras (pp. 107-143). Campinas: Editora Unicamp.

Cury, C. R. J. (2005). Quadragésimo ano do parecer CFE n. 977/65. Revista Brasileira de Educação, 30, 7-20. 
D’Amico, R., Vermigli, P., \& Canetto, S. S. (2011). Publication productivity and career advancement by female and male psychology faculty: the case of Italy. Journal of Diversity in Higher Education, 4(3), 175-184.

De Meis, L., \& Leta, J. (1996). O perfil da ciência brasileira. Rio de Janeiro: Editora UFRJ.

De Meis, L., \& Longo, P. H. (1990). The training of Brazilian biochemists in Brazil and in developed countries: costs and benefits. Biochemical Education, 18, 182-188.

De Meis, L., Arruda, A. P., \& Guimarães, J. (2007). The impact of science in Brazil. IUBMB Life, 59, 227-234.

Denton, M., Prus, S., \& Walters, V. (2004). Gender differences in health: a Canadian study of the psychosocial, structural and behavioural determinants of health. Social Science \& Medicine, 58(12), 2585-2600.

Duffy, R. D., Martin, H. M., Bryan, N. A., \& Raque-Bogdan, T. L. (2008). Measuring individual research productivity: a review and development of the integrated research productivity index. Journal of Counseling Psychology, 55(4), 518-527.

Duque, R. B., Ynalvez, M., Sooryamoorthy, R., Mbatia, P., Dzorgbo, D.-B. S., \& Shrum, W. (2005). Collaboration paradox: scientific productivity, the internet, and problems of research in developing areas. Social Studies of Science, 35(5), 755-785.

Editorial (2010). Wanted: women in research. [Editorial]. Nature Neuroscience 13(3), 267.

Espeland, W. N., \& Stevens, M. A. (2008). A sociology of quantification. European Journal of Sociology, 49(3), 401-436.

Ferreira, L. M., Furtado, F., \& Silveira, T. S. (2009). Relação orientador-orientando. O conhecimento multiplicador. Acta Cirúrgica Brasileira, 24(3), 170-172. 
Ferreira, S. M. S. P. (2010). Em busca de novas métricas de avaliação da produção científica em ciências da comunicação. Observatório (OBS*) Journal, 4(1), 323348.

Field, A. (2009). Discovering statistics using SPSS ( $3^{\text {a }}$ ed.). Londres, Inglaterra: SAGE.

Fox, M. F., \& Faver, C. (1985). Men, women, and publication productivity among social work academics. Sociological Quarterly, 26(4), 537-549.

Fox, M. F., \& Mohapatra, S. (2007). Social-organizational characteristics of work and publication productivity among academic scientists in doctoral granting departments. The Journal of Higher Education, 78, 542-571.

Frese, M., \& Zapf, D. (1994). Action as the core of work psychology: A German approach. In H. C. Triandis, M. D. Dunnette, \& J. M. Hough (Eds), Handbook of industrial and organizational psychology (Vol. 4, 2nd ed., pp. 271-340). Palo Alto, CA: Consulting Psychology Press.

Gardner, S. K. (2007). "I heard it through the grapevine": doctoral student socialization in chemistry and history. Higher Education, 54, 723-740.

Gardner, S. K. (2008). What's too much and what's too little? The process of becoming an independent researcher in doctoral education. The Journal of Higher Education, 79(3), 326-350.

Gardner, S. K. (2009). The development of doctoral students: Phases of challenge and support. (ASHE Higher Education Report, 34(6)), San Francisco, CA: Jossey-Bass.

Garfield, E. (1996). What Is The Primordial Reference For The Phrase 'Publish Or Perish'?". The Scientist 10(12),11.

Girves, J. E., \& Wemmerus, V. (1988). Developing a model of graduate student degree progress. Journal of Higher Education, 59(2), 163-189. 
Glänzel, W. (2001). National characteristics in international scientific co-authorship relations. Scientometrics, 51(1), 69-115.

Glänzel, W., Leta, J., \& Thijs, B. (2006). Science in Brazil. Part 1: A macro-level comparative study. Scientometrics, 67(1), 67-86.

Glaser, J. (2001). Macrostructures, careers and knowledge production: A neoinstitutionalist approach. International Journal of Technology Management, 22, 698-715.

Golde, C. M. (2005). The role of the department and discipline in doctoral student attrition: Lessons from four departments. Journal of Higher Education, 76, 669700.

Golde, C. M. (2010). Entering different worlds. Socialization into disciplinary communities. In S. K., Gardner, \& P. Mendoza (Eds.), On becoming a scholar: Socialization and development in doctoral education (pp. 79-96). Sterling, VA: Stylus Publishing.

Golde, C. M., \& Dore, T. M. (2004). The survey of doctoral education and career preparation: the importance of disciplinary contexts. In D. H. Wulff, A. E. Austin, \& Associates (Eds.), Paths to the professoriate. Strategies for enriching the preparation of future faculty (pp. 19-45). San Francisco, CA: Jossey-Bass.

Gonzalez-Brambila, C., \& Veloso, F. M. (2007). The determinants of research output and impact: a study of Mexican researchers. Research Policy, 36, 1035-1051.

Goulden, M., Mason, M. A., \& Frasch, K. (2011). Keeping women in the science pipeline. Annals of the American Academy of Political and Social Science, 638, 141-162. 
Green, S. G. (1991). Professional entry and the adviser relationship. Group \& Organization Studies, 16(4), 387-407.

Green, S. G., \& Bauer, T. N. (1995). Supervisory mentoring by advisors: relationships with doctoral student potential, productivity, and commitment. Personnel Psychology, 48(3), 537-562.

Gresham, J. J. (1994). From invisible college to cyberspace college: computer conferencing and the transformation of informal scholarly communication networks. Interpersonal Computing and Technology, 29(4), 37-52.

Hamovitch, W., \& Morganstern, R. (1977). Children and the productivity of academic women. Journal of Higher Education, 48(6), 633-645.

Hargens, L., McCann, J. C., \& Reskin, B. F. (1978). Productivity and reproductivity: fertility and professional achievement among research scientists. Social Forces, 57, $154-163$.

Hartley, N., \& Dobele, A. (2009). Feathers in the nest: establishing a supportive environment for women researchers. The Australian Educational Researcher Journal, 36(1), 43-58.

Hilmer, C. E., \& Hilmer, M. J. (2007). On the relationship between the student-advisor match and early career research productivity for agricultural and resource economics Ph.D.s. American Journal of Agricultural Economics, 89(1), 162-175.

Hunter, L. A., \& Leahey, E. (2010). Parenting and research productivity: new evidence and methods. Social Studies of Science, 40(3), 433-451.

INEP - Instituto Nacional de Estudos e Pesquisas Educacionais Anísio Teixeira (2013). Censo da Educação Superior de 2012. Recuperado em 27 de setembro de 2013 de http://portal.inep.gov.br/. 
Jacobs, J. A., \& Winslow, S. E. (2004). Overworked faculty: job stress and family demands. The Annals of the American Academy of Political and Social Science, $596,104-129$.

Jaffe, K., Caicedo, M., Manzanares, M., Gil, M., Rios, A., Florez, A., ... \& Davila, V. (2013). Productivity in physical and chemical science predicts the future economic growth of developing countries better than other popular indices. PLOS ONE, 8(6): e66239. doi:10.1371/journal.pone.0066239.

Jin, B. H., Rousseau, R., Suttmeier, R. P., \& Cao, C. (2007). The role of ethnic ties in international collaboration: The overseas Chinese phenomenon. In D. TorresSalinas, \& H. F. Moed (Eds.), Proceedings of the ISSI 2007, $11^{\text {th }}$ International Conference of the International Society for Scientometrics and Informetrics (pp. 427-436). Madrid: CSIC.

Jonas, K., \& Lebherz, C. (2008). Social psychology in action. In M. Hewstone, W. Stroebe, \& K. Jonas (Eds.), Introduction to social psychology: a European perspective (4th ed.) (pp. 316-344). Malden: Blackwell.

Katz, J. S., \& Martin, B. R. (1997). What is research collaboration? Research Policy, 26(1), 1-18.

Kaulisch, M., \& Enders, J. (2005). Careers in overlapping institutional contexts. The case of academy. Career Development International, 10(2), 130-144.

Kerr, G., \& Goss, J. (1997). Personal control in elite gymnasts: the relationships between locus of control, self-esteem and trait anxiety. Journal of Sport Behavior, 20, 69-82.

Knight, J., \& De Wit, H. (1995). Strategies for internationalization of higher education: historical and conceptual perspectives. In H. De Wit (Ed.), Strategies for 
internationalisation of higher education: A comparative study of Australia, Canada, Europe and the United States of America (pp. 5-32). Amsterdam: European Association for International Education.

Koku, E., Nazer, N., \& Wellman, B. (2000). Netting scholars: online and offline. American Behavioral Scientist, 43 (Special issue, Mapping Globalization), 1-19.

Krebs, H. A. (1967). The making of a scientist. Nature, 215, 1441-1445.

Kyvik, S. (1990). Motherhood and scientific productivity. Social Studies of Science, 20, 149-160.

Kyvik, S., \& Teigen, M. (1996). Child care, research collaboration, and gender differences in scientific productivity. Science, Technology, and Human Values, 21(1), 54-71.

Lacombe, B. M. B., \& Chu, R. A. (2006). Buscando as fronteiras da carreira sem fronteiras: uma pesquisa com professores universitários em administração de empresas na cidade de São Paulo. Balassiano, Moisés; Costa, Isabel de Sá Affonso. Gestão de Carreiras-dilemas e perspectivas. São Paulo: Atlas, 109-133.

Laudel, G. (2001). Collaboration, creativity and rewards: why and how scientists collaborate. International Journal of Technology Management, 22, 762-781.

Laudel, G., \& Gläser, J. (2008). From apprentice to colleague: the metamorphosis of early career researchers. Higher Education, 55, 387-406.

Lawani, S. M. (1986). Some bibliometric correlates of quality in scientific research. Scientometrics, 9(1,2), 13-25.

Lawrence, P. A. (2003). The politics of publication. Nature, 422, 259-261.

Leahey, E. (2006). Gender differences in productivity: research specialization as a missing link. Gender \& Society, 20(6), 754-780. 
Lee, S., \& Bozeman, B. (2005). The impact of research collaboration on scientific productivity. Social Studies of Science, 35, 673-702.

Leta, J. (2003). As mulheres na ciência brasileira: crescimento, contrastes e um perfil de sucesso. Revista de Estudos Avançados, 17(49), 271-284.

Leta, J., \& Batista, P. D. (2009). Brazilian authors' scientific performance: does gender matter? Proceedings of ISSI $2009-12^{\text {th }}$ International Conference of the International Society for Scientometrics and Informetrics, Rio de Janeiro, 1, 343353.

Leta, J., \& Chaimovich, H. (2002). Recognition and international collaboration: the Brazilian case. Scientometrics, 53(3), 325-335.

Leta, J., Glanzel, W., \& Thijs, B. (2006). Science in Brazil. Part 2: sectorial and institutional research profiles. Scientometrics, 67(1), 87-105.

Leta, J., Lannes, D., \& De Meis, L. (1998). Human resources and scientific productivity in Brazil. Scientometrics, 41(3), 313-324.

Levin, S. G., \& Stephan, P. E. (1991). Research productivity over the life cycle: evidence for academic scientists. The American Economic Review, 81(1), 114 -132.

Lewinson, G. (2001). The quantity and quality of female researchers: a bibliometric study of Iceland. Scientometrics, 52(1), 29-43.

Lightfield, E. T. (1971). Output and recognition of sociologists. The American Sociologist, 6(2), 128-133.

Lima, R. A., Velho, L., \& Faria, L. I. L. (2007). Indicadores bibliométricos de cooperação científica internacional em bioprospecção. Perspectivas em Ciência da Informação, 12, 50-64. 
Lima, R. A., Velho, L., \& Faria, L. I. L. (2012). Bibliometria e avaliação da atividade científica: um estudo sobre o índice H. Perspectivas em Ciência da Informação, 17, 3-17.

Lin, N. (1999). Social networks and status attainment. Annual Review of Sociology, 25, 467-88.

Long, J. S. (1990). The origins of sex differences in science. Social Forces, 68, 1297 1315.

Long, J. S. (1992). Measures of sex differences in scientific productivity. Social Forces, $71,159-178$.

Long, J. S., \& McGinnis, R. (1985). The effects of the mentor on the academic career. Scientometrics, 7, 255-280.

Luna, G., \& Cullen, D. (1998). Do graduate students need mentoring? College Student Journal, 32(3), 322-330.

Mallon, M., Duberley, J., \& Cohen, L. (2005). Careers in public sector science: orientations and implications. R\&D Management, 35(4), 395-407.

Martins, R. C. R. (1991). A pós-graduação no Brasil: uma análise do período 1970-90. Educação Brasileira, 13(27), 93-119.

Matias, M., \& Fontaine, A. (2012). A conciliação de papéis profissionais e familiares: o mecanismo psicológico de spillover. Psicologia: Teoria e Pesquisa, 28(2), 235243.

Mazerolle, M. J. (2006). Improving data analysis in herpetology: using Akaike's Information Criterion (AIC) to assess the strength of biological hypotheses. Amphibia-Reptilia, 27, 169-180. 
McDonough, P., \& Strohschein, L. (2003). Age and the gender gap in distress. Women \& Health, 38(1), 1-20.

McLean, C. P., \& Anderson, E. R. (2009). Brave men and timid women? A review of the gender differences in fear and anxiety. Clinical Psychology Review, 29, 496505.

Meadows, A. J. (1999). A comunicação científica. Brasília: Briquet de Lemos.

Meneghini, R., \& Packer, A. L. (2006). Articles with authors affiliated to Brazilian institutions published from 1994 to 2003 with 100 or more citations: II identification of thematic nuclei of excellence in Brazilian science. Anais da Academia Brasileira de Ciências, 78, 855-883.

Meneguini, R. (1991). Performance of Brazilian scientists with previous Ph.D. training in Brazil and in developed countries: the case of chemists. Ciência e Cultura, 43(5), 343-346.

Meneguini, R., \& Packer, A. L. (2007). Is there science beyond English? Initiatives to increase the quality and visibility of non-English publications might help to break down language barriers in scientific communication. EMBO Reports, 8, 112-116.

Miller, B. P., Duque, R., Shrum, W. (2012). Gender, ICTs, and productivity in lowincome countries: panel study. Science, Technology \& Human Values, 37(1), 30-63.

Mirowsky, J., \& Ross, C. E. (1995). Sex differences in distress: real or artifact? American Sociological Review, 60(3), 449-468.

Mueller, S. P. M. (2005). A publicação da ciência: áreas científicas e seus canais preferenciais. DataGramaZero - Revista de Ciência da Informação, 6(1). Recuperado em 12 de julho de 2013 de: < http://www.dgz.org.br/fev05/F_I_art.htm> 
Mugnaini, R., Carvalho, T., \& Campanatti-Ostiz, H. (2006). Indicadores de produção científica: uma discussão conceitual. In D. A. Poblacion, G. P. Witter, \& J. F. M. Silva (Orgs.), Comunicação e produção científica. Contexto, indicadores e avaliação (pp. 59-79). São Paulo: Ed. Angellara.

Nakhaie, M. R. (2002). Gender differences in publication among university professors in Canada. Canadian Review of Sociology, 39, 151-179.

Nolen-Hoeksema, S. (1987). Sex differences in unipolar depression: evidence and theory. Psychological Bulletin, 101(2), 259-282.

NSERC Natural Sciences and Engineering Research Council of Canada (2010). Women in science and engineering in Canada. Recuperado em 2 de julho de 2013 de: www.nserc-crsng.gc.ca/_doc/ReportsRapports/Women_Science_Engineering.

Nurullah, A. S. (2010). Gender differences in distress: the mediating influence of life stressors and psychological resources. Asian Social Science, 6(5), 27-35.

O’Brien, K. R., \& Hapgood, K. P. (2012). The academic jungle: ecosystem modelling reveals why women are driven out of research. Oikos, 121, 999-1004.

OECD (2005). Economic Surveys: Brazil 2005. OECD Publishing.

Ogbogu, C. O. (2013). Work-Family role conflict among academic women in Nigerian Public Universities. The West East Institute International Academic Conference Proceedings, Orlando.

Oliveira, M. A. P. S., Lima, S. M. V., \& Borges-Andrade, J. E. (1999).

Comprometimento no Trabalho e Produção Científica entre Pesquisadores. Revista de Administração, 34(3), 12-20.

Olinto, G. (2011). A inclusão das mulheres nas carreiras de ciência e tecnologia no Brasil. Inclusão Social, 5(1), 68-77. 
Packer, A. L., \& Meneghini, R. (2006). Articles with authors affiliated to Brazilian institutions published from 1994 to 2003 with 100 or more citations: I - the weight of international collaboration and the role of the networks. Anais da Academia Brasileira de Ciências, 78, 841-853.

Packer, A. L., \& Meneguini, R. (2007). Learning to communicate science in developing countries. Interciência, 32(9), 643-647.

Paglis, L. L., Green, S. G., \& Bauer, T. N. (2006). Does adviser mentoring add value? A longitudinal study of mentoring and doctoral student outcomes. Research in Higher Education, 47(4), 451-476.

Parker, J. N., Lortie, C., \& Allesina, S. (2010). Characterizing a scientific elite: the social characteristics of the most highly cited scientists in environmental science and ecology. Scientometrics, 85, 129-143.

Persson, O., Glänzel,W., \& Danell, R. (2004). Inflationary bibliometric values: the role of scientific collaboration and the need for relative indicators in evaluative studies. Scientometrics, 60(3), 421-432.

Poblacion, D. A., \& Oliveira, M. (2006). Input e output: Insumos para o desenvolvimento da pesquisa. In D. A. Poblacion, G. P. Witter, \& J. F. M. Silva (Orgs.), Comunicação e Produção Científica. Contexto, indicadores e avaliação (pp. 59-79). São Paulo: Ed. Angellara.

Primack, R. B., \& O’Leary, V. E. (1989). Research productivity of men and women ecologists: a longitudinal study. Bulletin of the Ecological Society of America, 70, $7-12$. 
Ptacek, J. T., Smith, R. E., \& Dodge, K. L. (1994). Gender differences in coping with stress: when stressors and appraisal do not differ. Personality and Social Psychology Bulletin, 20(4), 421-430.

Reskin, B. (1978). Scientific productivity, sex, and location in the Institution of Science. American Journal of Sociology, 83, 1235-1243.

Roos, D. H., Calabró, L., Jesus, S. L. H., Souza, D. O., Barbosa, N. V., \& Rocha, J. B. T. R. (2014). Brazilian scientific production in areas of biological sciences: a comparative study on the modalities of full doctorate in Brazil or abroad. Scientometrics, 98(1), 415-427.

Royal Society (2011). Knowledge, networks and nations: global scientific collaboration in the 21 st century. London: The RS.

Santos, C. M. (2003). Tradições e contradições da pós-graduação no Brasil. Educação \& Sociedade, 24(83), 627-641.

Scandura, T. A. (1992). Mentorship and career mobility: an empirical investigation. Journal of Organizational Behavior, 13, 169-174.

Schaal, K., Tafflet, M., Nassif, H., Thibault, V., Pichard, C., Alcotte, M...., \& Toussaint, J.-F. (2011). Psychological balance in high level athletes: gender-based differences and sport-specific patterns. PLoS One, 6(5), 1-9.

Schlosser, L. Z., Lyons, H. Z., Talleyrand, R. M., Kim, B. S. K., \& Johnson, W. B. (2011). Advisor-advisee relationships in graduate training programs. Journal of Career Development, 38(1), 3-18.

Schwartzman, S. (2005). Os desafios da educação no Brasil. In S. Schwartzman, \& C. Brock (Orgs.), Os desafios da educação no Brasil (pp. 9-50). Rio de Janeiro: Nova Fronteira. 
Shin, J. C., \& Cummings, W. K. (2010). Multilevel analysis of academic publishing across disciplines: research preference, collaboration, and time on research. Scientometrics, 85, 581-594.

Shrum, W. (2005). Reagency of the internet, or, "How I became a guest for science." Social Studies of Science, 35(5), 723-754.

Sidone, O. J. G., Haddad, E. A., \& Mena-Chalco, J. P. (2014). Scholarly publication and collaboration in Brazil: the role of geography. Textos para Discussão. Núcleo de Economia Regional e Urbana da Universidade de São Paulo - NEREUS, São Paulo.

Soares, G. A. D., Souza, C. P. R., \& Moura, T. W. (2010). Colaboração na produção científica na Ciência Política e na Sociologia brasileiras. Sociedade e Estado, 25(3), $525-538$.

Solla Price, D. J. (1976). O desenvolvimento da ciência: Análise histórica, filosófica, sociológica e econômica. Rio de Janeiro: Livros Técnicos e Científicos. [Tradução de Little Science, Big Science, 1963].

Sonnenwald, D. H. (2007). Scientific collaboration. Annual Review of Information Science and Technology, 41(1), 643-681.

Stack, S. (2004). Gender, children and research productivity. Research in Higher Education, 45(8), 891-920.

Stroebe, W. (2010). The graying of academia. Will it reduce scientific productivity? American Psychologist, 65(7), 660-673.

Sylvester, R. (2002). Mapping international education: a historical survey 1893-1944. Journal of Research in International Education, 1(1), 90-125. 
Symonds, M. R. E., Gemmell, N. J., Braisher, T. L., Gorringe, K. L., \& Elgar, M. A. (2006). Gender differences in publication output: towards an UnBiased metric of research performance. PLOS ONE, 1(1): e127.doi:10.1371/journal.pone.0000127.

Teodorescu, D. (2000). Correlates of faculty publication productivity: a cross-national analysis. Higher Education, 39, 201-222.

Thorsteinsdóttir, O. H. (2000). External research collaboration in two small science systems. Scientometrics, 49(1), 145-160.

Tinto, V. (1975). Dropout from higher education: a theoretical synthesis of recent research. Review of Educational Research, 45, 89-125.

Tinto, V. (2012). Leaving college. Rethinking the causes and cures of student attrition. (Apêndice B: Towards a Theory of Doctoral Persistence). Chicago: The University of Chicago Press.

Toutkoushian, R. K., \& Bellas, M. L. (1999). Faculty time allocations and research productivity: gender, race and family effects. The Review of Higher Education, 22(4), 367-390.

Turner, C. S. V., \& Thompson, J. R. (1993). Socializing women doctoral students: minority and majority experiences. The Review of Higher Education, 16, 355-370.

Turner, L., \& Mairesse, J. (2003). Explaining individual productivity differences in scientific research productivity: how important are institutional and individual determinants? An econometric analysis of the publications of French CNRS physicists in condensed matter (1980-1997). Conferência em homenagem a Zvi Griliches, Paris, França.

Vanz, S. A. S., \& Stumpf, I. R. C. (2010). Colaboração científica: revisão teóricoconceitual. Perspectivas em Ciência da Informação, 15(2), 42-55. 
Velho, L. (2001). Formação de doutores no país e no exterior: estratégias alternativas ou complementares? Revista Dados, 44(3), 607-631.

Velho, L., \& León, E. (1998). A construção social da produção científica por mulheres. Cadernos Pagu, 10, 309-344.

Velloso, J., \& Velho, L. (1997). Política de bolsas, progressão e titulação nos mestrados e doutorados. Cadernos de Pesquisa da Fundação Carlos Chagas, 101, 50-81.

Vianna, M. J. B. (2005). As práticas socializadoras familiares como locus de constituição de disposições facilitadoras de longevidade escolar em meios populares. Educação \& Sociedade, 26(90), 107-125.

Wagner, C. S., \& Leydesdorff, L. (2005a) Mapping the network of global science: comparing international co-authorships from 1990 to 2000. International Journal of Technology and Globalisation, 1(2), 185-208.

Wagner, C. S., \& Leydesdorff, L. (2005b). Network structure, self-organization, and the growth of international collaboration in science. Research Policy, 34(10), 16081618.

Walsh, J. P., \& Hong, W. (2003). Secrecy is increasing in step with competition. Nature, 422, 801-802.

Wanner, R. A., Lewis, L. S., \& Gregorio, D. I. (1981). Research productivity in academia: a comparative study of the sciences, social sciences and humanities. Sociology of Education, 54, 238-253.

Weidman, J. C. (2010). Doctoral student socialization for research. In S. K. Gardner, \& P. Mendoza (Eds.). On becoming a scholar: Socialization and development in doctoral education. (pp. 45-55). Sterling, VA: Stylus Publishing. 
Weidman, J. C., \& Stein, E. L. (2003). Socialization of doctoral students to academic norms. Research in Higher Education, 44(6), 641-656.

Weidman, J. C., Twale, D. J., \& Stein, E. L. (2001). Socialization of graduate and professional students in higher education: A perilous passage? (ASHE Higher Education Report, vol. 28, n. 3). San Francisco, CA: Jossey-Bass.

Wolfinger, N. H., Goulden, M., \& Mason, M. A. (2010). Alone in the ivory tower. Journal of Family Issues, 31(12), 1652-1670.

Wolfinger, N. H., Mason, M. A., \& Goulden, M. (2008). Problems in the pipeline: gender, marriage, and fertility in the ivory tower. The Journal of Higher Education, $79,388-405$.

Xie, Y., \& Shauman, K. A. (1998). Sex differences in research productivity: new evidence about an old puzzle. American Sociological Review, 63, 847-870.

Yamamoto, O. H., Tourinho, E. Z., Bastos, A. V. B., \& Menandro, P. (2012). Produção científica e produtivismo: há alguma luz no fim do túnel? RBPG. Revista Brasileira de Pós-Graduação, 9, 727-750.

Ynalvez, M. A., \& Shrum, W. M. (2011). Professional networks, scientific collaboration, and publication productivity in resource-constrained research institutions in a developing country. Research Policy, 40(2), 204-216.

Zainab, A. N. (1999). Personal, academic and departmental correlates of research productivity: a review of literature. Malaysian Journal of Library \& Information Science, 4(20), 73-110.

Zalta, A. K., \& Chambless, D. L. (2012). Understanding gender differences in anxiety: the mediating effects of instrumentality and mastery. Psychology of Women Quarterly, 36(4), 488-499. 
Zar, J. H. (1984). Biostatistical analysis (2 ${ }^{\mathrm{a}}$ ed.). New Jersey: Prentice Hall.

Zull, J. E. (2012). The brain, learning, and study abroad. In M. Vande Berg, M. Paige, \& K. H. Lou. (Eds.), Student learning abroad (pp. 162-187). Virginia: Stylus Publishing. 


\section{Anexo 1 - Questionário}

\section{ASPECTOS HUMANOS DA PRODUÇÃO CIENTÍFICA}

Obrigada por aceitar o convite! (refere-se ao convite enviado por e-mail).

Como havia dito, preciso complementar algumas informações que não fazem parte do CV Lattes. Para isso elaborei este questionário, cujo objetivo é tentar revelar alguns dos aspectos humanos que afetam a produção científica.

Para que eu possa concluir a pesquisa, peço que você responda a todas as perguntas. A sua participação é muito importante.

Esta pesquisa atende às exigências éticas sobre pesquisas com seres humanos. Ao clicar em "seguinte", você estará concordando em participar. Caso tenha alguma dúvida, fique à vontade para entrar em contato comigo. Meus contatos são: xxx.

Muito obrigada pela sua colaboração e pelo seu tempo.

Jussara P. Prado

(doutoranda PSTO/UNB) 


\section{Existem 21 perguntas neste inquérito}

Fase pré-universitária

Para começar, gostaria de saber um pouco sobre o apoio educacional que você recebeu da sua família, durante o ensino fundamental e médio.

\section{Suporte educacional familiar}

(Na sua família, quem era o principal responsável pela sua educação formal - ajuda com as tarefas escolares, reunião de pais e mestres, acompanhamento de notas, boletim, etc.?)

* Se selecionar a opção 'Outro', por favor especifique a sua escolha utilizando o respectivo campo de texto.

Por favor, selecione apenas uma das seguintes opções:

Mãe.

Pai.

Irmão/irmã.

Avô/avó.

Não havia este tipo de suporte na minha família.

Outro

\section{Escolaridade}

(Esta pessoa tinha estudado até que nível?)

* Responda a esta pergunta apenas se as seguintes condições são verdadeiras:

Por favor, selecione apenas uma das seguintes opções:

Ensino fundamental incompleto ou abaixo.

Ensino fundamental completo.

Ensino médio.

Ensino superior incompleto.

OEnsino superior completo ou acima. 


\section{Profissão}

(E em que trabalhava?)

*Responda a esta pergunta apenas se as seguintes condições são verdadeiras:

Por favor, selecione todas as que se aplicam:

Atividade relacionada à área de educação.

Atividade relacionada à área de pesquisa.

$\square$ Profissional liberal.

$\square$ Comércio ou autônomo.

$\square$ Servidor público.

$\square$ Celetista.

$\square$ Não tinha emprego formal.

Outro:

\section{Conhecimento sobre ensino superior}

(Sua família ou pessoas de seu círculo social tinham algum conhecimento sobre ensino superior - conheciam alguma universidade ou tinham informações sobre as formas de acesso?)

* Por favor, selecione todas as que se aplicam:

Sim. Havia pessoas da minha família com formação universitária.

Sim. Havia pessoas do meu convívio social com formação universitária.

$\square$ Mesmo não tendo formação universitária, algumas pessoas da minha família e/ou convívio social tinham informações sobre o ensino superior

Não. As pessoas da minha família ou convívio social não tinham acesso à informações sobre o ensino superior

\section{Experiência internacional}

(Informe se sua família tinha alguma experiência internacional ou contato com outro(s) país(es)).

*Por favor, selecione todas as que se aplicam:

$\square$ Residência temporária no exterior.

$\square$ Viagem para o exterior. 
Parente próximo vivendo no exterior.

Nenhuma experiência internacional ou contato com pessoas que viviam em outros países.

Outro:

\section{Doutorado}

As perguntas a seguir referem-se ao seu doutorado e ao seu orientador de doutorado.

\section{Eventos científicos}

Enquanto doutorando, você apresentou os resultados de sua pesquisa em algum evento científico?

*Por favor, selecione apenas uma das seguintes opções:

Sim

Não

\section{Colaboração com o orientador}

Você possui alguma publicação em colaboração com seu orientador de doutorado?

*Por favor, selecione apenas uma das seguintes opções:

Sim

Não

\section{Início da carreira - Primeiros 10 anos após o doutorado}

(As perguntas abaixo se referem à sua atuação profissional durante os primeiros 10 anos de carreira acadêmica após a conclusão do doutorado.)

$\underline{8 \text { Durante os primeiros } 10 \text { anos da sua carreira após o doutorado, com que frequência }}$ você participou de eventos científicos no exterior?

*Por favor, selecione apenas uma das seguintes opções:

Nunca.

Poucas vezes.

Quase todo ano.

Anualmente.

Duas vezes por ano ou mais. 
9 Durante os primeiros 10 anos da sua carreira após o doutorado, você orientou alunos em quais modalidades?

*Por favor, selecione todas as que se aplicam:

$\square$ Iniciação científica.

Mestrado.

$\square$ Doutorado.

$\square$ Não orientei.

10 Durante os primeiros 10 anos da sua carreira após o doutorado, você colaborou cientificamente com outros pesquisadores?

*Por favor, selecione todas as que se aplicam:

$\square$ Sim. Da mesma instituição.

$\square$ Sim. De outras instituições no Brasil.

$\square$ Sim. De instituições no exterior.

Não colaborei.

\section{Tempo de carreira}

11 Você tem ao menos vinte anos de carreira acadêmica?

*Por favor, selecione apenas uma das seguintes opções:

Sim

Não

(Se sua resposta foi 'sim', as três questões anteriores serão apresentadas novamente.)

Desta vez, responda em relação aos últimos 10 anos de carreira.

\section{Últimos 10 anos de atuação profissional}

As perguntas abaixo se referem à sua atuação profissional durante os últimos dez anos de carreira.

12 Como explicado anteriormente, responda considerando os últimos 10 anos de carreira. Com que frequência você participou de eventos científicos no exterior?

*Responda a esta pergunta apenas se as seguintes condições são verdadeiras: 
Por favor, selecione apenas uma das seguintes opções:

Nunca.

Poucas vezes.

Quase todo ano.

Anualmente.

Duas vezes por ano ou mais.

13 Da mesma forma, considerando os últimos 10 anos de carreira, você orientou alunos em quais modalidades?

*Responda a esta pergunta apenas se as seguintes condições são verdadeiras:

Por favor, selecione todas as que se aplicam:

$\square$ Iniciação científica.

$\square$ Mestrado.

Doutorado.

Não orientei.

14 Ainda com relação aos últimos 10 anos de carreira, você colaborou cientificamente com outros pesquisadores?

*Responda a esta pergunta apenas se as seguintes condições são verdadeiras:

Por favor, selecione todas as que se aplicam:

$\square$ Sim. Da mesma instituição.

$\square$ Sim. De outras instituições no Brasil.

Sim. De instituições no exterior.

Não colaborei.

\section{Eventos pessoais/profissionais}

(Durante o doutorado e ao longo da carreira acadêmica, eventos impactantes de sua vida pessoal e profissional podem afetar sua produção científica.) 
15 Eventos.

(Informe o ano em que os eventos abaixo ocorreram. Deixe o campo em branco, caso não se aplique.)

Ano Ano Ano Ano Ano

Casamento

Nascimento de filhos

Crise pessoal ou familiar

Crise profissional

16 Caso deseje, detalhe os eventos marcados acima e/ou outros que você considere $\underline{\text { relevantes. Informe o ano em que ocorreram. }}$

Por favor, escreva aqui a sua resposta:

\section{Vida pessoal $x$ Carreira acadêmica}

(Refletindo sobre os conflitos entre demandas pessoais e acadêmicas desde o início do doutorado até a fase atual de sua carreira.)

17 Em qual(is) desta(s) fase(s) você vivenciou (ou está vivenciando) mais conflitos entre demandas pessoais/familiares e demandas acadêmicas?

*Por favor, selecione todas as que se aplicam:

$\square$ Doutorado.

$\square$ Início da carreira - primeiros dez anos.

$\square$ Últimos anos da carreira.

$\square$ Não experimentou conflitos.

$\square$ Outro:

18 Como você administrou (administra) estes conflitos?

Responda a esta pergunta apenas se as seguintes condições são verdadeiras: 
*Por favor, selecione todas as que se aplicam:

$\square$ Priorizando as demandas acadêmicas.

$\square$ Priorizando as demandas pessoais.

$\square$ Buscando equilibrar as demandas pessoais e acadêmicas.

$\square$ Tenho dificuldade em administrar estas demandas.

Não se aplica.

Outro:

\section{Identificação}

Obrigada por ter chegado até aqui. Como dito no e-mail/convite, preciso que você se identifique para que eu possa relacionar as suas respostas com os dados do CV Lattes. Mas fique tranquilo(a) quanto ao sigilo destas informações. Serão usadas de forma generalizada e apenas para fins desta pesquisa.

19 Nome completo

*Por favor, escreva aqui a sua resposta:

$20 \underline{\text { Sexo }}$

Feminino

Masculino

21 Informe o ano em que você nasceu.

*Por favor, escreva aqui a sua resposta: 
Muito, mas muito obrigada mesmo, pela sua participação!

Fique certo de que sua identidade será preservada e nenhuma informação será divulgada individualmente.

Por favor, entre em contato comigo em caso de dúvida.

Submeter o seu inquérito

Obrigado por ter concluído este inquérito. 